\title{
INFORMED CONSENT IN CATASTROPHIC DISEASE RESEARCH AND TREATMENT*
}

\author{
Alexander Morgan Capron $\dagger$
}

Introduction: The Artificial Heart f................... 341

I. Catastrophic Disease Research and Treatment .... 350

A. The Nature of Catastrophic Disease ........................ $\quad 350$

B. Major Participants Besides the Patient-Subject .......... 353

II. A Functional Approach to Informed Consent ...... 364

A. The Functions of Informed Consent ......................... 364

1. To Promote Individual Autonomy ................. 364

2. To Protect the Patient-Subject's Status as a Human Being ................................................ 366

3. To Avoid Fraud or Duress ........................... 369

4. To Encourage Self-Scrutiny by the PhysicianInvestigator ................................................. 371

5. To Foster Rational Decisionmaking ............... 374

6. To Involve the Public ...................................... 376

B. Problems of Effecting Informed Consent .................. 376

1. The Impact of the Inner World .................... 377

2. The Impact of the Outer World .................... 381

3. The Impact of the Relationship ................... 383

4. The Role of "Faith" ........................................ 387

III. The Informed Consent Model in Perspectrve ......... 392

A. Division of Authority .......................................... 392

1. Doctor and Patient ....................................... 392

* This article is adapted in part from the forthcoming book, Katz \& Capron, Catastrophic Diseases-Who Decides What?, to be published in 1975 by Russell Sage Foundation. Other portions of the book provide greater detail on the problems in the catastrophic disease research and treatment process and on the conflicting goals and competencies of the various participants; in the concluding section of the book, recommendations are presented as possible means of resolving some of the problems discussed in this article. The study which led to the book was supported by the National Center for Health Services Research and Development, U.S. Department of Health, Education, and Welfare, under H.S.M. 110-69-213. Grateful acknowledgement is made to Jay Katz for his invaluable comments and suggestions and to Russell Sage Foundation for permission to publish this article.

$\dagger$ Assistant Professor of Law, University of Pennsylvania. B.A. 1966, Swarthmore College; LL.B. 1969, Yale University. Law Clerk to Chief Judge Bazelon, 1969-70. 
2. Official Review

a. Prevention of Dangerous Treatment ............... 396

b. Compelling Life-Saving Treatment 398

B. Resolving Conflicts in the Case Law: A Hybrid Cause of Action

1. Disclosure and Comprehension ...................... 404

2. Causation ..................................................... 418

C. "Consent" for the Legally Incompetent ...................... 423

IV. EPILOGUE

\section{Introduction: The Artificial Heart}

Early in March 1969, Haskell Karp, a forty-seven-year-old printing estimator from Skokie, Illinois, was admitted to St. Luke's Episcopal Hospital in Houston, Texas. Mr. Karp, who had suffered from a progressively worsening heart condition for ten years, came to Houston to be treated by Dr. Denton Cooley, the world-renowned cardiac surgeon. Over the next month, Mr. Karp received medical treatment and his condition was studied by a number of physicians associated with the hospital. He was examined intermittently by Dr. Cooley. The Houston physicians confirmed the diagnosis reached by Karp's physicians in Illinois of moderate pulmonary hypertension and fibrosis and decomposition in the left lateral wall of his left ventricle. "Dr. Cooley suggested that Mr. Karp's desire for a more active and productive life-style could best be achieved by a heart transplant. Mr. Karp rejected this suggestion and preferred to undergo ventriculoplasty surgery (wedge procedure) which Dr. Cooley had developed."1

Because the resection of the left ventricle might not succeed, Dr. Cooley was determined to rely on a heart transplant as a backup alternative, which he persuaded Mr. Karp to accept. But the bloom was already off the rose of cardiac grafting; many of the transplant teams which had been performing the operation enthusiastically only a year before had ceased doing them, and the remaining groups, like Dr. Cooley's, found that public disaffection resulted in few people offering organs for transplantation. This led Dr. Cooley to plan for a new step

${ }^{1}$ Karp v. Cooley, 349 F. Supp. 827, 829 (S.D. Tex. 1972), aff'd, 493 F.2d 408 (5th Cir. 1974). 
with Mr. Karp, never before tried with a human being-the implantation of a completely artificial heart. Since there was only a "70-30" chance of his surviving the ventriculoplasty, ${ }^{2}$ Dr. Cooley explained to Mr. Karp, "if death appeared imminent . . . his heart would be removed and a mechanical heart substitute (sometimes referred to as the Cooley-Liotta mechanical heart) inserted." 3 Controversy was later to develop over whether Dr. Cooley assured the Karps that "there is a donor heart that will be available and that we will use if there's that need for it," with the artificial heart being employed for a brief period only, ${ }^{4}$ rather than telling them "at that time there was no heart donor available, nor any prospect of one."5

${ }^{2}$ Mrs. Karp's recollection was "that Dr. Cooley had said that in his own personal experience he had less than a five per cent chance of failure [with the wedge procedure] and that it 'seemed like it hardly ever failed.' " $493 \mathrm{~F} .2 \mathrm{~d}$ at 413-14.

${ }^{3} 349$ F. Supp. at 830.

4 So Mrs. Karp was to testify. 493 F.2d at 413 . She remembered Dr. Cooley telling them that "the mechanical device would be used for only 30 minutes while the donor was being prepared." Id.

So the district court found, $349 \mathrm{~F}$. Supp. at 830, drawing directly on Dr. Cooley's testimony, which is also quoted in the court of appeals' opinion, 493 F.2d at 414 . His testimony continues: "I told [Mr. Karp] that I did not know whether [finding a suitable donor] would take a matter of hours or days, weeks, or maybe not at all, but [the mechanical heart] would sustain his life and give us another possibility of salvaging him through heart transplantation." Id.

The court of appeals agreed with the trial judge's conclusion that Mrs. Karp's testimony did not create a "conflict in substantial evidence," under Boeing Co. v. Shipman, 411 F.2d 365, 374 (5th Cir. 1965) (en banc), on which both courts relied for the standard for directing verdicts, because she had not been present when Dr. Cooley spoke with Mr. Karp late on the evening of April 2, 1969. Her testimony concerned a conversation that Dr. Cooley had with them about $6: 30$ or 7:00 p.m. on April 3 when he came to have them sign the consent form for the three-step operation. After telling them about the urgency of the operation, Dr. Cooley reassured her, "don't worry about the shock element to your husband because I told him exactly what I told you now last night." Mrs. Karp recalled her husband replying, " 'Honey, he told me this last night.' He said, 'Go ahead. We'll sign the agreement." " 493 F.2d at 413.

The appellate tribunal also found that the "consent form is consistent with Dr. Cooley's testimony of what he told Mr. Karp," id. at 421, and that it provided the best evidence of what was agreed to. The relevant portion of the form stated:

In the event cardiac function cannot be restored by excision of destroyed heart muscle and plastic reconstruction of the ventricle and death seems imminent, I authorize Dr. Cooley and his staff to remove my diseased heart and insert a mechanical cardiac substitute. I understand that this mechanical device will not be permanent and ultimately will require replacement by a heart transplant.

Id. at 412 n.4. Yet on the two disputed issues-the availability of a donor heart and the length of time the artificial heart would be used-the consent form appears to shed little or no light. It says nothing about the first, and on the second merely states that the device "will not be permanent" but will "ultimately" be replaced by a cadaver heart. 
In Mrs. Karp's recollection, Dr. Cooley pressed her husband to go forward with the operation by telling him that an aneurysm in his heart was "about to burst" and that the medical team was uncertain "whether we can even wait [until] tomorrow."6 In Dr. Cooley's view it was Mr. Karp who grew impatient with waiting for a donor, ${ }^{7}$ but there was no question that $\mathrm{Mr}$. Karp's condition took such a turn for the worse-his pacemaker was no longer able to stimulate adequate cardiac functionthat he was near death as he was wheeled into the operating theater. Anesthesia had to be administered at an accelerated pace so that the surgery could begin quickly. ${ }^{8}$ After $\mathrm{Mr}$. Karp had been hooked up to the heart-lung bypass machine, the repairs were performed on his left ventricle, in which Dr. Cooley found much more scar tissue and much less viable muscle than he had hoped. ${ }^{9}$ When the doctors tried to start the heart up again, it went into fibrillation; an electrical shock was used to steady the rhythm, but the contraction was too weak to support life. Mr. Karp's heart was then removed and the mechanical one was inserted.

Dr. Cooley said that the mechanical heart functioned very well and $\mathrm{Mr}$. Karp responded to stimulation within 15 or 20 minutes after the incision was closed. His blood pressure was well sustained according to Dr. Cooley and he showed signs of cerebral activity. Dr. Keats [the anesthesiologist] said that Mr. Karp was

${ }^{6} I d$. at 413 . Dr. Cooley insisted at trial that he would never say an aneurysm could burst, and that although he wrote an article in which "burst aneurysm" appeared, the heart condition dealt with there was different than Mr. Karp's and the statement was credited to another doctor. 349 F. Supp. at 836.

7493 F.2d at 414.

${ }^{8} \mathrm{Dr}$. Arthur S. Keats, the anesthesiologist, testified that, having put Mr. Karp to sleep and put a tube down his windpipe to assist his breathing, he sent word to Dr. Cooley that they " 'had better go ahead with the operation as expeditiously as possible, otherwise the patient may not last long enough to have the operation." "Dr. Cooley hurried to complete the surgery in which he was then engaged; upon entering the Karp operating room, he found the patient " 'mottled and blue' " and concluded that Karp was " "virtually moribund" " at that time. Id. at 416.

9 During the operation, Dr. Cooley, in his own words, "discovered a situation for which wedge resection could not be beneficial," but he went ahead anyway because he "'felt a moral obligation to try.'" Id. n.6. Mrs. Karp contended that the physicians had carried out the ventriculoplasty negligently and had abandoned it improperly in order to undertake the procedure which really interested them, the insertion of the mechanical heart device. The Fifth Circuit panel concluded that this "theory has no evidentiary foundation." Id. at $417 \mathrm{n.8}$. 
amazingly well following the operation, that the records reflect that he was responding reasonably to commands within 20 minutes postoperatively. Dr. Keats testified that the endotracheal tube was removed about 1:20 a.m. [approximately eleven hours after the operation], and that he saw Mr. Karp some time the next morning at which time he was responsive and could communicate. ${ }^{10}$

Mrs. Karp then joined Dr. Cooley in making appeals over the news media for a heart donor, and some sixty-four hours after the implantation of the mechanical heart, it was replaced by a human one. ${ }^{11} \mathrm{Mr}$. Karp's condition nevertheless deteriorated further. His production of urine, low after the first operation, ceased completely after the transplant. He died of pneumonia and kidney failure at 3:15 p.m. on April 8, about thirty-two hours after receiving the cadaver organ and four days after his initial surgery.

The extraordinary events that took place in Houston in April 1969 obviously generate many critical issues. ${ }^{12}$ Although this initial attempt at mechanical replacement of the heart has not yet been repeated, ${ }^{13}$ it may eventually be viewed as the first

${ }^{10} \mathrm{Id}$. at 417. itself.

11 The transplantation of a human heart into Mr. Karp is a controversial saga in

On 7 April Mrs. Barbara Ewan, a candidate-donor, was admitted to Saint Luke's. She had been flown to Houston from Lawrence, Massachusetts, by a chartered air ambulance. She had been in a coma at the Lawrence General Hospital since 19 March. Forty-eight hours before her trip to Houston, after a period of anoxic arrest, tests had shown her to be suffering from irreversible brain damage. After a telephone conference between physicians in Houston and Lawrence and a meeting of Mrs. Ewan's closest relatives, family consent had been given for her to be taken to Houston to donate her heart to Mr. Karp. . . . Ninety minutes after her arrival in Houston, Mrs. Ewan was formally pronounced dead from a stroke, by four doctors who were not members of the prospective transplant team. Her heart was immediately implanted into Mr. Karp.

R. Fox and J. Swazey, The Courage to Fail: A Social View of Organ Transplants AND Dialysis 152-53 (1974). The artificial heart was front page news across the country, which helps to explain why Mrs. Karp's "plea" was answered by the donation of a heart from two thousand miles away.

${ }^{12}$ See generally U.S. DeP'T of Health, Education, and Welfare, National Heart and Lung Institute, Artificial Heart Assessment Panel, The Totally Implantable Artificial Heart: Economic, Ethical, Legal, Medical, Psychiatric AND SOCIAL IMPLications (1973).

${ }^{13}$ Attention has now shifted from the total-heart pump back to perfecting a left ventricular assist device, a version of which underwent initial clinical trials in 1963- 
step in a biomedical development of greater importance than human heart transplantation. ${ }^{14}$ As such, it could contribute to a redefinition of life and death and even of what it means to be "human," to a renewed debate about the allocation of scarce and very precious resources, and to a reconsideration of the policies behind the direction in which health care is moving in this country.

Even without looking to the future, Denton Cooley's implantation of the experimental device in place of Haskell Karp's heart in itself dramatically illustrates the questions raised by innovation in the treatment of life-threatening illness, and indeed by all modern, highly technological medicine. At what point is it permissible to proceed with a radically new medical intervention? What role do the hopes and fears of physicians and their colleagues and competitors, patients and their families, hospital administrators, and public officials play in decisionmaking? How ought the risks of medical innovation be assessed and distributed? Central to these is the allocation of authority among the participants in the decisionmaking process-in particular, the extent to which persons who are the patient-subjects of clinical research should become informed decisionmakers. ${ }^{15}$

67. See, e.g., DeBakey \& Hall, Orthotopic Cardiac Prosthesis, 7 Cardovasc. Research Center Bull. 127 (1969). If basic problems are overcome, such devices will probably be tested soon as a means of tiding patients over following major surgery that has employed cardiopulmonary bypass; thereafter, their use for long-term assistance is also contemplated. See R. Hegyeli \& M. Machesko with ASSISTANCE of L. Richardson, The Left Ventricular Assist Device-Assistance to Failing Girculation 53-56 (1974).

14 The first cardiac transplant in man was performed in January 1964, using a chimpanzee heart when an expected human donor proved unavailable. See Hardy, Chavez, Kurrus, Neely, Eraslan, Turner, Fabian \& Labacki, Heart Transplantation in Man, 188 J.A.M.A. 1132 (1964). Nearly four years elapsed before Dr. Christiaan Barnard performed the next heart transplant, this time using a human donor; his operation triggered the world-wide rush in 1968. See Surgeons Cheer Rising Transplant Score, Medical WorL.d News, Sept. 27, 1968, at 26.

15 Of the many issues touched by the Karp case, only this one is treated in this Article. The issue of human experimentation, never well defined by counsel or by the judges, is of interest here only as it relates to the patient's decisionmaking; the courts apparently believed that there was no basis for "the experimentation count" in the complaint if the physicians, whatever their scientific curiosity, had also been motivated by a therapeutic intent to save Mr. Karp's life. Nor is the Article concerned with three other issues in the case to which the courts devoted much attention, all relating to the exclusion of evidence: a film showing portions of the Karp operation; records of a Baylor University Committee which investigated the operation; and the testimony of Dr. Michael DeBakey, Dr. Cooley's academic superior and major com- 
In resolving this latter issue in the action for wrongful death brought against Dr. Cooley and his colleagues, ${ }^{16}$ the courts looked to Natanson $v$. Kline, ${ }^{17}$ the seminal opinion in which the Kansas supreme court announced that physicians would be liable for breaching their obligation

to disclose and explain to the patient in language as simple as necessary the nature of the ailment, the nature of the proposed treatment, the probability of success or of alternatives, and perhaps the risks of unfortunate results and unforeseen conditions within the body .... ${ }^{18}$

The basic premise from which the Natanson court operated - that everyone has the right to decide for himself what shall be done to his person-is a fundamental tenet of English and American common law. The importance of volition in the medical context was forcefully stated sixty years ago by Judge Cardozo in Schloendorff $v$. Society of New York Hospital:

Every human being of adult years and sound mind has a right to determine what shall be done with his own body; and a surgeon who performs an operation with-

petitor as a thoracic surgeon, whom the plaintiffs tried to subpoena as an expert witness but who declined, in the trial judge's chambers, to express any opinion about the propriety of the operation. See notes 247-53 infra \& accompanying text. All these points were decided adversely to the plaintiffs by the trial and appellate courts.

${ }^{16}$ Karp v. Cooley, 349 F. Supp. 827 (S.D. Tex. 1972), aff'd, 493 F.2d 408 (5th Cir. 1974). After nine days of trial, the trial judge granted the defendant physicians' motion for a directed verdict; the court of appeals affirmed.

17186 Kan. 393, 350 P.2d 1093, clarified and rehearing denied, 187 Kan. 186, 354 P.2d 670 (1960). The Fifth Circuit noted that "[t] $]$ he modern development is generally recognized as beginning with Natanson v. Kline . . ." 493 F.2d at 419 n.9 (citation omitted). Since the courts were exercising diversity jurisdiction, they relied on Texas law, as articulated primarily in Wilson v. Scott, 412 S.W.2d 299 (Tex. 1967), which in turn relied on Natanson and principally on Aiken v. Clary, 396 S.W.2d 668 (Mo. 1965).

18186 Kan. at 410,350 P.2d at 1106 . The last fifteen years have seen a flood of "informed consent" cases pour forth across the country in the wake of Natanson. The Kansas court's decision may have been so influential in part because it was so confused. $C f$. 34 S. CAL. L. Rev. 217 (1961); note 20 infra. The case did not, of course, create any wholly new legal concepts, nor was it without precedent, see, e.g., Theodore v. Ellis, 141 La. 709 , 75 So. 655 (1917); Hunter v. Burroughs, 123 Va. 113 , 96 S.E. 360 (1918); and the Natanson court drew upon a number of prior opinions in other jurisdictions, particularly Salgo v. Leland Stanford Jr. Univ. Bd. of Trustees, 154 Cal. App. 2d 560, 317 P.2d 170 (1957), which had brought the issue of consent to a similar resolution. 
out his patient's consent commits an assault, for which he is liable in damages. ${ }^{19}$

But the Kansas court did plow new ground. ${ }^{20}$ It moved the legal concept of consent beyond simple assault and battery law; it recognized that for the right to self-determination to have meaning for the patient, it must be conjoined with a right to the information he or she would need to formulate an intelligent opinion. Natanson and its progeny thus carried the law beyond merely giving body to "the wish on the part of the individual to be his own master . . . to be a subject, not an object," 11 to include the rational processes involved in the desire

to be moved by reasons, by conscious purposes which are [his] own, not by causes which affect [him], as it were, from outside, ... above all, to be conscious of [himself] as a thinking, willing, active being, bearing responsibility for his choices and able to explain them by reference to his own ideas and purposes .... ${ }^{22}$

19211 N.Y. 125, 129, 105 N.E. 92, 93 (1914). Accord, Pratt v. Davis, 224 Ill. 300, 79 N.E. 562 (1906); Mohr v. Williams, 95 Minn. 261, 104 N.W. 12 (1905); Rolater v. Strain, 39 Okl. 572, 137 P. 96 (1913).

${ }^{20}$ Immediately after Natanson was decided, the Supreme Court of Missouri handed down Mitchell v. Robinson, 334 S.W.2d 11 (Mo. 1960), holding it to be a jury question whether physicians had been negligent in failing to inform their patient of the dangers of shock therapy. The Mitchell court was very unclear about what it was up to, and the Natanson opinion has proven more influential, although both had to be clarified, Natanson on rehearing, $187 \mathrm{Kan}$. 186, 354 P.2d 670 (1960), and in Williams v. Menehan, 191 Kan. 6, 379 P.2d 292 (1963), and Mitchell in Aiken v. Clary, 396 S.W.2d 668 (Mo. 1965). Waltz and Scheuneman, Informed Consent to Therapy, 64 Nw. U.L. REv. 628 (1970), observe that the doctrine "has achieved a status in the law of medical malpractice unmatched both in speed of growth and bulk of commentary," and cite nearly a score of articles dealing with the doctrine, id. n.1, which have since been supplemented by countless others, see, e.g., Kessenick \& Mankin, Medical Malpractice: The Right to be Informed, 8 U.S.F.L. REv. 261 (1973); Note, Informed Consent to Medical Treatment, 61 CaLIF. L. Rev. 634 (1973); Note, Informed Consent-A Proposed Standard for Medical Disclosure, 48 N.Y.U.L. REv. 548 (1973); Note, The Patient-Physician Relationship: Present Law and Trends for the Future Implied in Cobbs v. Grant, 8 U.S.F.L. REv. 320 (1973); Comment, Informed Consent as a Theory of Medical Liability, 1970 WIs. L. REv. 879; Note, Informed Consent and the Dying Patient, 83 YALE L.J. 1632 (1974); Note, Restructuring Informed Consent: Legal Therapy for the Doctor-Patient Relationship, 79 Y ALE L.J. 1533 (1970). Most of the cases are collected in Cobbs v. Grant, 8 Cal. 3d 229, 239-40, 502 P.2d 1, 7, 104 Cal. Rptr. 505, 511-12 (1972), and Comment, Informed Consent in Medical Malpractice, 55 CaLIF.

L. REv. 1396, 1397 n.5 (1967). See also note 198 infra.

21 I. BERLIN, Two CoNCEPTS of LiberTy 16 (1958).

$22 I d$. 
In the past decade, the courts have developed a number of ways of applying the doctrine of informed consent. The legal points still at issue-whether the wrong involved is properly regarded as an assault and battery without consent (where full disclosure is absent) or as malpractice (the failure to inform being seen as a breach of professional duty), ${ }^{23}$ or whether the extent of disclosure required ought to be judged by standards set by a physician's fellow practitioners or by what lay jurors would want to know in similar circumstances ${ }^{24}$ - have been debated largely as formal rules rather than in terms of the purposes and function of the doctrine. It is not difficult to see why this has occurred. It is to be expected that courts would focus on the purposes of a legal rule if the major arguments about the rule were teleological. A rule might be supported if, for example, it reduced the number of accidents or favored a partic-

${ }^{23}$ Traditionally, a physician was liable in an action for battery when he did something to a patient for which he had not obtained permission. See, e.g., Bang v. Charles T. Miller Hosp., 251 Minn. 427, 88 N.W.2d 186 (1958) (as part of prostate operation spermatic cords were tied off without patient's prior knowledge or consent); Moore v. Webb, 345 S.W.2d 239 (Mo. App. 1961) (eight lower teeth extracted while patient, who had agreed to removal of two, was under sodium pentathol); Corn v. French, 71 Nev. 280, 289 P.2d 173 (1955) (mastectomy performed when patient had limited consent to a biopsy); Hively v. Higgs, 120 Ore. 588, 253 P. 363 (1927) (tonsils removed during course of minor operation on patient's nose). The battery theory has been carried forward in some of the modern "informed consent" cases. See, e.g., Dow v. Kaiser Foundation, 12 Cal. App. 3d 488, 90 Cal. Rptr. 747 (1970) (held, physician's willful and unreasonable withholding of material information constitutes battery). On the other hand, the majority of courts, following Natanson, have characterized failure to obtain "informed consent" as giving rise to a cause of action based on negligence. See Plant, An Analysis of "Informed Consent", 36 Fordham L. Rev. $639,648-55$ (1968). Occasionally, courts have permitted plaintiffs to proceed either in battery or in negligence on a given set of facts, see, e.g., Belcher v. Carter, 13 Ohio App. 2d 113, 234 N.E. 2d 311 (1967). Some courts have held that battery lies if there is no informed consent at all, but that if the defendant obtained "informed consent" he or she may still be liable for malpractice for breaching the medical community's standard of disclosure. Shetter v. Rochelle, 2 Ariz. App. 358, 409 P.2d 74 (1965); of. Cobbs v. Grant, 8 Cal. 3d 229, 237, 502 P.2d 1, 8, 104 Cal. Rptr. 505, 512 (1972).

${ }^{24}$ In its clarification of its first opinion in Natanson the Kansas supreme court declared that "expert testimony of medical witnesses is required to establish whether [the physician's] disclosures are in accordance with those which a reasonable medical practitioner would make under the same or similar circumstances." 187 Kan. at 190, 354 P.2d at 673. Recently, that viewpoint has been squarely repudiated in three forceful decisions. Canterbury v. Spence, 464 F.2d 772 (D.C. Cir.), cert. denied, 409 U.S. 1064 (1972); Cobbs v. Grant, 8 Cal. 3d 229, 502 P.2d 1, 104 Cal. Rptr. 505 (1972); Wilkinson v. Vesey, 110 R.I. 606,295 A.2d 676 (1972). It seems likely that these opinions will prove influential and attract further courts to this position. See also note 155 infra. 
ular group in society. Informed consent rules do not, however, lead to any particular treatment decisions, and the rule cannot be favored because of the possible therapeutic outcomes it will produce. Indeed, the decisional outcomes are less predictable than if the authority were put instead in the hands of other decisionmakers such as physician-investigators. This is an instance, then, of the purpose of a rule being to promote interests rather than to lead to certain ends; in this case, they are the interests of patient-subjects. An analysis of informed consent that goes beyond the legal formulae themselves must inquire into the functions served by the doctrine, not in bringing about "better" results but in promoting choices made by persons for themselves and for which they can take responsibility.

The catastrophic disease process provides a good crucible in which to formulate and test a theory of informed consent because it calls forth active and intense participation by all the actors in the drama of modern, technological medicine: physician-investigators who invent and apply the new techniques of treatment; patient-subjects in whom these techniques have their ultimate (and sometimes highly beneficial) trial runs; organized professional bodies which usually guide or support and occasionally curtail the work of the pioneers in their fields; and organs of the state which fund education and research and increasingly intervene in the actual supervision of clinical innovation. The analysis presented here leads to the conclusion that for both theoretical and practical reasons the treatment of the diseases in question is best undertaken when all the participants can behave as collaborators, each with a vital interest and an independent voice in the steps to be followed.

Central to this inquiry is an examination of the functions and limitations of informed consent, from which it is possible to evaluate particularly the authority which should be wielded by patient-subjects in the catastrophic disease process. The treatment of these conditions typically involves highly specialized and often experimental care, usually provided by persons other than the patient's primary physician and frequently carrying unknown risks. The "model" of decisionmaking developed here will also have much to say about the duties and responsibilities which physicians and patients have toward one another in other areas of health care. A functional analysis of informed consent, with a clear recognition of the limitations 
inherent in the decisionmaking process, suggests that giving patient-subjects a greater say in decisions relating to their treatment alternatives can be a powerful force for " "personalization' in technical decisions made in the modern medical context." 25 The doctrine of informed consent, though still in evolution, ought not to be viewed narrowly through the lenses of malpractice and battery, but should be recognized as a ground for recovery with its own rules of conduct, causation, and damages.

\section{Catastrophic Disease Research and Treatment}

\section{A. The Nature of Catastrophic Disease}

In the past decade, the cost of medical care has risen substantially. Even relatively uncomplicated illnesses can involve considerable expense and inconvenience, and an individual who develops a condition serious enough to require repeated medical attention, and perhaps hospitalization, faces the prospect of a heavy drain on his financial resources, even if part of the bill is borne by private or government-funded health insurance. At the same time the range of therapy for most diseases has been greatly increased by new drugs and other medical devices, which place some previously incurable and inevitably fatal conditions within the power of medicine to delay, if not control.

While all illness carries with it some threat to life and imposes some economic burdens, these factors are especially pronounced in certain diseases. These diseases, which are termed "catastrophic," more often than not represent disaster for those they strike. Fatal unless promptly treated, yet with a course of therapy so financially burdensome as to be beyond the usual resources of most persons, a catastrophic illness may radically alter a person's existence and accustomed way of life, leaving his private affairs and family life in disorder. ${ }^{26}$ Other factors,

${ }^{25}$ Note, Restructuring Informed Consent: Legal Therapy for the Doctor-Patient Relationship, 79 Y ALE L.J. 1533, 1534 (1970).

${ }^{26}$ Thus, for a condition to be considered a catastrophic disease, as the term is used here, some form of treatment must be available which at least will sustain life for a period of time. Therefore, for example, fatal automobile accidents or other sudden fatal traumas are not catastrophic diseases for the purposes of this Article, although they may have a profound effect on a family if they deprive it of its primary wage-earner. 
such as the psychological and social impacts of such conditions on patients and their families, though not necessary to a definition of the diseases, are the nearly universal consequences of them.

Different catastrophic diseases may raise somewhat different issues for analysis, but for purposes of developing a decisionmaking model, one group-those heart ${ }^{27}$ and kid-

${ }^{27}$ Nearly nine million Americans suffer from some form of heart disease, accounting for about 720,000 deaths annually, 200,000 of them among individuals under 65 years old. Although leaders in the field hope that preventive measuresrestrictions in diet, curtailment of cigarette smoking, better detection and treatment of rheumatic fever and hypertension-will eventually reduce this staggering toll, at present the only treatment for the patient facing imminent cardiac death is the replacement of his damaged heart with a healthy heart from a person who has just died of other causes. Work is also under way to develop a totally implantable artificial pump, but success still appears to be a number of years away. See notes 1-14 supra \& 228-30 infra \& accompanying text.

At present there are practical limits to cardiac transplantation. Among persons with coronary heart disease (the largest category), the critical limitation is its sudden onset, often without prior indications, and the occurrence of death before the patients reach a hospital. Moreover, until an effective circulatory assist device is developed, many patients for whom cardiac replacement might be indicated will die before the necessary arrangements can be made. Even the availability of such a device will not save all coronary victims. Based on intensive, longitudinal studies of $183 \mathrm{pa}$ tients with coronary heart disease, and assuming the widespread availability of a circulatory assist device, a National Heart Institute Task Force concluded that only "30 were potential candidates for total cardiac replacement," a ratio of about one in six. Ad Hoc Task Force on Cardiac Replacement, National Heart Institute, Cardiac Replacement: Medical, Ethical, Psychological and Economic ImpliCATIONS II (1969).

For some time to come few of those who suffer from heart disease will be treated by having their damaged organ replaced by a healthy one from another person or an artificial substitute. The major roadblock remains the problem of rejection. Once that problem is solved, the number of heart replacements could rise to a level which would be an order of magnitude greater. The N.H.I. Task Force estimated that at such a time transplantation would jump from the existing (1969) level of 100 operations per year to an annual figure of about 12,000. Id. 16. (The Task Force's estimate was on the high side even when made. While 101 transplants were performed in 1968 on a worldwide basis, only 54 were American. In 1972, the last year for which published data is available, only 14 cardiac transplants were performed in the United States. ACS/NIH Organ Transplant Registry, Third Scientific

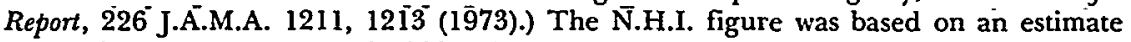
that $6 \%$ of the approxmately 200,000 persons under 65 who die from heart disease would then become candidates for heart replacement. The Task Force increased its estimate to $16 \%$, or 32,000 candidates, if a satisfactory circulatory assist device and an artificial heart were also available.

A heart transplant costs in excess of $\$ 20,000$, the bulk of which goes for postoperative care. At the moment most of this money is provided by N.H.I. research funds, insurance, and private sources, including (in effect) contributions by the hospitals and physicians involved. The cost of an artificial pump, and its implantation, would probably be about that of a transplant.

Heart disease is, therefore, likely to remain a catastrophic disease of major proportions-killing or crippling the hundreds of thousands it strikes, imposing a 
ney ${ }^{28}$ conditions which are susceptible to treatment through organ transplantation or support by artificial means-is especially illuminating. The lessons to be learned from an examination of the problems of informed consent in this context, which

heavy financial burden on those who can be treated, and creating the sometimes even heavier psychological burden of uncertainty about offering and accepting treatment for all involved, be they patients, relatives and friends, physicians, or researchers.

${ }^{28}$ As a catastrophic illness, chronic renal disease and the concomitant uremia present a somewhat different picture than heart disease. For one thing, its incidence is much lower. On the basis of death certificates, it is estimated that 28,000 people die each year of primary kidney disease, including nephritis, nephrosis, kidney infections, and polycystic diseases of the kidney. Additionally, approximately 20,000 die of hypertension with arteriolar nephrosclerosis and 50,000 die of other forms of hypertension; a small portion of these can be counted as "kidney deaths," in that they would benefit from hemodialysis (treatment on an "artificial kidney").

On the other hand, a second and perhaps more striking aspect of kidney disease is that the greater success rate of therapy (compared with heart replacement) creates a much larger pool of potential candidates for treatment at present. Although transplantation of the kidney continues to be far from risk-free, due largely to immunological difficulties, this procedure is the most frequently performed type of transplantation; its frequency (currently about 2,500 per year) increases while that of heart transplantation declines. One reason for its success is that since kidneys come in pairs live donors can be used, which increases the probability of finding a good immunologic "match" among a patient's immediate relatives. Moreover, hemodialysis permits patients to be maintained until they are adequately prepared for transplantation or until a suitable organ can be found. By compensating for their diseased kidney, this therapy also puts patients in a healthier state prior to their surgery than in the case with cardiac recipients. Of course, some patients are maintained for long periods of time on hemodialysis, which is employed as a life-sustaining treatment in its own right.

Despite these differences, the treatments for end-stage kidney disease share with cardiac replacement two important characteristics: they are costly and they may provoke severe psychological tension for all concerned. The cost of transplanting a kidney is about the same as the cost of replacing a heart, better than $\$ 20,000$ (this figure will be somewhat larger if a live donor is involved). Because of its continuous nature, dialysis is even more expensive. The cost for this procedure ranges from about $\$ 35,000$ per year for in-hospital dialysis to about $\$ 6,500$ per year for dialysis carried out in a patient's home, after an initial expenditure of $\$ 3,000$ for equipment as well as the expense of home alterations (plumbing and so on).

The psychological reverberations of kidney transplantation probably exceed those of the heart operation because, in addition to a large element of uncertainty or risk, in many cases the life-saving organ will have come from another living human being, rather than from a cadaver. And even the problems inherent in such a two-way psychic debt are probably not as great as the difficulties encountered by patients undergoing chronic dialysis, who two or three times a week must spend from six to sixteen hours attached to a machine to "purify" their blood. See generally Calland, Iatrogenic Problems in End-stage Renal Failure, 287 NEw ENG. J. Med. 334 (1972); Renal Failure: The Agony and the Ecstasy, 222 J.A.M.A. 829 (1972) (editorial). Moreover, pre-existing psychopathology is often made more severe by the shifts in the dialysand's metabolic state. 
has been the object of recent, dramatic medical attention, should, nonetheless, be useful for the analysis of these problems in the setting of other catastrophic illnesses and ordinary diseases as well.

\section{B. Major Participants Besides the Patient-Subject}

The thrust of informed consent, as that doctrine is viewed here, is to make the patient-subject an active and informed participant in the decisions which must be made in research on, and treatment of, catastrophic diseases. But the creation of a model of informed consent also requires an understanding of the authority exercised by the other major participants in the catastrophic disease process: the physician-investigators, the professions, and the state. ${ }^{29}$ The roles played by these actors are relevant for their direct influence on the patient-subject's capacity to make an informed judgment on some proposed therapy. ${ }^{30}$ But their activities also attain an independent significance in that they largely control the nature and number of choices put before the patient-subject.

Physician-investigators ${ }^{31}$ probably constitute the most important of these external centers of power. It is they who bear the responsibility for initiating the processes of biomedical advance that create new possibilities for the treatment of catastrophic illnesses.

The professional participants in the catastrophic disease process come from a variety of professional backgrounds, but two broad groupings can be identified: those with and those

${ }^{29}$ In this section, the discussion centers on physician-investigators and their peers; the role and authority of the state are treated more fully at text accompanying notes 127-49 infra.

${ }^{30}$ See text accompanying notes 103-09 infra (the impact of the physician-patient relationship on informed consent).

31 This designation is somewhat inaccurate. The group of participants encompassed in this label includes not only M.D.'s but also Ph.D.'s from a variety of disciplines as well as nurses, social workers, psychologists, and paramedical personnel. Little attention has been paid to defining the authority and responsibility of the various members of "the team" in the catastrophic disease decision-making process. The traditional assumption has been that, since all of them work in medical settings, a physician or group of physicians should have ultimate authority. This assumption requires re-examination. For example, with respect to decisions involving the weight to be given to tissue typing in the selection of recipients, the question must be explored whether greater, or even primary, authority should not rest with an immunologist rather than a surgeon. 
without prior clinical training and experience, many of the latter being graduates of basic science programs. Within both groups the extent of prior experience varies considerably. ${ }^{32} \mathrm{Be}-$ yond the attainment of a professional degree, no formal mechanisms have been established for certifying a person competent to experiment or treat in areas which, like catastrophic disease, are at the "frontiers of knowledge" with all the uncertainties, responsibilities, and hard choices that such work implies. ${ }^{33}$

Although professional bodies exercise some supervision in this area through control of the educational process and formal (awards, editorial control of professional journals) and informal ("reputation") mechanisms, there are indications that little training or supervision is addressed to the most problematic questions of medical innovation. If they are to play a more active role, professional groups will have to examine whether standards of training and certification should be promulgated for the professionals working in innovative settings such as catastrophic diseases, and whether the extent of their authority should not be circumscribed until such training has been obtained. One necessary facet of education, training for professional responsibility, has generally been neglected in all professional education and is of particular importance for those working at the frontiers of knowledge. ${ }^{34}$

Improvement in ethical socialization is desirable at every phase of medical training. In medical school, for example, the teachers who now instill the value of research as they talk about their own research projects

${ }^{32}$ The senior persons, who head these programs, are generally professionals of long clinical experience, while the rest of the participants range from recent graduates, often of great promise, to seasoned veterans. For example, when Christiaan Barnard performed the first heart transplantation he was not considered to be among the group of senior cardiac surgeons who were engaged in extensive preliminary work for the eventual performance of this operation.

${ }^{33}$ In theory, any person who wishes to work in this complex and highly specialized field can do so, though, in practice, a number of informal mechanisms exist to brake rash practices, such as restrictions on access to clinical settings (for which one must first be recognized by peers and hospital boards), the fear of malpractice suits, the need for referrals of patients (which again is based on prior recognition of one's professional worth), and the like.

${ }^{34}$ See Katz, The Education of the Physician-Investigator, 98 Daedalus 480 (1969). Indoctrinating professionals as to what is "good" or "bad" ethical behavior would, of course, not only be impossible but would also be offensive. But there are opportunities for the exploration of the complex problems posed by modern medicine to increase awareness and, in turn, thoughtful analysis of these problems. At least this could lead to physician-investigators saying less often than they do now-when 
ought to address themselves in proper measure to the ethical problems that occur in such research. For it is only when medical students see that their teachers are taking research ethics as a continuing and serious concern that they will themselves come to define it in the same way. ${ }^{35}$

It is also necessary for educators, and physician-investigators generally, to recognize the extent to which the questions they face in the catastrophic disease treatment process force them to look for answers beyond "medical ethics," as it is traditionally conceived. The customary assumption is that the problems presented are to be resolved by the conscience, educated or otherwise, of the physician; but it is quickly apparent that more than individual ethics are implicated in decisions about the allocation of scarce resources or the definition of death.

Concern about the training for professional responsibility has other roots as well. Investigative medicine confronts physician-investigators with numerous conflicting pressures and clinical uncertainties. To the resolution of these complex problems they bring their own unexamined biases and value preferences, which always tend to exert a greater influence when conflicting intentions cannot readily be reconciled or when consequences cannot be easily ascertained. ${ }^{36}$

An examination of the motivations of physician-investigators may begin to reveal the pressures under which they operate and the reasons for the intensity as well as the variation

confronted with questions about why they had not considered alternative ways of proceeding or why they assumed they could proceed as they did-_"I never thought of it."

${ }^{35}$ B. Barber, J. Lally, J. Makarushka \& D. Sullivan, Research on Human Subjects: Problems of Social Control in Medical Experimentation 191 (1973) [hereinafter cited as BARBER].

${ }^{36}$ For example, some professionals have stated without documentation that unrelated persons should not be used as organ donors because their psychological motivations as volunteers are suspect. This is the policy adopted in the United States. Hamburger, Protection of Donor Rights in Renal Transplantation, in BIOMEdical Science and the Dilemma of Human Experimentation 44 (V. Fattorusso ed., 1967). Others disagree. Fellner \& Schwartz, Altruism in Dispute, 284 NEw ENG. J. MED. 582 (1971). One wonders to what extent unexplored personal feelings have entered into these pronouncements and, more generally, to what extent prior systematic education for professional responsibility can bring to the surface those personal and professional beliefs and values which distort and obscure finding appropriate answers to such questions as by what authority, under what circumstances, and in the presence of what psychopathology offers by unrelated donors should be refused. 
of their response to this challenge. Curiosity is often identified as the major motivation behind the desire to contribute to scientific knowledge which leads a person into innovative medicine. From her studies of young children, Anna Freud has concluded that in addition to curiosity-the drive to solve "the riddles of their surroundings," which may motivate a child to become a biomedical researcher-one finds also the intertwined impulses of maiming and curing, and the desire to possess magical powers.

In every nursery school, the nursery school teacher is prepared that ... a hospital will be established, and this hospital will be usually for insects, frogs or lizards or any other small animals that can be found .... Sometimes, especially when it is an insect, legs will be pulled off beforehand so that a patient is produced, and the patient is cured afterwards. Which means that the child's wish to help and to cure is still very close to the wish to hurt and to maim. . . . The older and more socially adapted he becomes, the more this aggressive wish can be submerged under a strong urge to help. ... I remember very vividly when I was a child, myself, of being impressed by those fairy tales usually placed somewhere in the middle ages, where an unusually trained or gifted medical man took up straightforwardly the battle with death, and proved that he could conquer death at any time and save his patients. Death was his enemy. He was the savior and the hero. And this image behind the medical profession that they are the heroes strong enough and wise enough to conquer death or at least to put off and postpone death is certainly an idea which is attractive to many people. ${ }^{37}$

All of these drives-to search, to maim and cure, to be invincible-may guide a medical career; although natural feelings, they are not fully accepted, but are given other names. George Sarton also assigns a central place to curiosity as a deep and ancient human trait, inexorably tied with man's ascent from the primitive world. But while it may be "the mother of

${ }^{37}$ Freud, The Doctor-Patient Relationship, in J. KATZ WITH ASSISTANCE of A. Capron \& E. Glass, Experimentation with Human Beings 642-43 (1972) [hereinafter cited as KATZ]. 
science," just as necessity is the mother of invention, curiosity is not, in Sarton's view, adequately described as a simple desire for knowledge. "The motives of primitive scientists . . . were perhaps not very different from those of our contemporaries; they varied considerably from man to man and time to time and then as now covered the whole gamut from complete selflessness, reckless curiosity, and spirit of adventure down to personal ambition, vainglory and covetousness." 38

Renée Fox and Judith Swazey, who have studied one particular group of physician-investigators-transplant surgeonsextensively, give further indications of the interaction of personal and professional drives in motivating medical research. The transplanters, fiercely competitive and highly motivated, believe that "courage" or "guts" are the sine qua non of their profession. They find joy not only in making medical discoveries but in combating death, which they attack with indefatigable zeal and a fervor which may be traced to the fundamentalist religious background which Fox and Swazey found was shared by some of them. Thus, it is not surprising that a failure of their interventions often leads to a terrible feeling of defeat.

Transplant surgeons see themselves . . . as "pioneers," "trail blazers" whose explorations carry them beyond the safely reassuring boundaries of established medical knowledge and technique. . . . [T]hey are also keenly aware of the risks they are incurring through their willingness to work "in modern acute medicine at its extreme" and to make "radical departures" from what is conventionally accepted [in the field of medicine]. ${ }^{39}$

This "pioneer" complex characterizes physician-investigators engaged in the other innovative and adventuresome aspects of catastrophic disease treatment as well. The same driving ambition to conquer death is found among the developers of hemodialysis as among the transplanters. Since the original work of Willem Kolff, the physicians involved in dialysis have had to pursue their work against great odds-which involved not only seemingly inexorable natural forces but also

${ }^{38}$ G. Sarton, A History of Science 16 (1952).

${ }^{39}$ See R. Fox \& J. Swazey, supra note 11, at 111 (citations omitted). 
neglect or opposition from colleagues. ${ }^{40}$ Those who eventually established the success of dialysis treatment manifested great faith in the ultimate value of the new therapy in the face of great uncertainty. Their optimism was often reinforced by a need for them to reassure and encourage their patient-subjects to continue with the arduous treatment regimen.

The significance of the physician-investigator's personal commitment to his work became starkly evident in the controversy surrounding long-term dialysis in the early 1960's. The introduction of the new technique, based on the shunted cannulas which obviated the need for repeated venepuncture, was met with skepticism, especially in those kidney centers which were dedicated to improving transplantation and which viewed dialysis as merely a "holding" procedure to maintain the patient until a donor could be found. Dr. Belding Scribner, the shunts' inventor and major proponent, was almost alone in reporting success with dialysis. Since his team in Seattle regarded chronic dialysis as "our baby," they were untiring in pushing on with the procedure despite the criticism of their fellows. Indeed, competition played an important part in their efforts. As Dr. Scribner very insightfully stated, in recalling the Seattle group's driving ambition and motivation,

This factor was pin-pointed by [Dr. George] Schreiner at a private meeting in about 1963 when he accused me in front of my peers of making dialysis work just to satisfy my ego. I was resentful and embarrassed at the time, but probably I should have been pleased. ${ }^{\mathbf{4 1}}$

The pressures operating on and within physician-investigators arise from working in an area which constantly forces them to confront death and their lack of knowledge and adequate resources to combat it effectively. The result is that physician-investigators must cope with dual motivations-to save lives and to accumulate knowledge. Though the two motivations may complement one another, they do not do so necessarily-for example, there may be conflict in the process of selecting organ donors among healthy volunteers or of deter-

\footnotetext{
${ }^{40}$ Fox, $A$ Sociological Perspective on Organ Transplantation and Hemodialysis, 169 AnN. N.Y. ACAD. SCr. 406, 410-11 (1970).

${ }^{41}$ Personal communication, B. Scribner to J. Katz \& A. Capron.
} 
mining when a donor is sufficiently close to death to justify the removal of an organ. ${ }^{42}$

Although the motivation to safeguard life is central to the physician's training and self image, ${ }^{43}$ it may come up short against the need to make choices among several recipients who might benefit to varying extents from receiving a transplant. ${ }^{44}$ Patient-subjects have been selected on the basis of the contributions they can make to science, in the hope that others will eventually benefit. In the quest to pierce ignorance, procedures may also have to be tried which actually could shorten life if complications cannot be controlled. On the other hand, the desire to gain knowledge may be impaired by the traditional posture of exposing only moribund patients to new and unknown procedures. ${ }^{45}$

The strain of knowledge versus healing thus seems an inescapable facet of the clinical researcher's role. While the search for new knowledge and techniques is a part of all physicians' professed task, the physician-investigator may actually be obliged to conduct research and advance medical science in order to justify the privileges held by experimental medicine and to reaffirm the primacy of human life as a cultural value. ${ }^{46}$

Personal as well as professional factors enter into the decisions of physician-investigators. Though increasingly stressed, the conflictual implications of personal ambitions for success and fame on physician-investigators' activities have not been sufficiently acknowledged or explored. The myth of the dedicated and unselfish physician-scientist is still all too uncritically asserted. While it is hard, if not impossible, to differentiate among personal ambition, the striving for excellence, and the

42 Castelnuovo-Tedesco, Cardiac Surgeons Look at Transplantation-Interviews with Drs. Cleveland, Cooley, DeBakey, Hellman and Rochelle, 3 Seminars in PsYch. 5, 13 (1971).

${ }^{43}$ See Freud, supra note 37.

14 Ist Ann. John F. Kennedy Symposium on Recent, Significant DevelopMENTS IN MEDicine \& SuRgery (1968) (quoted in Fox, supra note 40, at 419).

45 Such patients are not necessarily the best subjects for research, since the failure of the intervention could in part rest on their already debilitated state rather than on the procedure itself. And investigations with moribund patient-subjects confront investigators with the dilemma of having "at once to prolong life, alleviate suffering, and respect the right of patients to die mercifully and with dignity . . .." Fox, supra note 40 , at 406 .

${ }^{46}$ Swazey \& Fox, The Clinical Moratorium: A Case Study of Mitral Value Surgery, in Experimentation with Human Subjects 315, 348 (P. Freund ed. 1969). 
quest for knowledge, it should at least be acknowledged that personal motivations are an ever-present and inevitable concomitant of advances in science. ${ }^{47}$ The absence of any recognized, legitimate place for such desires in the accepted model of professional decisionmaking may lead physician-investigators to underestimate the importance of self-interest in their decisions and to overvalue the significance they assign to more socially acceptable, altruistic motivations. This only serves to complicate the physician-investigator's "split personality," 48 by raising anxiety over the true motivation for his choices.

To note that physician-investigators may not be ideally suited to make decisions about catastrophic diseases alone is not to suggest, however, that at present they have a free hand to do so. There are a number of restraints, formal and informal, on a physician's freedom to do as he chooses. A major limitation is the scarcity of resources, both monetary and human. ${ }^{49}$ Perhaps even more important, especially in a research area such as the development of treatment for catastrophic diseases, is the uncertainty of outcome of his choices. ${ }^{50}$

Uncertainty reinforces the drive for knowledge, for only knowledge and experience can defeat uncertainty. But uncertainty also brakes this motivation, for it engenders personal anxieties about the impact of a new procedure on the patientsubject and social anxieties about the liabilities which physicianinvestigators and science might incur if a new intervention proves more detrimental than non-intervention would have.

These forces came together dramatically in a highly unusual medical development, the heart transplant moratorium that began in November 1968. That nearly complete cessation of the new procedure came about when physician-investigators

${ }^{47}$ See BARBER, supra note 35 , at 59-60.

${ }^{48}$ One physician, with long experience in clinical research, has identified in this "split personality" a "wide cleavage" between the physician's primary concern for "intimate, personal responsibility in caring for sick people" and the interests of the investigator "goaded by divine discontent and impelled by curiosity as well as ambition for renown" which "sometimes suppresses the physician [in his personality] altogether." Bean, A Testament of Duty-Some Strictures on Moral Responsibilities in Clinical Research, 39 J. Lab. Clin. Med. 3, 4 (1952).

${ }^{49}$ See Fox, supra note 40 , at 418.

so This was initially recognized as a major problem for physicians by Talcott Parsons, see T. Parsons, The Social System 447-54 (1951), and Renée C. Fox has written extensively on this theme. Fox, supra note 40 , at $406-07$. 
concluded that it was premature, that the risks to patients were not matched by expected benefits, and that the danger of a public disaffection with the entire process was great. ${ }^{51}$ While much of the impetus for the moratorium came from the investigators' peers and administrative superiors, it is still reassuring that research medicine has some self-control. Yet this example also illustrates that physician-investigators have been left almost entirely to their own devices in coping with the problems posed by such dramatic developments as organ transplantation; the startling curtailment of the cardiac operations, like the equally dramatic rush to perform transplants which preceded it, may have represented a very bad allocation of resources.

In addition to the internal restraints flowing voluntarily from physician-investigators, the major external restraints on research are imposed by codes of ethics, peers, hospitals, institutional review committees, and the law generally. Beginning with

${ }^{51}$ Swazey and Fox have recently called attention to the phenomenon of "the clinical moratorium," which they consider "generic to the process of therapeutic innovation." See Swazey \& Fox, supra note 46, at 315. They define it "to mean a suspension of the use of a still experimental procedure on patients, a suspension which may last for weeks, months, or years depending on the particular case." Id. 316. It represents a period of "reflection, re-evaluation, and study for the research physicians formerly conducting clinical trials. During this time, they often return to laboratory experiments in an attempt to solve certain of the problems that led them temporarily to cease human trials." Id. 345. Swazey and Fox also state that such moratoria can result by virtue of "internal" or "external" pressures. The internal pressures originate within "the research physician who feels that he ought to discontinue clinical trials," while the external pressures "are generated by the opinions of colleagues or lay persons that trials should not proceed, and by the actions they may take to implement their judgment." Id. 346. Moreover, these pressures may be invoked formally (for example, by withdrawing operating privileges from individual surgeons or halting a procedure altogether) or informally (for example, by colleagues' pleas that the reputation of surgery would be damaged if trials were continued). The concept of clinical moratorium, as so defined, merely points to the variety of potential mechanisms existing in clinical and investigative medicine to pause and reflect about the current state of a particular intervention.

From the vantage point of hindsight, the informal mechanisms reveal all their capricious weaknesses. They allowed, in the case of mitral valve surgery in the 1920's for example, the erroneous views of one of the world's most prominent cardiologists, Sir James Mackenzie, to exert undue influence over the progress of cardiac surgery, and the ingrained beliefs of referring physicians to halt the pioneering work initiated by the English surgeon Souttar. They tend to function inconspicuously and thereby to preclude a public review of the merits of maintaining a moratorium. Many of these same weaknesses are also inherent in the more formal moratorium mechanisms. Finally, Swazey and Fox's description of "moratoria" illustrates again a characteristic of medical practice generally: the influence on decisionmaking of personal beliefs and attitudes which have major consequences because of the absence of procedural mechanisms for challenging them. 
the "basic principles" set forth by the Nuremberg judges, numerous attempts have recently been made to propose "improved" codes of ethics to guide medical research. ${ }^{52}$ The proliferation of such codes testifies to the difficulty of promulgating a set of rules which do not immediately raise more questions than they answer. By necessity these codes have to be succinctly worded and, being devoid of commentary, their meaning is subject to a variety of interpretations. Moreover, since they generally aspire to ideal practices, they invite judicious and injudicious neglect. Consequently, as long as they remain unelaborated tablets of exhortation, codes will at best have limited usefulness in guiding the daily behavior of investigators.

Law, though generally an important external restraint, has had little to say about medical research except through HEW regulations. Judges in malpractice settings have made pronouncements about informed consent and the right to selfdetermination, and these doctrines will most likely be applied to the research setting when such litigation comes before courts. ${ }^{53}$ However, the special problems of research medicine may require a sustained dialogue between law and medicine in order to define, independently of the existing law for malpractice situations, the ambit of the authority of physicianinvestigators in human research. ${ }^{54}$ Finer tuning of the process is needed than that which can be supplied by retrospective damage awards (spread through insurance, in any case) or criminal sanctions, or prospective funding cut-offs, based on past missteps by the physician-investigators. Furthermore, researchers are understandably made particularly anxious by shifting, and ever more complicated, legal requirements.

The cumulative effect of the restraints upon physicianinvestigators is to impede the drive for developing new treat-

52 "The need to identify and to develop acceptable standards of care as an aid to the courts ... . began to receive limited but respectable support in the clinical research community in the late 1950's and early 1960's." Curran, Governmental Regulation of the Use of Human Subjects in Medical Research, 98 Daedalus 542, 545-46 (1969).

${ }_{53}$ See, e.g., Karp v. Cooley, 493 F.2d 408 (5th Cir. 1974); Kaimowitz v. Michigan Department of Mental Health, Civil No. 73-19434-AW (Cir. Ct. Wayne County, Mich., July 10, 1973); Halushka v. University of Sask., 52 W.W.R. (n.s.) 608 (Sask. Ct. App. 1965).

${ }_{54}$ Cf. National ${ }^{-}$Research Äct, 42 U.S.C.A. \$ 2891-1 note (1974) (establishing National Commission for the Protection of Human Subjects of Biomedical and Behavioral Research). 
ment modalities for catastrophic disease for a variety of reasons. ${ }^{55}$ Many, particularly some dedicated investigators, regard this as an unfortunate state of affairs. Other commentators have agreed with Hans Jonas that the advancement of knowledge should not be the primary objective:

Let us not forget that progress is an optional goal, not an unconditional commitment, and that its tempo in particular, compulsive as it may become, has nothing sacred about it. Let us also remember that a slower progress in the conquest of disease would not threaten society, grievous as it is to those who have to deplore that their particular disease be not yet conquered, but that society would indeed be threatened by the erosion of those moral values whose loss, possibly caused by too ruthless a pursuit of scientific progress, would make its most dazzling triumphs not worth having. ${ }^{\mathbf{5 6}}$

It does not appear that mechanisms have yet developed to mediate, in a rational and understandable fashion, between these polar viewpoints. One cannot be sure that the present allocation of authority-with most of it lodged with physicianinvestigators, subject to sudden, ad hoc alterations-has worked to the benefit of patient-subjects, science, society, or even investigators themselves. Hence it should be profitable to inquire whether such controls as sharing of authority with persons other than the transplant surgeon and his or her fellow physician-investigators, through the participation of patients in decisionmaking, ${ }^{57}$ peer consultation and review, and regulation by the profession and state, could prove to be useful safeguards.

${ }^{55}$ This problem is dramatically illustrated by an example from a scientific field unrelated to catastrophic diseases. A scientist interested in interspecies hybridization believes that important knowledge may be gained from studying the genetic mix resulting from breeding human beings and the higher apes. He is aware of the possible social, legal, and ethical problems arising from such investigations, yet wonders whether they may not be outweighed by the resulting knowledge. Yet he can turn to no one to learn whether society might not wish to approve his work. See Remington, An Experimental Study of Man's Genetic Relationship to Great Apes, by Means of Interspecific Hybridization, in KaTz, supra note 37 , at 461 .

${ }^{56}$ Jonas, Philosophical Reflections on Experimenting with Human Subjects, 98 DaEdalus 219, 245 (1969).

${ }^{57}$ The rest of this Article centers on the decisionmaking authority of patientsubjects; the roles of the professions and the state come in for greater analysis in the other parts of the book. 


\section{A Functional Approach to Informed Consent}

The "informed consent model" of decisionmaking developed here is intended to illustrate and explore the extent and limits of patient-subjects' authority and capabilities as the "beneficiaries" of the new treatments for catastrophic diseases and at the same time as the "means" through which such new treatments are developed. "Informed consent" is seen not as a highly formalized event through which the physician-investigator insulates himself from liability, but as an ongoing process through which the physician-investigator and patient-subject, along with other relevant participants including the latter's relatives, continually rededicate themselves to their joint endeavor or withdraw from it if they wish. The model attempts to incorporate a realistic view of the limitations and constraints that psychological forces and personal interrelationships place on informed and voluntary decisionmaking.

\section{A. The Functions of Informed Consent}

\section{To Promote Individual Autonomy}

The requirement of informed consent has two parts, both of which must be met before a medical intervention is permissible: first, that sufficient information is disclosed to the patient so that he can arrive at an intelligent opinion, and second, that the patient agrees to the intervention being performed. The latter facet in particular reflects the concern, traditional in western societies, that the autonomy of each person be respected. This principle is embodied in two great branches of the law: contracts and torts. Protection of the patient's autonomy is accomplished by means of a treatment contract between the physician and patient. Even though the terms of such a contract are usually not reduced to writing, its existence is a prerequisite for therapy. In addition to using the flexibility of contract law (which supplies a basic relationship for the parties while permitting them to vary its specifics according to their needs), the courts have also relied upon tort law to regulate the doctor-patient relationship. In sum, as an Illinois appellate court declared in Pratt $v$. Davis,

the free citizen's first and greatest right, which underlies all others-the right to the inviolability of his per- 
son, in other words, his right to himself-is the subject of universal acquiescence, and this right necessarily forbids a physician or surgeon, however skillful or eminent, who has been asked to examine, diagnose, advise, and prescribe ... to violate without permission the bodily integrity of his patient by a major or capital operation, placing him under anaesthetics for that purpose, and operating on him without his consent or knowledge. ${ }^{58}$

The obvious connection between bodily independence and independence of choice does not mean that autonomy serves only to insulate people from each other. On the contrary, autonomy is a value which deserves to be promoted, through a doctrine of informed consent and elsewhere in the law as well, because it encourages better interactions between the patient-subject and others. In protecting his autonomy of choice, the doctrine assures the patient that in going to a physician he will not be trapped into decisions which he does not want; the absence of such assurance would increase the inclination to delay seeking medical intervention even for serious conditions. By promoting trust and confidence between patient and physician, informed consent requirements may thus advance rational decisionmaking. ${ }^{59}$ Furthermore, autonomy is centrally associated with the notion of individual responsibility. The freedom to make decisions for oneself carries with it the obligation to answer for the consequences of those decisions. The requirement of consent for medical interventions thus serves to remind all the participants of their agreement concerning the procedure and their acceptance of those things which arise from its proper execution.

${ }^{58}$ Pratt v. Davis, 118 Ill. App. 161, 166 (1905), aff'd, 224 Ill. 300,79 N.E. 562 (1906). The rights of autonomy and inviolability of which the Illinois court spoke are creatures of private, not public, law. Although a similar statement might describe a person's rights vis-à-vis the state, what is usually at issue in the informed consent context are the rights which help define the relationship of patient to physician. Constitutional law may, however, come into the picture when the assistance of the state is sought by a physician in enforcing his wishes on a nonconsenting patient. See notes $134-49$ infra \& accompanying text.

${ }^{59}$ See text accompanying notes 81-85 infra. Cf. Comment, Valid Consent to Medical Treatment: Need the Patient Know? 4 DuQuesNe L. REv. 450, 458 (1966). 


\section{To Protect the Patient-Subject's \\ Status as a Human Being}

The "inviolability of one's person," of which the Pratt court spoke, goes beyond the philosophical notion of autonomy and reflects a deep-seated feeling about what it means to be "human." This concept is a complex but very important one, which partakes of remarkably contradictory connotations. ${ }^{60}$ Though part of the concern for human beings contained in our culture relates to protecting people physically, ${ }^{61}$ part also relates to the respect which is deemed proper for "nonphysical" aspects of humans, such as their power of thought. This mental component of the concept of "humanness" is expressed through the first facet of the informed consent rule: the requirement that the patient be informed. By emphasizing the importance of involving the patient in decisionmaking in a genuine fashion, this facet of the rule gives further recognition to his or her status as a human being. As Margaret Mead has perceptively commented,

To fail to acquaint a subject of observation or experiment with what is happening-as fully as is possible within the limits of the communication system-is to that extent to degenerate him as a full human being and reduce him to the category of dependency in which he is not permitted to judge for himself. ${ }^{62}$

Paul Ramsey has observed that informed consent is an important example of the faithfulness among people that is normative for all moral interaction. "The principle of an informed consent is the cardinal canon of loyalty joining men together in medical practice and investigation." ${ }^{63}$

${ }^{60}$ On the pejorative side, the human aspect is disapproved at both extremes: "To err is human, to forgive divine," and "Untouched by human hands." Contrarily, the term "human" is applied to suggest the sanctity of conduct, event, or rule, most particularly in the prohibitions against killing (which protect, in the normal course, humans but not other animals or machines) and the condemnation of conduct such as that of the Nazis in the concentration camps, who failed even to accord their prisoners "the status of human beings."

${ }^{61}$ But see Calabresi, Reflections on Medical Experimentation in Humans, 98 DaEdalus 387 (1969).

${ }^{62}$ Mead, Research with Human Beings: $A$ Model Derived from Anthropological Field Practice, 98 Daedalus 361, 375 (1969).

${ }^{63}$ P. Ramsey, The Patient as Person 5 (1970). He goes on to explain:

Consent as a canon of loyalty can best be exhibited by a paraphrase of Rein- 
For informed consent to create a true "joint enterprise," or what Talcott Parsons calls an "associational collectivity,"64 between physician-investigator and patient-subject, the latter's right to full information and to give or withhold assent must be scrupulously respected. ${ }^{65}$ The partnership of physicianinvestigator and patient-subject is based on the mutual recognition that the subject, as a human being, retains the authority to determine what will be done to himself and to receive an explanation of all proposed procedures from his professional collaborator. The enterprise in which both are engaged -whether clinical research or ordinary therapy-requires the cooperation of both for its success, or indeed for its very existence. Thus, it is not for the physician, any more than for the patient, to command the other's participation, whether directly or by turning the consenting process into a charade, a symbolic but contentless formality.

The danger always exists that a physician's belief in the potential benefits of a new medical procedure, such as heart transplantation, will subtly erode his willingness to regard his patient as a full partner in the undertaking. This is especially true as medical procedures become increasingly complicated and a corps of specialists, rather than a lone physician, treats

\begin{abstract}
hold Neibuhr's celebrated defense of democracy on both positive and negative grounds: "Man's capacity for justice makes democracy possible; man's propensity to injustice makes democracy necessary." Man's capacity to become joint adventurers in a common cause makes the consensual relation possible; man's propensity to overreach his joint adventurer even in a good cause makes consent necessary. In medical experimentation the common cause of the consensual relation is the advancement of medicine and benefit to others. In therapy and in diagnostic or therapeutic investigations, the common cause is some benefit to the patient himself; but this is still a joint venture in which patient and physician can say and ideally should both say, "I cure."
\end{abstract}

Id. 5-6 (footnote omitted).

${ }^{64}$ Parsons sees the associational collectivity as something less than a true joint enterprise since he doubts that research subjects can stand on an equal footing with the investigators. Parsons, Research with Human Subjects and the "Professional Complex," 98 Daedalus 325, 344 (1969). John Fletcher's empirical research on ethics in the consent situation at N.I.H.'s Clinical Center in Bethesda provides striking instances of patient-subjects who saw their human status being affirmed through their decision to collaborate in nontherapeutic research. See Fletcher, Realities of Patient Consent in Medical Research, 1 Hastings Center Studies 39, 44-46 (1973).

${ }_{65}$ This posture of course does not preclude a patient-subject explicitly instructing his physician not to tell him. He may do so for many reasons, including complete faith in his physician's actions. See Putensen v. Clay Adams, Inc., 12 Cal. App. 3d 1062, 1083-84, 91 Cal. Rptr. 319, 333 (1970). 
a patient for a catastrophic disease. The physician, often a surgeon, who is in charge of this veritable army ${ }^{66}$ undeniably has the upper hand in the doctor-patient relationship. ${ }^{67}$ Indeed, he may be the originator of a new technique which offers a desperate patient a "chance for cure" which he cannot get from any other practitioner. ${ }^{68}$ Yet if the patient's authority is seen as being at an end once he takes the step of initiating the relationship-if he is taken as having given a blanket consent to all steps directed by the physician-investigator-not only will his status as a human being be diminished, but rational decisionmaking may be seriously undermined. Having the patient place himself entirely within the physician's hands has been an accepted part of medical ideology, justified by the physician's concern for the patient's well-being and his alleged need for complete freedom to undertake whatever steps are believed necessary to promote it. But the risk is great, especially in experimental medicine, that the patient's abdication of his decisionmaking authority will convert him from an end in himself to a means that can be employed along with others at the physician's command to serve the goal of the procedure, as defined by the physician and his peers. One need not even

${ }^{66}$ Military analogy is an apt description not merely of the size of the medical team but of its hierarchical organization. The members of the team, particularly those who are not physicians, are likely to defer to the primary physician-investigator, not only on close matters of judgment but even when they are convinced he or she is doing something scientifically or ethically wrong. Most of the engineers and technicians who worked on the preparation for the implantation of the artificial heart into Mr. Karp figured out that a human trial was being planned, but, with one exception, they did not voice objections (although they believed animal testing to have been inadequate) and did not notify Dr. DeBakey (although they concluded that Drs. Cooley and Liotta were operating behind DeBakey's back and without his permission). R. Fox \& J. Swazey, supra note 11, at 161-64, 197-200.

${ }^{67}$ Among the members of the transplant team, only one or two-the surgeon and, perhaps on a more sustained basis, the immunologist who must supervise the difficult postoperative period and administer the immunosuppressive drugs to fight tissue rejection-will have personal contact with the patient; even this contact will probably be more fleeting than that of the patient with his referring physician or "family doctor."

${ }^{68}$ This was dramatically illustrated in the only implantation of a mechanical heart substitute to date. See Karp v. Cooley, 349 F. Supp. 827 (S.D. Tex. 1972), aff'd, 493 F.2d 408 (5th Cir. 1974). In that case, the patient had experienced severe heart troubles for ten years and was near death when he went to Houston to be treated by Dr. Denton Cooley, who was then the only surgeon willing to attempt an "artificial heart" operation. The patient signed a consent for the temporary use of a mechanical heart replacement in case an attempt to reconstruct his own heart (ventriculoplasty) were unsuccessful. See note 5 supra. 
observe that in clinical research an experiment may succeed without restoring the patient-subject to health, to conclude that the requirement of an ongoing collaboration among the participants, expressed through a process of renewed "informed consents," is needed to protect the human status of all.

\section{To Avoid Fraud and Duress}

While these humanistic or philosophical aspects of informed consent clearly have practical aspects as well, the requirement serves additional practical functions. One consequence of truly informed consent is to remove, or at least to diminish, the danger of fraud and duress. ${ }^{69}$ The legal model of the doctor-patient relationship should, of course, recognize the very real limitations on rationality which serve to undermine the useful force of the informed consent rule; these are discussed more fully later in this Article. Yet the model constructed by the law of informed consent still has validity: to the extent that the physician-investigator engages the patientsubject in a comprehensive and comprehensible discussion of the proposed treatment, he reduces the likelihood of misleading or overbearing the patient-subject. The danger that the physician will neglect this duty is probably greater in the case of standard therapy than it is for the major interventions which are of concern here. Nevertheless, physician-investigators' understandable desire to avoid discussing difficult and painful matters and incurring the risk of upsetting the patientsubject, as well as the pressures of time and economics which operate in the catastrophic disease context, may tend to undermine careful adherence to the letter of the law. ${ }^{70}$

Without legal intervention, ${ }^{71}$ the idea that the treatment contract would be bargained out between equals is somewhat

${ }^{69}$ The first point in the judgment against the Nazi prison camp physicians, the "Nuremberg Code," requires that research participants be enlisted "without the intervention of any element of force, fraud, deceit, duress, over-reaching or other ulterior form of constraint or coercion." Edmond Cahn describes the use of necessitousness as the "engineering" of consent, Cahn, The Lauryer as Scientist and Scoundrel: Reflections on Francis Bacon's Quadricentennial, 36 N.Y.U.L. REv. 1, 11 (1961); consent can also be "engineered" through more subtle means, such as the exploitation of the physician-patient differential in knowledge.

${ }^{70}$ The avoidance of discussion by physicians with patients, which may become a tool of witting or unwitting deception, is discussed in Note, supra note 25, at 1541-55.

7' Physicians' self-regulation may also be designed to prevent fraud and overreaching; the Hippocratic Oath's admonition against "seduction" may encompass not 
naive; indeed, the patient usually finds himself faced with an agreement which is à prendre ou à laisser. ${ }^{72}$ In such case, two remedies present themselves: the law can either remove the choice from the hands of the weaker party (in this instance, the patient-subject) or it can attempt to buttress his ability to exercise choice by erecting certain formal requirements of disclosure. Since the former would represent an abandonment of the basic principles of individual freedom, resort to it is usually limited to situations in which a repeated pattern has demonstrated that "as a matter of law" agreements of the type in question are unconscionable, in that they do not result from the unfettered exercise of rational choice. ${ }^{73}$ In the doctor-patient context, the trend seems to be toward the second alternative, the establishment of rules of disclosure. While this process has not become formalized in Miranda-style ${ }^{74}$ requirements as yet, most medical centers have their own "informed consent" forms for patients, and the federal government has issued a "guide" for the protection of human subjects which sets forth the elements of informed consent:

1. A fair explanation of the procedures to be followed, and their purposes, including identification of any procedures which are experimental;

2. A description of any attendant discomforts and risks reasonably to be expected;

only sexual misconduct "but also, as the Oxford Universal Dictionary adds, 'acts of seducing a person to err in conduct or belief' and 'the condition of being led astray." " Katz, The Regulation of Human Research-Reflections and Proposals, 21 Cun. RESEARCH 785 (1973).

${ }^{72}$ Cf. Kessler, Contracts of Adhesion-Some Thought About Freedom of Contract, 43 Colum. L. Rev. 629 (1943).

${ }^{73}$ See, e.g., Williams v. Walker-Thomas Furniture Co., 350 F.2d 445 (D.C. Cir. 1965); 25 U.S.C. $\S \S 81-88$ (1970) (limitations on Indians' right to contract); N.Y. GeN. Obligations Law § 5-321 (McKinney 1964) (contract exempting lessor from liability for negligence void as against public policy). The same provision may be valid as to one group and invalid as to another; cognovit clauses (confession of judgment) have been upheld where a debtor effectively waived his rights, D.H. Overmyer Co. v. Frick Co., 405 U.S. 174 (1972), but declared unconstitutional when applied to debtors with incomes below $\$ 10,000$, Swarb v. Lennox, 314 F. Supp. 1091 (E.D. Pa. 1970), aff'd, 405 U.S. 191 (1972).

${ }^{74}$ Miranda v. Arizona, 384 U.S. 436 (1966). This case established strict procedures for what has to be told to persons who are subjected to custodial police interrogation. Cf. Note, supra note 25, at 1561-62 (suggesting "formal rules of disclosure").

Midway between these two approaches is one perhaps best exemplified by the federal government's approach to cigarette smoking. Rather than banning it outright in light of the practice's demonstrably deleterious effects on the user's health (which 
3. A description of any benefits reasonably to be expected;

4. A disclosure of any appropriate alternative that might be advantageous for the subject;

5. An offer to answer any inquiries concerning the procedures;

6. An instruction that the person is free to withdraw his consent and to discontinue participation in the project or activity at any time without prejudice to the subject.

... No such informed consent, oral or written, ... shall include any exculpatory language through which the subject is made to waive, or to appear to waive, any of his legal rights, including any release of the organization or its agents from liability for negligence. ${ }^{75}$

Thus, by detailing the obligation of physician-investigators to warn their patient-subjects fully about their rights, such statements increase the likelihood that the informed consent rule will help to avoid intentional and unintentional fraud and duress.

\section{To Encourage Self-Scrutiny by the Physician-Investigator}

The requirement of disclosure contained in the informed consent rule raises some perplexing problems for a physician working on the frontiers of catastrophic disease treatment. Perhaps foremost among these is the question: How can one make known to patient-subjects the risks and benefits of new and often untried techniques? A partial response to this query is that one can at least be candid with the patient about the unknown nature and experimental status of the treatment offered as well as about the existence of other established methods, inadequate as they may be. Beyond this, however, the physi-

would be deprivation of the right to contract) or requiring that certain information be conveyed (which was the approach taken initially by the FCC in requiring "equal time" for anti-smoking advertisements), Congress finally banned cigarette commercials from the air waves, counting on the beneficial effects of a lack of "information" (i.e., advertising) while also requiring a health warning to be placed on each cigarette package.

${ }^{75}$ U.S. Dep't of Health, Education \& Welfare, The Institutional Guide to DHEW Policy on Protection of Human Subjects 7 (1971) (footnote omitted), as amended by 39 Fed. Reg. 18914 (1974). Cf. 21 C.F.R. $\$ 130.37$ (1973) (F.D.A. policy on informed consent). 
cian-investigator has the additional duty of discovering as much as reasonably possible about the new techniques he proposes to employ. At a minimum this would include making a thorough inventory of the risks of such techniques which have been described in the literature by other investigators. In most situations it would also encompass the duty to explore this aspect of the proposed procedure through animal experimentation and the like to uncover risks of any consequence; this duty is reflected in the accepted principle of biomedical research, independent of the law of informed consent, that human trials ought to be undertaken only after a medical innovation has been shown in animal tests to be relatively risk-free, as compared with its potential benefits. Thus, knowledge sufficient to justify the use of an innovative procedure should usually also suffice for the purpose of consent.

Although some risks will remain "unknown," a candid physician-investigator can still involve his subjects in a valid informed consent process. This would be encouraged if consent to "unknown risks" is taken to include only those "unknown risks" of which the subject is made aware. Such a position does not involve a contradiction in terms, for the patient-subject can certainly be informed of the existence of certain risks whose probability and degree cannot be precisely predicted. There are others which the patient-subject cannot be said to have accepted since the investigator did not anticipate them; it may reasonably be assumed that in most cases the latter category would be very small. The consent is nevertheless valid if the person giving it has been alerted to this residual risk in all clinical research; if the risks exceed this small category and should have been anticipated by a prudent physician-investigator, he would be liable for not discovering and disclosing them. A distinction also exists between risks to which it was reasonable to expose a patient-subject and those which were unreasonable. A physician-investigator who proceeded in the latter instance would of course not be able to assert "consent" as a defense to a claim of negligence. ${ }^{76}$ Nor does this impose an unjustified limitation on the patient's right to contract as he chooses-even for "unreasonable" procedures to be performed. In a free, liberal society an individual may well have such a

${ }^{76}$ Accord, Waltz \& Scheuneman, supra note 20 , at 632-35. 
right, but the doctrine of informed consent has a more limited frame of reference, which is the physician-patient relationship. The physician's authority is limited to doing those things which professional opinion holds to be of potential benefit to the patient. This limitation thus inheres in the agreement between the parties.

The need to obtain the patient-subject's informed consent thus tends to enhance the scientific validity and the safety of the trials of new medical procedures in man. This derives from the "reflexive effect [of the obligation to obtain consent] on the management of the experiment itself," as Professor Paul Freund has pointed out. ${ }^{77}$

To analyze an experiment in terms of risks and benefits to particular groups by way of presentation for consent is a salutary procedure for self-scrutiny by the investigator-like the preparation of a registration statement by a corporation issuing securities. ${ }^{78}$

If, for example, the surgeons engaged in the initial heart transplants had felt they had to give a full explanation of the risks of graft rejection to the proposed cardiac recipients, they might have proceeded more slowly in the light of the rather disheartening results which had been reported in animal trials and in human kidney transplants at that time when immunosuppressive techniques were still in their infancy.

As useful as the informed consent requirement may be in encouraging professional self-scrutiny and thereby avoiding thoughtless disrespect of patient-subjects, there is no reason to believe that the end result is assured. Indeed, rather than undertake this process, physician-investigators may instead raise arguments over whether their subjects have the capacity to understand what they are told. Yet this is "a displacement from the real issue, which is the dread of an open and searching dialogue between the investigator and his subject. This displacement is caused by the unacknowledged anxiety over making the invitation in the first place."79 The rules constructed by the law for medical practice and research may thus force

\footnotetext{
77 Freund, Legal Frameworks for Human Experimentation, 98 DAEDALUs 314, 323 (1969).

${ }^{78}$ Id.

${ }^{79} \mathrm{Katz}$, supra note 71 , at 787 .
} 
the profession to confront this underlying anxiety, ${ }^{80}$ or they may themselves be rendered ineffective by these undeniable yet unspoken psychological forces.

\section{To Foster Rational Decisionmaking}

Thus far emphasis has been placed on the role of informed consent in protecting patients' autonomy from coercion or disrespectful usage. The preceding section, however, has begun to suggest that reliance on consent can also help physician-investigators to carry out their responsibilities more satisfactorily. The beneficial effects of informed consent in promoting rationality of decisionmaking about catastrophic disease treatment and research go beyond influencing the investigator. The requirement of informed consent symbolizes a commitment to making the process of developing new therapies a joint enterprise. By actively encouraging the biomedical professionals to include the patient-subject in the decisional process, informed consent serves to place him on a plane with the physician-investigator and to involve him as a person in the work-not merely as an object on which it is being performed. For the participants to remain on the same plane requires a commitment that they view each other not only as equally important individuals but also as joint participants in decisionmaking. Accomplishing this will require, beyond a change in attitude, learning how to communicate to patient-subjects those aspects of the proposed research which will allow them to make decisions at least as rationally as they have made others about their lives. ${ }^{81}$ If the basic elements of information and agreement (as suggested in this Article and in documents such as the HEW guidelines ${ }^{82}$ ) are faithfully adhered to, patientsubjects can help to promote rational decisionmaking.

A rule of informed consent congenial to the model of catastrophic disease decisionmaking elaborated here would view patient-subjects as exercising a major influence on the plans of physician-investigators. Thus, they can also become guarantors of their own rights to autonomy and dignity, by

\footnotetext{
${ }^{80}$ See notes 53-54 supra \& accompanying text.

${ }^{81}$ The difficulties with which "rational decisionmaking" must contend are discussed in the text accompanying notes 87-123 infra.

${ }^{82}$ See note 75 supra \& accompanying text.
} 
exercising a check over the judgment of physicians who all too often may be biased by their strong desire to "conquer disease."

Moreover, there is no objective, "medical" way to determine the proper treatment for an individual, since disease itself is not an objective concept but depends upon the degree of dysfunction experienced under given conditions by each individual. Thus rationality in resource allocation is possible only when the individuals who bear the costs and receive the benefits from the allocation determine the value of the outcomes. The determination whether a particular project will yield returns to science and society in excess of its costs is best made by biomedical researchers and representatives of the collectivity (to the extent that such an issue is capable of resolution at all). But who, other than the patient-subjects, can determine whether the benefits of a procedure, conventional or experimental, outweigh the burdens that will be imposed on them? If responsibility follows choice in a system of voluntary interactions, the costs of the system will be minimized when the placement of responsibility (with the consequent incentive to avoid harm) determines who shall have authority to exercise choice. ${ }^{83}$

Some physician-investigators have always been acutely aware of the value of the old adage "two heads are better than one." Their commitment to informing and consulting with their patient-subjects has been based on a recognition of the value of intelligent and dedicated partners, be they patients or fellow scientists. A well-informed patient, after all, is more alert to facts about his own condition that may be of great significance to the investigator, and he also feels freer about reporting what he experiences to his physician, without fear

${ }^{83}$ Cf. G. Calabresi, The Costs of Accidents (1969). Placing the power of choice with the patient-subject, although necessary to an efficient resource allocation, is not sufficient for it, since some patient-subjects may be "irrational" decisionmakers, may be unaware of the potential costs of their decisions, or may be able to externalize those costs onto others. Nevertheless, there are economic reasons (as well as the other functions served by informed consent as discussed in the text) why patientbased decisionmaking, even if somewhat "irrational," may still represent the leading "second-best" allocation of authority, because the difficulty and expense of giving decisional power to a proxy may easily outweigh any marginal increment in rationality. Most attempts at substitute decisionmaking have been cumbersome and costly. See, e.g., 39 Fed. Reg. 30648 (1974) (proposed amendments to HEW regulations on research with subjects who have limited capacity to consent); notes 205-17 infra \& accompanying text. 
of upsetting him or losing his support. Similarly, a "patientpartner" is better able to endure the often arduous period of recuperation. ${ }^{84}$ Many physician-investigators recognize the value of such dedication and take the opportunity of medical publication or meetings to give credit and thanks to their "coadventurers." 85

\section{To Involve the Public}

A final function of informed consent in this model looks outside the physician-patient setting to an involvement of the larger society, since the obtaining of consent can be important for a doctor's, or a medical center's, public relations. ${ }^{86}$ Informed consent may also function beyond the area of public reputation and serve to increase society's awareness about human research. This phenomenon is particularly noticeable in the area of organ transplantation. The need to obtain consent from large numbers of potential donors for the removal of their kidneys after death has led to an extensive program of information about renal transplant programs. While the motivation for this information campaign was to recruit individual donors, it also enlightened the public at large about a new development in medicine. The general public thereby becomes an informed decisionmaker, able through legislative actions and the like to accelerate, halt, or alter transplant efforts according to its evaluation of the details disclosed.

\section{B. Problems of Effecting Informed Consent}

Any doctrine of "informed consent" must take account of the limitations on patient-subjects' capacity to make intelligent and insightful choices. Some of these constraints are inherent in the intellectual faculties, psychological forces, and social pressures affecting the participants, while others result from personal, professional, and societal judgments about the scope of the authority which patient-subjects should be allowed

\footnotetext{
${ }^{84}$ See notes 111-23 infra \& accompanying text.

${ }^{85}$ See Fox, Some Social and Cultural Factors in American Society Conducive to Medical Research on Human Subjects, 1 CuIN. Pharm. \& Therap. 423, 432-41 (1960).

${ }^{86}$ The reverse is certainly true: a physician who develops the reputation of using his patients as guinea pigs for his studies or medical innovations without their informed consent will be avoided by those who know that reputation. See Kidd, Limits of the Right of a Person to Consent to Experimentation on Himself, 117 SCIENCE 211, 212 (1953).
} 
to exercise. An awareness of these problems on the part of all the participants should aid in overcoming the failures of communications, understanding, and intelligent decisionmaking that now distort the process; furthermore, an understanding of the limitations is crucial for the construction of a useful analytical model.

\section{The Impact of the Inner World}

In contemporary society the importance of unconscious forces on personal conduct is increasingly acknowledged, though the extensive scope and pervasive effect of these influences is often still resisted. To note the existence of such unconscious forces does not, of course, deny the role in decisionmaking played by the conscious mind, which is likewise the product of environmental influences and hereditary preconditions. Yet the impact of unconscious drives and feelings is probably particularly great when it comes to the pressing issues which are involved in catastrophic disease treatment: life and death, giving and receiving, mutilation and restoration.

A revealing study by Drs. Carl $H$. Fellner and John $R$. Marshall $^{87}$ illustrates this point. Their work concerns kidney transplantation, which is unusual among medical procedures in turning a healthy person into a "patient," since a living person who donates a kidney is at some immediate risk (death or disability through the operative procedure) and a much smaller long-term risk (should his or her remaining kidney fail). Needless to say, this unique situation sets up special strains for physicians as well as donors and donees. Fellner and Marshall interviewed a group of live kidney donors after (and in a few cases before) surgery, concerning the reasons for their decision to donate a kidney to a close relative and the process by which the decision was reached. They had assumed that the donors would make up their minds at the end of the lengthy process during which they were first told of the need for a kidney, then subjected to medical examinations, and finally informed of the transplant team's conclusions about their suitability and of the risks of giving up a kidney. Fellner and Marshall were surprised to discover that the decisions of the donors were ap-

${ }^{87}$ Fellner \& Marshall, Kidney Donors-The Myth of Informed Consent, 126 AM. J. Psychiat. 1245 (1970). 
parently made long before there had been an opportunity for adequate information-gathering and considered balancing of pros and cons:

Not one of the donors weighed alternatives and rationally decided. Fourteen of the 20 donors and nine of the ten donors waiting for surgery stated that they had made their decision immediately when the subject of the kidney transplant was first mentioned over the telephone, "in a split-second," "instantaneously," and "right away." Five said they just went along with the tests hoping it would be someone else. They could not recall ever really having made a clear decision, yet they never considered refusing to go along either. As it became clear to each of them toward the end of the selection process that he was going to be the person most suited to be the donor, each had finally committed himself to the act. However, this decision too occurred before the sessions with the team doctors in which all the relevant information and statistics were put before these individuals and they were finally asked to decide.

Of all the subjects who made their initial decision on the telephone upon first hearing of the possibility of the kidney transplant, none had consulted his or her spouse. When questioned about this particular circumstance each explained that the spouse later on had either been neutral or reinforced the decision. To the hypothetical question of "What would you have done if your spouse had said no?" each answered,"I would have gone ahead and done it anyway." 88

Similarly, the few relatives who failed to show up for the initial blood test (ABO compatibility was used as the preliminary screening device) also had made their decision instantaneously and only later developed the "necessary" reasons to support their action.

The phenomenon observed by Fellner and Marshall may not establish, as they believe, that the kidney donors failed to decide "rationally." While it is possible to articulate all the elements and processes of formal, rational decisionmaking, ${ }^{89}$ too

${ }^{88}$ Id. 1247.

${ }^{89}$ See, e.g., Nomos VII-Rational Decision (C. Friedrich ed. 1964); H. Lasswell, The Decision Process (1956). 
little is known about actual human thought processes to preclude from the realm of the rational all decisions arrived at "instantaneously." Yet the fact that a decision, once reached, seems not to be subject to reconsideration as additional, arguably material information is supplied raises questions about whether optimum choices are being made. At the least, the phenomenon observed by Fellner and Marshall (which one may safely assume is not restricted to decisionmaking about renal transplants) would suggest that to be effective, the model of the informed decisionmaker propounded depends upon a collaborative give and take beginning with the earliest contact of physician-investigator and patient-subject. At a minimum the latter should be made aware, as early as possible, of an outline or sketch of the project on which he is being asked to embark, even if some of the potential steps are still far in the distance. There will, of course, be a need to review each step as it materializes, but the practice of waiting, as is the prevailing practice, until the very point of the intervention (for example, the night before major surgery, after the patient has already checked into the hospital) seriously undermines the patient's comprehension and voluntariness, which are supposedly embodied in his "informed consent." 90

The results of the Fellner-Marshall study raise the additional issue whether, given the not inconsiderable risks and the suddenness of the decision, the donors were in any way mentally unbalanced; they conclude not. Dr. Harrison Sadler and his colleagues found strikingly similar results among genetically unrelated kidney donors; these physicians also clearly believe that the donations were proper and were made for "healthy" reasons. Sadler and the San Francisco transplant team found no indications that their donors manifested psychopathology, character disorders, or infantile impulses which would undercut the altruism of their acts; the "primary motive" of these unrelated donors "was not in the drives but in the very personal area of self-identity, a self-ideal quite uncon-

90 See Schonberg, Informed Consent, 230 J.A.M.A. 38 (1974). The possibility of some, albeit limited, freedom of choice after the patient-subject has "crossed the bridge" is suggested by Professor Fletcher's finding that "the decision to enter research [among the patients he studied at the clinical center in Bethesda] was made prior to entering the hospital, though decisions about particular studies and their related demands were not made until after admission." Fletcher, supra note 64, at 40. 
scious to them at the time."91 Although the donors were unaware of these factors and thus could not take them into account in "rational" decisionmaking, Sadler concluded that their decisionmaking was nevertheless psychologically coherent. The decisions were dominated by nonrational forces, which seemed nevertheless to be an integral part of their overall personality structure; accordingly, no doubts are raised about the donor's competency nor is it likely that they will disavow their decisions, as they might attempt to do had the decisions resulted from psychopathology.

The most remarkable and universal quality of this group was their aura of sureness which pervaded the whole transplant encounter. They "knew" they would respond to the appeal. (They spoke of an "inner quickening-as though an already programmed circuit had been aroused.") They "knew" their response was wholesome, and they "felt sure" that they would match and be chosen and that the operation and postoperative period would be successful and uncomplicated. ${ }^{92}$

The donors of kidneys are not the only ones in whom the decisional process is deeply affected by "inner forces" which do not comport with the "model" of conscious and careful choice. The burden of disease also alters kidney transplant recipients' thinking, because of both the physiological changes and psychological difficulties they experience. As with other life-threatening conditions, the physician's disclosure to the patient that he has end-stage renal disease usually brings on depression, ${ }^{93}$ followed by "denial" which "functions as a buffer after unexpected shocking news, allows the patient to collect himself and, with time, mobilize other, less radical defenses."94 For terminal patients, denial of their condition and its gravity may thus have certain adaptive value, and this psychological process is exhibited by most patients at some point. ${ }^{95}$ This de-

${ }^{91}$ Sadler, Summary Notes on a Clinical Decision-Making Model, May 9, 1972 (unpublished memorandum by one of our consultants).

${ }^{92}$ Sadler, Davison, Carroll \& Kountz, The Living, Genetically Unrelated, Kidney Donor, 3 Seminars in Psych. 86, 92 (1971).

${ }^{93}$ B. Glaser \& A. Strauss, Awareness of Dying 121 (1965).

${ }^{94}$ E. Kübler-Ross, ON Death and Dying 35 (1969).

${ }^{95}$ Although differing somewhat about the sequence, the in-depth psychological studies of patients with terminal illnesses portray patients as passing through a num- 
fense may, however, seriously interfere with the patient's ability to make realistic decisions, especially since he is also probably suffering from feelings of helplessness, dependency, and further depression. "Those factors ... repressed by the denial alter the orderly processing of data, and decisions made at this level are processed by mechanisms which fail to account completely for reality factors and give them symbolic quality in keeping with the dominant wish." 96

Taken together, the startling evidence about kidney donors' and recipients' decisionmaking illustrates and confirms the importance of internal and often unperceived influences on decisionmaking about accepting or rejecting interventions in catastrophic illness. It also serves to emphasize the need for attention to matters such as time and expectations in the administration of the informed consent requirement.

\section{The Impact of the Outer World}

More readily apparent, but not much easier to quantify, are the environmental influences on patients.

A family member is dying of renal disease, and his best chance for survival with a tolerable life is to be the recipient of a kidney from a relative whose tissue-type closely matches his own. No matter how scrupulously low-keyed and sensitive the medical team's process of screening candidates may be, the fact remains that . . . prospective donors are under very great inner and outer pressure to give an organ to their suffering relative who, in turn, is under extraordinary pressure to receive one. ${ }^{97}$

Fellner and Marshall found that while families did not necessarily decide who would be the donor, they often determined who would be excluded from consideration, either to

\footnotetext{
ber of "stages" of attitude, behavior, and feeling after they learn of their condition. See, e.g., B. Glaser \& A. Strauss, supra note 93, and E. Kübler-Ross, supra note 94. While these studies thus contradict the accepted medical folklore about the way patients react to "the truth," see text accompanying notes 111-23 infra, they also indicate that patients' ability to work their way through the stages beyond denial and depression is highly dependent on their having candid, trusting relations with their physician and other hospital personnel.

${ }^{96}$ Sadler, supra note 91 , at 6.

${ }^{97}$ Parsons, Fox \& Lidz, The "Gift of Life" and Its Reciprocation, 39 Soc. ReSEARCH 367,413 (1972).
} 
protect that person or to reflect the intra-familial belief that he or she is "unsuitable." The opinions of family and friends did not need to be expressed overtly to be influential. The pronounced effect of environmental stimuli on the decision to volunteer for any procedure has been well recognized.98 It strains credibility to think, for example, that the teenage children who were asked to give up a kidney for their ailing twin had any difficulty in perceiving the response expected from them even when they were told that the choice was entirely "up to you." Whatever they really thought of their fate, once their parents had had them tested in the hospital and had petitioned for permission to authorize surgery, it is not surprising that they uniformly told judges and psychiatrists that they desired to donate a kidney. ${ }^{99}$

Heavy psychological burdens that can seriously distort any process of informed and rational decisionmaking are not restricted to organ donors and recipients but affect patients on hemodialysis as well. In those centers in which dialysis was viewed as a stop-gap until the patients could have their kidneys replaced, the spirits of the patients would rise with the approach of each long holiday weekend, for they knew that there would be a large number of automobile accidents, which would heighten their chances to receive a kidney from an accident victim. This macabre "holiday syndrome" had an equally sinister backlash: if the weekend passed without a suitable donor becoming available, deep depression would spread through the dialysis units. Such a state of mind is clearly not conducive to a sound or lucid decisional process, especially on whether to persevere with the arduous dialysis regimen.

Similarly, some families feel pressured to provide dialysis at home because of many physicians' preference for its lower cost (over treatment in a kidney center) and such other advantages as fewer medical complications, flexible scheduling, and reduction of cross-infections between dialysands. Despite some reports of "psychologic improvement, family unity and a feeling of self-confidence and accomplishment," it must be recognized that not all families truly want or are really able to

${ }^{98}$ Rosenbaum, The Effect of Stimulus and Background Factors on the Volunteering Response, $53 \mathrm{~J}$. A Bnormal \& Soc. Psych. 118 (1956).

${ }^{99}$ See Curran, $A$ Problem of Consent: Kidney Transplantation in Minors, 34 N.Y.U.L. Rev. 891 (1959). 
take on the burden of caring for kidney failure at home. ${ }^{100}$

Finally, a patient-subject's concern for his family's economic and emotional well-being may weigh heavily in his decision to embark on a lengthy and perhaps risky treatment for his catastrophic illness. These factors probably affect decisions even in circumstances where the family professes indifference to its possible financial suffering or where outside funding sources are available to defray most of the expense. ${ }^{101}$

\section{The Impact of the Relationship}

Families do not exert the only "outside" influence on patient-subjects' decisionmaking. Indeed, in many respects the relationship of physician-investigator to patient-subject may have greater impact. A great deal has been written on doctorpatient interaction, especially concerning the "transferences" and "countertransferences" which are the hallmark of this process. ${ }^{102}$ The childlike expectations on the patient's part, encompassed in the transference concept, and the physician's reciprocal feelings, are nowhere more evident than in the treatment of life-threatening diseases. Any illness may undermine a person's normal ego strength; a crippling disease which puts a patient in a sickbed without prospect of recovery can call forth ultimate dependence, cooperation, and devotion to the all-powerful physician who possesses the magical means of curing him. This combination of infantile regression and projection of a parental image onto the physician has often been observed in treatment and research settings, particularly when

${ }^{200}$ See Blagg, Hickman, Eschbach \& Scribner, Home Hemodialysis: Six Years' Experience, 283 NEw ENG. J. MED. 1126 (1970) (continued severe stress with maladjustment found in $19 \%$ of home dialysands); DePalmer, Open Forum: Home Dialysis, 2 Dial. Transplant 10 (1973) (home dialysis not suitable in approximately $80 \%$ of cases); Friedman \& Kountz, Impact of HR-1 on the Therapy of End-Stage Uremia, 288 NEW ENG. J. MED. 1286 (1974) (concluding that problems of home dialysis "are only now emerging in perspective," making it too early to set a limit on extent of center dialysis).

${ }^{101}$ See Burton, Whither Dialysis and Renal Transplantation?, 230 J.A.M.A. 1403 (1974).

${ }^{102}$ Freud first used "transference" to describe the "striking peculiarity of neurotics" to develop strong emotional bonds with their analysts, S. Freud, Psychoanalysis, in 20 Standard Edition of the Complete Psychological Works of Sigmund Freud 265, 268 (J. Strachey ed. 1959). This phenomenon occurs generally in physician-patient relationships and is employed as a force to varying degrees by different psychotherapeutic schools. See Gill, Psychoanalysis and Exploratory Psychotherapy, 2 J. Am. Psychoanalytic Ass's 771 (1954). "Countertransferences" are the therapist's projections onto the patient of his own image and desires. 


\section{the patient has sought out the physician as a specialist, espe- cially "the outstanding specialist," in his field. ${ }^{103}$}

${ }^{103}$ The impact of these reciprocal and largely unconscious feelings and ideas is well illustrated by a few rather illuminating passages from Dr. Philip Blaiberg's account of his transplantation experience:

The day after my admission to Ward D 1, I was lying in bed with eyes closed, feeling drowsy and thoroughly miserable when I sensed someone at the head of my bed. I opened my eyes and saw a man. He was tall, young, good-looking with features that reminded me a lot of General Jan Christian Smuts in his latter years. His hands were beautiful; the hands of the born surgeon.

"Don't you know me?" he asked.

"No," I said with little interest, "I don't."

"I'm Professor Chris Barnard," he said.

"I'm sorry, Professor," I replied, "but I didn't recognize you. I have never seen you in person, and you look so different from your photographs in the Press."

He spoke earnestly. "Dr. Blaiberg, how do you feel about the prospect of a heart transplant operation? You probably know, don't you, that I am prepared to do you next?"

"The sooner the better," I said fervently, "and I promise you my full cooperation at all times."

Though our conversation was brief and he stayed only a few minutes, I was immediately impressed with the stature of the man and his air of buoyant optimism. He inspired me with the greatest confidence, an invaluable asset in the relations between a surgeon and his patient.

I felt somewhat better. Here was a man to whom I would willingly entrust my life. I came to know him well in the weeks and months that followed. $\mathrm{He}$ is a vital, determined, somewhat mercurial, personality, utterly dedicated to his profession.

$\cdots$

On the morning of December 21, 1967, I was surprised to see my wife walk into my ward at about $9: 30$. Her visits had always been in the afternoons because of her morning job.

"Aren't you working today?" I asked.

"No," she said. "I just felt I wanted to see you."

"The nurses have told me that Professor Barnard is also coming to see me this morning," I said.

It seemed strange and unusual, but I did not give the matter further thought. I accepted Eileen's explanation and believed Professor Barnard's visit would be mere routine. Soon afterward he walked in. Eileen rose to excuse herself.

"No, don't go," Professor Barnard said to her. "I want to speak to you together." I looked more closely at him. He was haggard and drawn as though he had not slept all night. He no longer resembled the handsome Smuts, to whom I had compared him, but more a martyred Christ. I felt a twinge of pity for him when I noticed the pain in his face and eyes. Something, I was sure, had happened to dampen the gaiety and boundless optimism I had seen before.

Professor Barnard spoke in low tones. "I feel like a pilot who has just crashed," he said. "Now I want you, Dr. Blaiberg, to help me by taking up another plane as soon as possible to get back my confidence."

Still I did not know what he was driving at. "Professor," I said, puzzled, "why are you telling me this? You know I am prepared to undergo a heart 
These strong dependencies and expectations running both ways between physician and patient affect, and even play havoc with, the rationality of the decisionmaking which was part of the preliminary "informed consent" model. Similarly, counter-transference phenomena probably also lie behind the policy of a number of physician-investigators not to permit kidney donations by non-related living donors. ${ }^{104}$ Where the doctor-patient relationship leads the transplanter to a degree of identification with the donor he may find it distressing to contemplate a donation "for no reason" (without the pull of family obligation) which poses a threat to the physician's highlyvalued bodily integrity. ${ }^{105}$ When a genetically unrelated but willing person is excluded from being a kidney donor, the transplant surgeon is, in effect, withholding his "informed consent" to the procedure. ${ }^{106}$

Additional complications are added when, as is often the case, the professional and his patient are of different, and even markedly separate, social classes. ${ }^{107}$ Besides their effect on the transference and countertransference reactions, such educational and class differences have an even more palpable effect on the degree of communication and comprehension which can be expected in the relationship. Furthermore, these barriers to doctor-patient communication may cumulate with any

transplant operation at any time you wish."

"But don't you know that Louis Washkansky is dead?" he asked. "He died this morning, of pneumonia."

It dawned on me why Eileen and Professor Barnard had paid me this unexpected visit. Now I knew the reason for his distress and agitation.

"Professor Barnard," I said at once, "I want to go through with it now more than ever-not only for my sake but for you and your team who put so much into your effort to save Louis Washkansky."

"Don't worry," he said a little more cheerfully now, "everything is going to be fine."

P. Blaiberg, Looking at My Heart 65-66, 69-70 (1968). (1971).

${ }^{104}$ See Fellner \& Schwartz, Altruism in Disrepute, 284 New Eng. J. MEd. 582

${ }^{105}$ Fellner and Marshall tell of a resident physician whose blood was used as a control in a leukocyte test and proved to be compatible with the proposed kidney recipient. When told of this finding, he immediately refused to be a donor without even being asked. Fellner \& Marshall, supra note 87, at 1247. This reaction contrasts with that which Fellner and Schwartz found among non-physicians.

${ }^{106}$ See Fellner, The Genetically Unrelated Living Kidney Donor: Unemployed and Unwanted, 1972 (unpublished memorandum by one of our consultants).

${ }^{107}$ See, e.g., R. Duff \& A. Hollingshead, Sickness and Society (1968); A. Hollingshead \& F. Redlich, Soctal Class and Mental Illness (1958). 
number of other factors: the doctor's preoccupation with other matters, particularly when he has a heavy caseload, as the leading physicians do; the natural desire of the hospital staff to "routinize" procedures, in order not to burden the patient with anxiety or themselves with the added chore of coping with that anxiety; and the inclination of physicians not to complicate patients' decisionmaking by reviewing with them the alternatives to the proposed treatment, on the probably faulty assumption that these questions had been gone over by someone else earlier in the process.

If experience in other areas provides any indication, patients may fail to absorb warnings even when physicians attempt to adhere scrupulously to the model of informed consent. ${ }^{108}$ In fact, the danger that physician-investigators will overreach their patient-subjects is probably greater in therapeutic settings than in ordinary experimentation outside the context of therapy, since a patient is very poorly situated to arrive at a disinterested weighing of the risks and benefits of the proposed new treatment or to turn it down if it seems to be favored by the physician to whom he probably already owes such great emotional (and perhaps financial) debts for his past care and on whom he is dependent for his future well-being. Moreover, the new, untried technique is probably offered despite its unknown qualities only because more conventional modalities have proven ineffective. As Francis Moore has observed, "People in this country have been weaned on newspaper accounts of exciting new cures. Particularly in the field of organ transplantation, patients are pressing their doctors to be the subject of innovation." 109 Thus, in the context of the physician-patient relationship there are many impediments to the patient's being able to exercise rational judgment about whether to undergo a new and experimental treatment proposed by his physician. ${ }^{110}$

${ }^{108}$ A study of highly-educated young men who were interrogated by FBI agents after they had turned in their draft cards (in protests against the war in Vietnam) indicated that despite clearly-delivered Miranda warnings, they nevertheless gave the agents statements (which could be used in court against them) although they had for the most part not intended or "wanted" to do so. Griffiths \& Ayres, $A$ Postscript to the Miranda Project: Interrogation of Draft Protestors, 77 Y ALE L.J. 300 (1967).

${ }^{109}$ Daedalus-National Institutes of Health, Proceedings of the Conference on the Ethical Aspects of Experimentation on Human Subjects 31 (1967).

110 If the pain and the fear of further deterioration and death which are experienced by catastrophic disease patients were to be intentionally imposed by one party to an agreement on another, the contract would probably be found invalid on grounds 


\section{The Role of "Faith"}

None of the forces that tend to undermine rationality are likely to be mitigated by the traditional training or orientation of clinical researchers. If anything, prevailing attitudes among physicians only serve to increase the impact of those influences.

First, as a judgment about communication and comprehension, most physicians doubt that their patients can be told simple, unvarnished information about their disease and the prospects for treatment. "[I]t is meaningless to speak of telling the truth, the whole truth, and nothing but the truth, to a patient. It is meaningless because it is impossible-a sheer impossibility." "11 Physicians are particularly likely to withhold information relating to diagnosis or prognosis, as opposed to the nature of a proposed intervention, not only because there is no such thing as "the truth" which can be conveyed, but also because they believe they have a "therapeutic privilege" to do so. ${ }^{112}$ Yet there are good reasons why such medical discretion should be narrowly confined. For one thing, a broadly defined privilege "would afford a perfect shield to cover the negligence of many [physicians] who were unable to reach a timely or accurate diagnosis of the true illness." 113

Furthermore, serious questions have been raised about the validity of the premise underlying the therapeutic privilegethat it is beneficial to the patient's course of treatment that he be protected from learning bad news about his condition. Professor Irving Janis has marshalled observational and psychoanalytic data which leads him to conclude that it is vital for patients to engage in "the work of worrying" if they are to be

of coercion. Within the constitutional matrix, if the agreement were one between a private citizen and a state official (such as a "plea bargain" between a criminal defendant and a prosecutor), the mere existence of pressures to reach an agreement, even when not exploited by the state official, would raise questions of coercion or undue inducement, although the pressures may be of lesser magnitude than those set up by the hope that an experimental treatment will relieve the burdens and risks brought on by severe illness. Cf. Ruebhausen \& Brim, Privacy and Behavioral Research, 65 Colum. L. Rev. 1184, $1199-1200$ (1965).

111 Henderson, Physician and Patient as a Social System, 212 New Eng. J. Med. 819,822 (1935).

${ }^{112}$ See, e.g., Bolam v. Friern Hosp. Mgt. Comm., [1957] 2 All E.R. 118 (defendant physicians found not negligent in failing to warn where it might interfere with treatment); 75 Harv. L. Rev. 1445 (1962) (duty should be based on patient's needs, not physician's practice).

${ }^{113}$ Smith, Therapeutic Privilege to Withhold Specific Diagnosis from Patient Sick with Serious or Fatal Illness, 19 TENN. L. REv. 349, 351 (1946). 
able to cope with their disease and treatment, among other stressful experiences. Particularly germane to a model of informed consent in surgery or dialysis for catastrophic illness is Janis' conclusion that

the arousal of some degree of anticipatory fear may be one of the necessary conditions for developing inner defenses of the type that can function effectively when the external dangers materialize. In many of the individual case studies we have examined, the patient had received very little information about the suffering that he would undergo and, in some cases, this lack of information seems to have been a major factor in determining the relative absence of anticipatory fear. One surmises that most people ignore problematical dangers of the future unless they receive specific warnings or predictions from respected authorities. The unpleasant task of mental rehearsal, which appears to be essential for developing effective danger-contingent reassurances, is apt to be shirked, even when a person knows that he is going to be exposed to some form of suffering or deprivation. ${ }^{114}$

Because of the exalted position of respect in which the physician is placed and because the patient is likely to expect the physician to protect him from all harm, it will most often be only the physician who can impart to the patient a more realistic view of what may develop during the illness and proposed treatment. If informed consent is to be a reality, physicians will either have to allocate more of their time to this activity or effect a change in the health care hierarchy so that other members of the treatment team are perceived as being important enough to do the work of warning, which must precede the patient's "work of worrying" and development of comprehension.

Though ignorance may not be bliss, physician-investigators are prone to rely on it not only to exploit the curative potential of patients' "faith" in the ordinary course of treatment but also to avoid what they regard as the even more worrisome consequences of disclosure where a life-threatening illness is involved. For example, ninety percent of physicians are reported

114 I. Janis, Psyghological Stress: Psychoanalytic and Behavioral Studies of Surgical Patients 352-53 (1958). 
to follow the policy of withholding the information that a patient has cancer, although they typically tell the patient's relative, so to avoid legal liability as well as to share the burden that the knowledge had placed on them and to enlist the family's cooperation in keeping the patient on the desired treatment regimen. ${ }^{115}$ Physicians seek by this course of conduct to maintain their patients' hope and to avoid the risk that a patient, knowing the end is near, will attempt to take his own life. The medical practice of withholding information appears to be based largely on personal predilection, supported by a shared value system among physicians, even though nearly all the doctors surveyed reported that "clinical experience" was the major factor in determining their policy on disclosure. Only a small percentage, however, had ever tried any policy other than their current one.

It was the exception when a physician could report known examples of the unfavorable consequences of an approach which differed from his own. It was more common to get reports of instances in which different approaches had turned out satisfactorily. Most of the instances in which unhappy results were reported to follow a differing policy turned out to be vague accounts from which no reliable inference could be drawn. ${ }^{116}$

While most physicians apparently believe that knowledge of a life-threatening disease is "the cruelest thing in the world,"117 they take a less emotional (and paternalistic) view of how they would like to be treated were their own physician to discover that they have cancer; most indicated that they would want to know the diagnosis. ${ }^{118}$ This double standard demonstrates the physicians' unresolved conflicts about disclosure, and interestingly enough puts them in line with what laymen state to be their own wishes regarding disclosure, which according to vari-

115 Oken, What to Tell Cancer Patients: A Study of Medical Attitudes, 175 J.A.M.A. 1120 (1961).

116 Id. 1124.

${ }^{117}$ This is a representative comment from interviews with physicians, who also used such terms as "a death sentence," "torture," and "hitting the patient with a baseball bat." Id. 1125 .

118 "The explanation usually given was that 'I am one of those who can take it' or 'I have responsibilities.' "Id. This difference in some physicians' attitude toward what they themselves wanted to know had no effect (or an inverse effect) on their policy toward other doctor-patients. 
ous studies is desired by seventy-seven to eighty-nine percent. ${ }^{119}$ This evidence has divergent implications for the informed consent model of catastrophic disease decisionmaking. On the one hand, the present attitude of physician-investigators, which may seriously detract from the possibility of establishing a mutually informed joint working relationship, will probably be difficult to overcome. This limitation on a mutual relationship leading to truly informed consent is self-imposed by one of the parties to the relationship-the physician-investigator-and its roots obviously run deep into the barriers to informed consent discussed in the previous sections. Consequently, it is unlikely that formal regulations on disclosure or mutuality of decisionmaking could have much immediate effect. On the other hand, if there is a genuine commitment to informed consent, it should be possible, perhaps by revisions in the training of physician-investigators, to bring about a change in their attitudes and practices. While the present policies have important psychological aspects, these could probably be overcome if medical instructors in both classroom and clinic were to demonstrate the feasibility and desirability of giving patient-subjects a meaningful role in making choices about their own treatment or nontreatment by providing them with the "truth" about their conditions and potential alternative therapies.

Such an approach has the advantage of taking realistic account of the state of knowledge that most patients achieve anyway, their physicians notwithstanding. ${ }^{120}$ Present medical practice carries the danger that when patients find out their real condition or the actual benefits, discomforts, and risks of their treatment they may lose confidence in the physician who "lied" to them or at least withheld important facts from them. Of course, a policy of informed patient decisionmaking does not require that the "cruel truth" be unloaded on the patient in a single interview. "The central question is not whether or not to tell a patient about his dim outlook, but who shall tell,

119 Feifel, The Function of Attitudes toward Death, in DEATH AND Dying: ATtritudes of Patient And Doctor (G.A.P. Symposium No. 11) 632, 635 (1965). This statistical result is fully supported by the impression gained through in-depth psychological studies. See, e.g., E. KüBLER-Ross, supra note 94.

120 "As at least three-quarters of the patients here studied became aware that they were probably dying, the question 'Should the doctor tell?' loses much of its force." Hinton, The Physical and Mental Distress of the Dying, 32 Q.J. MED. 1, 19 (1963). 
how much to tell, what to tell, how to tell, when to tell, and how often to tell." ${ }^{121}$ This formulation suggests that the primary obligation of professionals is to devise means of bringing the patient-subject into the decisionmaking process rather than creating excuses for keeping him out "in his own best interests." If the physician spends sufficient time with the patient, it should be possible to convey the necessary data to him in a comprehensible form.

Initially, most patients should be advised of the doctor's findings and the treatment planned. Frankness does not mean hopelessness. ... At the beginning, the patient need not be told more than the facts of the illness. His doctor's directness should convey a more important, non-verbal message that he will not be abandoned. Gratuitous reassurances, overly precise predictions, and philosophical precepts are to be avoided. ${ }^{122}$

A final advantage of the adoption of such a policy would be to decrease the possible exploitation of patient-subjects' too eager consent to research procedures. If physician-investigators adopt the new policy suggested here to guide their actions, they are less likely to misuse the undeniably great impact which a sudden disclosure of impending death can have on a patient, converting him from a rational, if ailing, person into a pliant subject who will consent to any experimental intervention "since he has no hope anyway." The abandonment of the physician's supposed blanket privilege to withhold information in the patient's "best interests" does not mean that the physician should be permitted to overpower his patient with a needlessly harsh or ill-timed presentation. ${ }^{\mathbf{1 2 3}}$ Nor

121 Weisman, The Patient with a Fatal Illness-To Tell or not to Tell?, 201 J.A.M.A. 646 (1967).

${ }^{122}$ Id. 646-47.

123

[T] he "best interests" doctrine is acceptable to the extent it mirrors the physician's Hippocratic duty to "do no harm," but . . . it should be abandoned to the extent it would permit a physician to substitute his judgment for his patient's. Thus, this modified "best interests" would place a floor under the standard of acceptable conduct by physicians, by refusing to excuse intentional or reckless harm to patients, without allowing this protection against potential harm to swallow up the patient's whole right to information and consent.

Capron, Legal Rights and Moral Rights, in Ethical Issues in Human Genetics 221, 241 n.22 (B. Hilton, D. Callahan, M. Harris, P. Condliffe \& B. Berkley eds. 1973). 
is "faith"- that is, a less than fully realistic belief in the physician and hope that the treatment will succeed-out of place in the treatment of catastrophic illnesses. Having been given "the facts" as the physician sees them, a patient is free to discount them in any way he wishes. It is only when his decisionmaking is manipulated over a sustained period of time, through the withholding of information or its deceptive presentation, that "faith" is misused.

There is certainly a place in medical innovation for the brave subject who, realizing that his life is near its end, decides selflessly to participate in research so that more can be learned about the disease that is killing him or about new possibilities of treating it; indeed, such subjects are probably crucial to "medical progress." But their participation should be based on an unpressured weighing of alternatives and not on a dejected view of their own worth or a desperate bid to maintain the friendship and support of a physician who, by the manner in which he informed them of their condition and the possibilities of treatment, has left them with the impression that he will abandon them if they fail to cooperate in his project.

\section{The Informed Consent Model in Perspective}

\section{A. Division of Authority}

This review of the developing case law and the philosophical and psychological considerations suggests that achieving truly informed and insightful participation of patient-subjects will be a difficult task. Yet it is an attempt worth making. Clarity about the division of authority is important for two reasons. First, it elucidates duties in the primary relationship between doctor and patient. Moreover, it serves to fit that relationship into the context of social roles and expectations. This is particularly noticeable in the case of experimental medicine, which has been subjected to increasing scrutiny by third parties.

\section{Doctor and Patient}

It would, of course, be easier to rely almost entirely on physician-investigators to handle decisions of medical intervention than to allow patient-subjects to become informed decisionmakers. That alternative would adhere closely to the traditional view of the doctor-patient relationship, which located all au- 
thority in the simple two-way, dominant party/submissive party interaction. Yet the physicians themselves are responsible for a number of departures from that traditional model. For example, the heart transplant moratorium placed major decisions in the hands of persons outside the two-party nexus of doctor and patient; certain choices arrived at by doctors and patients were thereby foreclosed by decisions reached by other physicians, hospitals, professional associations, and the like. Thus, there seems little reason to consider retaining the traditional model of physician-patient decisionmaking for its own sake, since if it ever existed in pure form, that day is long past.

There are other good reasons for moving from a doctoras-sole-authority model to an informed consent model. According patient-subjects the right to participate as informed decisionmakers in the catastrophic disease process will better enable them to protect themselves and their interests (a calculation which would probably be too complicated and burdensome to be performed well by a surrogate). This position does not suggest that patient-subjects will not make "mistakes" or pursue courses not "in their best interests," but they will be their best decisions, challenged when necessary by medical opinion to the contrary.

Although a full and frank partnership between physician-investigator and patient-subject is the aim of the informed consent model, the model recognizes that patients' decisional processes do not always operate in a rational and unfettered manner. Dying patients especially may be led, often in an unconscious fashion, to offer their cooperation in return for some special favor from those who are caring for them. Dr. Elisabeth Kübler-Ross sees in such bargaining "an attempt to postpone" something (such as an operation) that reminds the patient of how imperiled his life is; in exchange he may promise his "good behavior," perhaps in the form of an offer to let himself be used for scientific work that could lead to life-extending knowledge. ${ }^{124}$

An honest recognition of the "bargaining" nature of the doctor-patient relationship is particularly important when the

${ }^{124}$ E. KÜBLER-Ross, supra note 94, at 73-74. See also Guttentag, The Problems of Experimentation on Human Beings: The Physician's Point of View, 117 ScIENCE 209 (1953) (describing how the guilt of being ill may lead the patient to feel a need to make sacrifices for physician-investigators). 
physician-investigator is seeking to enroll the patient-subject in a procedure which is not solely for the latter's benefit. As suggested at the outset, "informed consent" should be viewed not as a single act but as a process of contracting, negotiating, and recontracting. ${ }^{125}$ In the treatment of, and research on, catastrophic diseases, this model of informed consent is the only realistic one, since the treatment process requires constant physical and psychic rededication over time by patient and physician alike. Dr. Harrison Sadler even suggests that "[a] basic requirement is a patient who is intelligent enough to negotiate" an "honorable and dignified working partnership and alliance ...."126

\section{Official Review}

The model of decisionmaking is not restricted to physician and patient but includes others as well, such as the physician's peers and officials of the state. Under the HEW regulations described above, "institutional review committees" pass on experimental interventions prior to their initiation. These committees are charged with ensuring that the benefits of the experiment outweigh its risks and that informed consent will be obtained from the patient-subjects. If such panels take their work seriously and are more than windowdressing, they can serve many of the same ends that are advanced through an informed consent model of decisionmaking: they may increase rationality, protect the human worth and dignity of experimental subjects (by preventing worthless research in which the sacrifice of any human interests would be a mistake), and encourage reflection on the part of investigators who will be concerned that their arguments be well thought-out so as to make a good impression on their peers. The committees may

125 The process by which the terms of the treatment contract are negotiated is illustrated by the intermittent contract between Dr. Denton Cooley and Haskell Karp in the month before the artificial heart implantation in the spring of 1969. See Karp v. Cooley, 493 F.2d 408, 412, 421 (5th Cir. 1974). In that instance, other deviations from the paradigm suggested here introduced serious deficiencies into the decisions reached. See notes 223-59 infra \& accompanying text.

${ }^{126}$ Sadler, supra note 91. Support from persons outside the physician-patient relation may also be needed by patient-subjects in order to work through their conflicting feelings (self-preservation versus gratitude to physician-investigators for their attention) and thus to maintain their freedom to withdraw or renegotiate the bargain when they have second thoughts. See Savard, Serving Investigator, Patient and Community in Research Studies, 169 ANN. N.Y. ACAD. SCI. 429 (1970). 
also facilitate physician-patient communication by suggesting improvements in the means used to obtain informed consent, and in appropriate instances by actually providing a person to facilitate communication between the "parties" in research.

The authority exercised by the institutional committees does, of course, point to a clash of principles between the autonomy of the patient on the one hand and the greater scientific rigor and safety which are the goal of official review on the other. This tension remains partially unresolved in the decisionmaking model presented here, and must await further experience for more complete articulation. But even now it is more apparent than real. The informed consent model is not violated by a physician-investigator's limitation on the range of medical interventions which he is willing to undertake with a patient-subject; ${ }^{127}$ nor is it when those limitations arise from formal or informal pressures placed on physician-investigators by their peers or others outside the doctor-patient contract. Many of those sources of influence-such as education, socialization, and the structure of the health professions-are too subtle and pervasive even to be perceived in the typical instances of patient-physician contracting; other informal but more apparent influences are the result of conscious choice on the part of persons other than the doctor and patient, though they are kept at a low level of visibility. But the problem with such sources of influence and even with the formal efforts of committees does not derive from their mere existence; there is an undeniable need for outside values to be represented, although this creates a tension with patient autonomy. Rather, the problem results (and the tension is sharply felt) because the proper boundaries of such influence are poorly drawn, the processes by which they operate remain unspecified, and the means by which they might be challenged are largely nonexistent. Thus, as standards for the operation of review committees evolve, these groups can be expected to be an increasingly important part of the experimental process.

It would be wrong, however, if the committees were to review individual consents and to disallow those which they felt were inadequately considered. If the patient-subject is competent and the requisites of the consenting process are

${ }^{127}$ See text accompanying note 76 supra. 
fulfilled, it is not for the committee, like a jury employing the objective standard of the "reasonable person," to second-guess the patient-subject and dictate his choices according to its own view of the rational. The major objection which would likely be interposed by institutional review committees or other representatives of collective decisionmaking on grounds of "rationality" is that the decisions made do not adequately protect life. Such interference by a committee could take the form of either refusing to sanction a person's participation in an experimental program or insisting that a person consent to a procedure which he or she does not want. ${ }^{128}$

\section{a. Prevention of Dangerous Treatment}

Since much of the commentary and criticism of experimental medicine has been directed at the "unethical" exposure of patient-subjects to unjustifiable risks, ${ }^{129}$ it might be expected that the first situation, where a representative of society prevents a willing patient-subject from going ahead, would be the more common. That does not appear to be the case. Most of the objections to unethical research have been grounded on the involvement of subjects who did not give valid consent, by reason of either insufficient information or lack of ability to make a free choice, and not on the theory that subjects' participation ought not be permitted.

As was suggested in part I of this Article, the exclusion of certain patient-subjects also results from the exercise of informal authority by physician-investigators and their professional colleagues, and apparently never rises to the the level of a formal decision by the state. The informal ban on unrelated living kidney donors for the past five years provides a dramatic case in point, since the supply of transplantable kidneys from other sources remains deficient. Although the treatment of kidney failure is supported by a major commitment of govern-

${ }^{128}$ Needless to say, these two situations are often hard to distinguish: if "no treatment" were the experimental procedure chosen by a patient who needed treatment to preserve his life and the state declined to sanction his decision, this might also be framed as the state insisting on an intervention which he opposed.

${ }^{129} \mathrm{H}$. BeEcher, Research and the Individual: Human Studies (1970); M. Pappworth, Human Guinea Pigs: Experimentation on Man (1967); Beecher, Ethics and Clinical Research, 274 New ENG. J. Med. 1354 (1966); Veatch \& Sollitto, Human Experimentation-The Ethical Questions Persist, Hastings Center ReP., June 1973 , at 1. 
mental resources, this policy decision-which comes from physicians' unwillingness to expose healthy persons to the risks of having a kidney removed if they are motivated only by altruism and not by family ties-rests unquestioned and unreviewed in medical hands.

Edmond Cahn has argued, however, that a patient-subject's consent should be passed upon by someone-by implication an official of the state-when the procedure involves substantial risks, and that when the risk of permanent physical or psychic mutilation is "serious . . . the consent should not be accepted."130 Cahn would rely on the physician-investigator's evaluation of "possible benefit to the ailing subject" rather than on "his consent" or "the possible increment of scientific knowledge" as the justification for risking something like "psychic mutilation" in a grievously ill person. ${ }^{131}$ The general cautions urged by Cahn find expression through the informal and formal (review committee) mechanisms which limit the biomedical interventions that are permitted and which screen out unsuitable patient-subjects. The greater formality of HEW-mandated review for projects conducted at institutions receiving federal research funds may increase extraprofessional scrutiny, but this will still concern only the permissibility of the research itself and not the legitimacy of a particular individual's consent.

Extraprofessional control over catastrophic disease decisions does arise through after-the-fact review, primarily in the context of medical malpractice litigation, but this is at most a minor constraint. Were an intervention a criminal act, the consent of the patient-subject could, of course, be disregarded by the state, either in attempting to prevent the event from occurring or in prosecuting the physician-investigator subsequently. ${ }^{132}$ Yet there is no indication that the acts to which cata-

${ }^{130}$ Cahn, Drug Experiments and the Public Conscience, in Drugs IN OUR SOcIETY 255, 264 (P. Talalay ed. 1964).

131 Id.

132 If the patient-subject's agreement to the intervention were found to be voluntary and informed, he would probably be unsuccessful in suing the physician-investigator for the intervention, albeit that it was criminal. For example, in Spead v. Tomlinson, 73 N.H. 46, 59 A. 376 (1904), the court assumed that a statute on the unauthorized practice of medicine made treatment by a Christian Science practitioner illegal, and that this statute was passed to benefit those such as the plaintiff who had been injured as a result of a violation of the statute. Nevertheless, it held that the plaintiff could not recover, because she had submitted to the treatment of her own choice; but it also noted that this act on her part would not have relieved the defendant of criminal liability, had he been so charged by the state. 
strophic disease patients have submitted come within the category of crimes. Moreover, for obvious practical reasons the cases provide illustrations of retrospective but never of prospective invalidation of the consent of competent persons in biomedical treatment. ${ }^{133}$

While there are advantages, both for the subject and for the scientific process more generally, in having professional review in advance of a proposed medical procedure, the intervention of state officials in forbidding a course of treatment does not seem appropriate on any but a paternalistic rationale inconsistent with the premises of informed consent. The state may legitimately decline to permit the use of collective resources (funds for medical care) where the collective benefits are outweighed by the risks or costs. But the voluntary participation of competent adults is not a collective resource, and the state's concern ends once it is assured that fraud and duress have not been employed in the process of informing and obtaining consent from the patient-subject.

\section{b. Compelling Life-Saving Treatment}

Although it would seem to involve a more severe interference with autonomy and free choice, the second type of state interference to protect subjects from unwise choices-the overriding of patient-subjects' choices not to undergo medical treatment-has occurred more frequently than the first. Apparently a more palpable and immediate threat to collective values is perceived when the choice is to forego treatment believed by others to be potentially helpful than when the choice is to accept treatment believed to be too risky. Two separate rationales explain these state-sanctioned interferences with the operation of the informed consent model. One rationale is well illustrated by an example outside the context of lifethreatening illness. In the early years of compulsory vaccination for contagious diseases, the objections of persons not want-

${ }^{133}$ As initially framed, the litigation over the propriety of the psychosurgery planned by the Lafayette Clinic in Detroit on sexual psychopaths at Ionia State Hospital would have had the court pass on the validity of "John Doe's" consent to participate. But that issue was mooted when he was released from the hospital, after the statute under which he had been committed was declared unconstitutional, and then withdrew his consent to the surgery. Kaimowitz v. Michigan Dept. of Mental Health, Civ. No. 73-19434-AW (Cir. Ct. Wayne County, Mich., July 10, 1973). 
ing to be inoculated were found to be outweighed by the public interest in preserving the health of other citizens. ${ }^{134}$ Vaccination is effective as a public health measure only when it is universally applied. Compulsion was therefore upheld in order to protect everyone and to prevent a few from attempting to get a "free ride" by obtaining the benefit of vaccinated neighbors without taking the risk themselves. The calculus of authority in such cases involves patient-citizen and state rather than patient-subject and physician; the decision to proceed despite the individual's unwillingness is grounded on the superior collective good, not on the superiority of medical judgment. What is involved here is a suspension in the operation of the informed consent model for a set of decisions to which it does not apply, rather than a contradiction of the model's premises concerning the division of authority.

Where refusal of life-saving treatment is at issue, the rationale for interference appears to be different. The state's primary interests here have been found to be a paternalistic concern to safeguard the individual from his own unwise decision, a ritualistic desire to uphold "the sanctity of life," and a collective interest in preserving each person's productivity for society's benefit. ${ }^{135}$ The most numerous and conspicuous examples of state imposition of life-saving treatment on unwilling patient-subjects are presented by those cases in which blood transfusions are refused, particularly by Jehovah's Witnesses. Judicial opinion on whether a person has a right to refuse lifesaving treatment is divided. Despite the religious basis of the patient's objections to the transfusion, a number of forceful opinions have held that a hospital in which a patient had sought care could force him or her to accept the treatment deemed necessary to save life. ${ }^{136}$

The opinion by Chief Justice Weintraub for the New Jersey Supreme Court in one of the leading cases, John F. Kennedy

\footnotetext{
${ }^{134}$ See, e.g., Jacobson v. Massachusetts, 197 U.S. 11 (1905).

${ }^{135}$ See Cantor, A Patient's Decision to Decline Life-Saving Medical Treatment: Bodily Integrity Versus the Preservation of Life, 26 RutGers L. REv. 228, 242-54 (1973).

${ }^{136}$ In Application of President and Directors of Georgetown College, 331 F.2d 1000 (D.C. Cir.), cert. denied, 377 U.S. 978 (1964), the court's decision to order the life-saving treatment was influenced by the fact that the patient had a young child who might have been adversely affected by the loss of a parent. Id. at 1008. This factor does not play a prominent role in the cases as a whole, however. Cf. Raleigh Fitkin-Paul Morgan Memorial Hosp. v. Anderson, 42 N.J. 421, 201 A.2d 537, cert. denied, 377 U.S. 985 (1964) (transfusion order for woman 32 weeks pregnant).
} 
Memorial Hospital v. Heston, ${ }^{137}$ would appear to expand the medical authority in decisionmaking about life-threatening conditions. Although the case involved the exercise of state power rather than decisionmaking solely by physicians (since the blood transfusion cases typically arise as petitions for the court to appoint a guardian), the court took a view of the medical profession's role at odds with the informed consent model:

Hospitals exist to aid the sick and the injured. The medical and nursing professions are consecrated to preserving life. That is their professional creed. To them, a failure to use a simple, established practice in the circumstances of this case would be malpractice, however the law may characterize that failure because of the patient's private convictions. ${ }^{138}$

The "patient's private convictions" are, however, the compass by which medical decisions are to be guided, with the law's protection when necessary, unless there is to be a complete reordering of the interests which are in conflict.

The cases mandating transfusions have little precedential value for decisionmaking by competent patients in the catastrophic disease process, however. First, in all cases but one the patients were found to be incompetent as a result of the debilitating effects of their illness or loss of blood. ${ }^{139}$ Second, the religious nature of the objection rendered ambiguous the choice made by the patient. This is illustrated by another leading case, Application of the President and Directors of Georgetown College. ${ }^{140}$ There Judge J. Skelly Wright found that though the

${ }^{137} 58$ N.J. 576,279 A.2d 670 (1971).

${ }^{138}$ Id. at 582, 279 A.2d at 673 . Particularly puzzling is the court's use of the term "malpractice," by which it apparently means a medical view of misconduct, eschewing the legal view of "malpractice," to which the term usually refers. There is no doubt, however, that the court accurately reflected medical values, particularly physicians' pronounced unwillingness to yield to death. See Parsons, Fox \& Lidz, supra note 97, at 395 , identifying the physician's "nearly absolute 'commandment' to combat the death of his 'patient'," but also detecting the emergence of a new "relativized ethic" in the face of the strains between medical and general societal values, id. 402-10.

${ }^{139}$ The exception, United States v. George, 239 F. Supp. 752 (D. Conn. 1965), concerned a Jehovah's Witness who would not consent to a blood transfusion, although he stated that he would not resist a court order directing it. Since the risks involved in transfusions are small and, in the absence of an unusual underlying pathology, the chances of therapeutic success are great, the transfusion cases are of problematic value in arriving at conclusions about patients' refusal of more substantial intervention.

140331 F.2d 1000 (D.C. Cir.), cert. denied, 377 U.S. 978 (1964). 
patient may have wanted to adhere to her religious beliefs and refuse to "drink blood," she did not desire the consequences of that choice, that is, she did not want to commit suicide. $\mathrm{He}$ concluded that ordering the transfusion would thus comport with her real though not her expressed wishes. ${ }^{141}$ In subsequent cases, Jehovah's Witnesses have gone out of their way to deny that court-ordered transfusions, as opposed to voluntary ones, are any more acceptable under their religious tenets, ${ }^{142}$ but it is clear that Judge Wright believed that this factor buttressed his decision. Finally, the emergency existing in the Georgetown College case impelled an order to permit the transfusion if the status quo were to be preserved until full argument could be had; failure to act, in Judge Wright's view, could have resulted in irreversible error. ${ }^{143}$ Of course, ordering the transfusion to avoid "mootness" not only amounted to ruling against the patient's contentions but also effectively mooted the case from the opposite perspective, since no issues remained once the patient recovered and was released from the hospital.

The more recent opinions (as well as some of the older ones) have refused to compel unwilling patients to undergo blood transfusions. The Supreme Court of Illinois, faced with an appeal from a probate judge's order appointing a guardian to consent to a transfusion of a Jehovah's Witness, held:

Knowing full well the hazards involved, she has firmly opposed acceptance of such transfusions, notifying the doctor and hospital of her convictions and desires, and executing documents releasing both the doctor and the hospital from any civil liability which might be thought to result from a failure on the part of either to administer such transfusions. . . . Even though we may consider appellant's beliefs unwise, foolish or ridiculous, in the absence of an overriding danger to society we may not permit interference therewith in the form of a conservatorship established

${ }^{141}$ Judge Wright also stated that he was able to avoid violating Mrs. Jones' religious beliefs, since he understood her to say that she could not request any blood but that it could be given to her "against [her] will." Id. at 1007. Accord, United States v. George, 239 F. Supp. 752, 753 (D. Conn. 1965); Powell v. Columbian Presbyterian Medical Center, 49 Misc. 2d 215, 216, 267 N.Y.S.2d 450, 452 (Sup. Ct. 1965).

${ }^{142}$ See, e.g., In re Osborne, 294 A.2d 372, 374-75 (D.C. 1972); In re Bentley, Misc. No. 65-74, 102 Daily Wash. L. Rptr. 1221, 1224 (D.C. Super., Apr. 25, 1974).

${ }_{143} 331$ F.2d at 1009-10. 
in the waning hours of her life for the sole purpose of compelling her to accept medical treatment forbidden by her religious principles, and previously refused by her with full knowledge of the probable consequences. ${ }^{144}$

In Heston, Chief Justice Weintraub based the state's authority to override a patient's refusal to accept life-preserving treatment directly on its power to prohibit suicide, but this reasoning has not persuaded most judges. A New York trial court held in Erickson v. Dilgard ${ }^{145}$ that the refusal of medical treatment by a competent adult, irrespective of religious reasons, does not fall under the criminal law's prohibition of suicide: " $[\mathrm{I}] \mathrm{t}$ is the individual who is the subject of a medical decision who has the final say and . . . this must necessarily be so in a system of government which gives the greatest possible protection to the individual in the furtherance of his own desires." 146

The courts have further narrowed the scope of governmental authority to interfere with treatment decisions in a number of cases involving arguably incompetent patients, whose wishes have nevertheless been respected. For example, a Wisconsin judge upheld the objections of a Mrs. Raasch to repeated amputation of her leg; although her condition prevented her from communicating verbally, she was "not incompetent" and her wishes (as expressed nonverbally) were to be respected. ${ }^{147}$ Similarly, an institutionalized mental patient who exhibited disordered reasoning was nonetheless allowed to refuse exploratory surgery for suspected carcinoma of the breast. The court declined to equate a decision considered "unwise, foolish or ridiculous" 148 by others with one which was in-

${ }^{144}$ In re Estate of Brooks, 32 Ill. 2d 361, 372-73, 205 N.E.2d 435, 442 (1965). The Illinois court placed heavy emphasis on the religious basis of Mrs. Brooks' objections; the case is thus primarily a first amendment "free exercise" decision.

14544 Misc. 2d 27, 252 N.Y.S.2d 705 (Sup. Ct. 1962).

${ }^{146} I d$. at 28,252 N.Y.S.2d at 706.

147 D. Hendin, Death as a Fact of Life 67-69 (1973).

${ }^{148}$ In $r e$ Yetter, 62 Pa. D. \& C.2d 619, 623 (C.P. Northampton County, 1973). Maida Yetter, a sixty-year-old woman, had been a resident of a state mental hospital for treatment of chronic undifferentiated schizophrenia for two years at the time of the hearing. Her brother sought authority to be appointed her guardian to consent to exploratory breast surgery for suspected cancer. Mrs Yetter had declined the operation because she feared that it would make her condition worse and would lead to her death, as she believed (apparently erroneously) that a similar operation had killed an aunt of hers. Mrs. Yetter's social worker described her as "lucid, rational and appear[ing] to understand that the consequences of her refusal included death," id. at 621, 
competent, provided that the decision showed that the patient had an understanding of the consequences of her various alternatives.

Practical reasons as well as principles ${ }^{149}$ support the disposition reached by the majority of the cases. Almost insuperable problems of administration would be presented if physicians or committees were free to second-guess the informed decisions made by patient-subjects. The only reason why this problem is not more pronounced at the present time is that the manner in which physicians now control the process of information-giving and decisionmaking probably reduces the likelihood that they will find themselves irreconcilably opposed to the choices made by their patients. If adherence to the informed consent model increases these instances, it is not clear that physicians would in fact welcome the power explicitly to override their patients' wishes in the name of society and of their professional commitment to maintaining life at all costs, as seems to be suggested by the decisions of Judge Wright and Chief Justice Weintraub.

\section{B. Resolving Conflicts in the Case Law: $A$ Hybrid Cause of Action}

To what extent is the "model" of informed consent developed here-one which, based on the purposes which the requirement of informed consent is supposed to serve, predicts various allocations of authority among the participants in the decisionmaking process-presently embodied in case law? This is a field characterized by major developments in the past few years. Yet, although a number of recent opinions have exhibited greater concern for the protection of patients' interests, further changes are needed if the doctrine is to operate in the way hypothesized in the model. Part of this problem can be traced

but subsequently she became delusional in her reasons for not consenting. At the hearing her delusions on this subject were shown when she gave as her reasons for refusing the operation its adverse effects on her ability to have babies and on her potential movie career. Although the physician was of the view that Mrs. Yetter could not reach a considered view about the surgery, the court declined to appoint a guardian, holding Mrs. Yetter to be competent to exercise her constitutional right of privacy by refusing life-prolonging treatment, since "there are no minor or unborn children and no clear and present danger to public health, welfare or morals." Id. at 623.

${ }^{149} C f$. Morris, Voluntary Euthanasia, 45 WASH. L. Rev. 239, 251-55 (1970), identifying three basic values which are relevant to choice about life-saving treatment as well as to euthanasia: prevention of cruelty, allowance of liberty, and enhancement of human dignity. 
to the dispute, mentioned at the outset, over whether an informed consent action properly sounds in battery or negligence.

The reasons for this difficulty are readily apparent. While a medical intervention without consent is a battery, many courts have declined to find that the absence of information invalidated the consent which had been obtained and have decided instead that it indicated a lapse in professional behavior-a part of the physician's obligation-to be judged by malpractice standards. Whichever theory was chosen, innumerable difficulties were faced in reaching results that squared with justice and common sense. Although the origins of the dichotomy are plain, there is no reason for it to detain the courts any longer. The courts should recognize that they are on the brink of creating a new ground for recovery: a hybrid of negligence and battery theories that is controlled by its own logic and is not confined by the rules which attach to either of its parent causes of action. . $^{150}$

The choice of negligence or battery theories determines a range of legal questions, such as the applicable statute of limitations and the distribution of the burden of proof on the various elements needed to establish or avoid liability. This discussion, however, will address only the central differences with which the courts have wrestled: establishing the amount that must be disclosed to the patient and determining whether the doctor's act caused the patient's injury.

\section{Disclosure and Comprehension}

From the outset, most judges have rejected the notion that there is an "absolute" duty to inform a patient of any and all risks and consequences expectable from an intervention. Instead, the extent of what a physician must tell his patient has usually been stated with the sort of uninformative circularity that the California district court of appeal employed in Salgo $v$. Leland Stanford Jr. University Board of Trustees: "full disclosure of facts necessary to an informed consent." 151 Under the negligence rationale, if a patient asserted that his physician had with-

${ }^{150}$ The Natanson court rejected the suggestion that informed consent be regarded as a hybrid; it adhered instead to the negligence theory. Natanson v. Kline, 187 Kan. 186,354 P.2d $670(1960)$.

${ }_{151} 154$ Cal. App. 2d 560, 578, 317 P.2d 170, 181 (1957). See Staffard v. Schultz, 42 Cal. 2d 767, 777, 270 P.2d 1, 7 (1954) ("full and complete" disclosure); Woods v. Brumlop, 71 N.M. 221, 227, 377 P.2d 520, 524 (1962) ("full and frank disclosure"). 
held information from him, the patient-plaintiff was generally obliged to show that the physician-defendant had deviated from what expert testimony showed to be the established, acceptable medical practice on disclosure in the community. ${ }^{152}$ This reliance on a professional standard was supported by the argument that the major reason for nondisclosure would be the physician's conclusion, as a result of his expert judgment, that disclosure would be harmful to the patient.

Courts following the assault and battery rationale were faced with a harder task. Whether information was withheld negligently, wilfully, or otherwise could make no difference under their theory, provided that the gap was sufficient to render nugatory the consent supposedly given by the patient; yet some information is perforce always left out by physicians, so liability would always attach if absolute disclosure were required. The courts were thus faced with two choices, neither really satisfactory. On the one hand, they could attempt to narrow the field of battery cases to those in which the operation performed was not the one to which the plaintiff had consented, and leave malpractice theories to cover situations in which information about the operation (for instance, risks) was not disclosed. ${ }^{153}$ The difficulty with this dichotomy is plain, however. What makes the physician's conduct objectionable in the first situation-that the patient has given "consent" under a misimpression of the relevant facts-is equally true of the second. At the least, the dividing line between omissions of fact and errors of description that fundamentally change what has been approved and thereby open the physician to liability for battery defies description. The second alternative, which some courts pursued, was to draw on the fiduciary relationship that a physician has to his patient and hold that a battery occurred when the physician wilfully or negligently breached the fiducial duty of disclosing "to his patient all material facts which reasonably should be known if his patient is to make an informed and intelligent decision." 154 This led to a groping for some standard

152 See note 24 supra.

${ }^{153}$ See Cobbs v. Grant, 8 Cal. 3d 229, 240, 502 P.2d 1, 8, 104 Cal. Rptr. 505, 512 (1972) (citing W. Prosser, Handbook of THE LAW OF Torts $\S 32$, at 165-66 (4th ed. 1971) for the proposition that limitation of the battery theory is the majority viewpoint).

${ }^{154}$ Hunter v. Brown, 4 Wash. App. 899, 906, 484 P.2d 1162, 1166 (1971), aff'd, 81 Wash. 2d 465, 502 P.2d 1194 (1972). 
of materiality beyond the plainly uninformative "full disclosure."

In three major recent opinions in this area, the courts seemed to take both routes. ${ }^{155}$ Most notably, the California supreme court in Cobbs v. Grant ${ }^{156}$ clearly adopted negligence rather than battery as the theory of recovery in that state, ${ }^{157}$ but at the same time rejected the "reasonable medical practice standard" which formed the backbone of the negligence theory. Paraphrasing the holding handed down earlier in 1972 by the Court of Appeals for the District of Columbia Circuit in Canterbury $v$. Spence, ${ }^{158}$ the California court held that "the patient's right of self-decision is the measure of the physician's duty to reveal. ... The scope of the physician's communications to the patient, then, must be measured by the patient's need, and that need is whatever information is material to the decision." 159

155 Prior to the trilogy of cases discussed in detail in the text, Canterbury v. Spence, 464 F.2d 772 (D.C. Cir.), cert. denied, 409 U.S. 1064 (1972); Cobbs v. Grant, 8 Cal. 3d 229, 502 P.2d 1, 104 Cal. Rptr. 505 (1972); Wilkinson v. Vesey, 110 R.I. 606,295 A.2d 676 (1972), several courts had abolished the medical community standard for informed consent, e.g., Woods v. Brumlop, 71 N.M. 221, 377 P.2d 520 (1962); Getchell v. Mansfield, 260 Ore. 174, 489 P.2d 953 (1971); Cooper v. Roberts, $220 \mathrm{~Pa}$. Super. 260, 286 A.2d 647 (1971), and since then more have followed, e.g., Riedinger v. Colburn, 361 F. Supp. 1073 (D. Idaho 1973); Fogal v. Genesee Hosp., 41 App. Div. 2d 468, 344 N.Y.S.2d 552 (1973); Trogun v. Fruchtman, 58 Wis. 2d 569, 207 N.W.2d 297 (1973), although one court has chosen to retain the rule, ZeBarth v. Swedish Hosp. Med. Center, 81 Wash. 2d 12, 499 P.2d 1 (1972). But see Miller v. Kennedy, 11 Wash. App. 272, 522 P.2d 852 (1974) (synthesizing ZeBarth with Canterbury, Cobbs, and Wilkinson, and rejecting the medical community standard). The pre-1972 cases are less significant than the 1972 trilogy: Woods dealt with the issue in a truncated fashion, Getchell confused "materiality" and the need for expert testimony on the risks which actually existed, and Cooper skipped over the problem of causation. Hence, this Article will draw primarily on Canterbury, Cobbs, and Wilkinson, which addressed the issues head-on and put a new stamp on the law.

${ }_{156} 8$ Cal. 3d 229, 502 P.2d 1, 104 Cal. Rptr. 505 (1972).

${ }^{157}$ The California cases were divided. The early case of Salgo v. Leland Stanford Jr. Univ. Bd. of Trustees, 154 Cal. App. 2d 560, 317 P.2d 170 (1957), had come up on a negligence action, which was accepted without much criticism; this view of the cause of action was followed in Dunlap v. Marine, 242 Cal. App. 2d 162, 51 Cal. Rptr. 158 (1966), and Tangora v. Matanky, 231 Cal. App. 2d 468, 42 Cal. Rptr. 348 (1964). But it was also held that in California "the cause of action which arises from medical treatment based on an uninformed consent sounds in battery and not negligence." Dow v. Kaiser Foundation, 12 Cal. App. 3d 488, 505, 90 Cal. Rptr. 747, 757 (1970). Accord, Berkey v. Anderson, 1 Cal. App. 3d 790, 82 Cal. Rptr. 67 (1969).

158464 F.2d 772, 787-88 (D.C. Cir.), cert. denied, 409 U.S. 1064 (1972).

1598 Cal. 3d at 245,502 P.2d at 11,104 Cal. Rptr. at 515. Canterbury v. Spence, 464 F.2d 772 (D.C. Cir.), cert. denied, 409 U.S. 1064 (1972), provides an excellent summary critique of reliance on explicit medical testimony on the scope of disclosure:

There are, in our view, formidable obstacles to acceptance of the notion that the physician's obligation to disclose is either germinated or limited by medical practice. To begin with, the reality of any discernible custom reflecting a professional concensus on communication of option and risk information to patients is open to serious doubt. We sense the danger that 
Without explicitly so declaring, the California court appears to have adopted a "subjective" standard for determining whether the information withheld from the patient should have been disclosed: the measure of materiality is "the patient's need," whatever the particular plaintiff needed to make up his or her own mind about whether to permit the medical intervention. The two other courts which have taken the lead in redefining consent, the Supreme Court of Rhode Island and the federal appellate court in the District of Columbia, approached the issue of materiality "from the physician's point of view," as two commentators had urged. ${ }^{160}$ In holding that the materiality of information is to be judged by what the law's mythical "reasonable person" would want to know, these courts retreated from the logic of their own reasoning. ${ }^{161}$

what in fact is no custom at all may be taken as an affirmative custom to maintain silence, and that physician-witnesses to the so-called custom may state merely their personal opinions as to what they or others would do under given conditions. We cannot gloss over the inconsistency between reliance on a general practice respecting divulgence and, on the other hand, realization that the myriad of variables among patients makes each case so different that its omission can rationally be justified only by the effect of its individual circumstances. Nor can we ignore the fact that to bind the disclosure obligation to medical usage is to arrogate the decision on revelation to the physician alone. Respect for the patient's right of self-determination on particular therapy demands a standard set by law for physicians rather than one which physicians may or may not impose upon themselves.

Id. at 783-84 (footnotes omitted). The difficulty of obtaining experts to testify, the so-called "conspiracy of silence," has also been given as a reason for not employing a professional standard to measure a physician's duty to inform. See Cooper v. Roberts, 220 Pa. Super. 260, 267, 286 A.2d 647, 650 (1971); Comment, Informed Consent in Medical Malpractice, 55 CALIf. L. Rev. 1396 (1967). The Supreme Court of Rhode Island doubted whether even the trial court's statutory power to appoint expert witnesses of its own was sufficient, in light of the economics of medical practice and malpractice insurance, to overcome this hurdle to plaintiff's prima facie case. Wilkinson v. Vesey, 110 R.I. 606, 623-24, 295 A.2d 676, 687 (1972).

160 Waltz \& Scheuneman, supra note 20 , at 639 . Waltz and Scheuneman disavow any intention of making the standard of materiality "subjective to the physician," claiming only that they want to avoid the complications of hindsight: "the correctness of [the physician's] decision must be assessed on the basis of the data then available to him." Id. n.41. Yet this begs the question. Without expecting omniscience from health professionals, it goes too far to cut their disclosure free of what the patientsubjects actually want and need to know and anchor it only to what data the professionals happen to have available about the patient-subjects.

161 Yet they plainly are uncomfortable with this result, leaving the reader ambivalent about how "objective" a standard is that speaks of a "reasonable man who finds himself in the position of the patient." Waltz \& Scheuneman, supra note 20 , at 640 (relied on in Canterbury v. Spence, 464 F.2d 772, 787 (D.C. Cir.), cert. denied, 409 U.S. 1064 (1972), and Wilkinson v. Vesey, 110 R.I. 606, 627, 295 A.2d 676, 689 (1972)). If this is nothing more than the usual "under all the circumstances" language common to negligence law, then it adds little. But it may be meant to suggest that 
The courts thus adopted an "objective" standard, rather than keying the definition to what information the actual patient needed for his or her personal decisionmaking process. The judges, like the commentators, recognized the subjective standard as "optimal" or "the ideal rule" to protect the interests that prompt the concern with "informed consent" in the first place, but then they backed away from this result for pragmatic reasons. ${ }^{162}$ It is not hard to understand the motivation for this outcome; for it might seem harsh to judge the materiality of information by "the patient's need," since a physician "obviously cannot be required to know the inner workings of his patient's mind."163 But an objective standard shares the basic fault of the "medical community" standard which these courts were abandoning. Adherence to what a group in the lay community believes to be "reasonable" may rob the patient of "the undisputed right ... to receive information which will enable him to make a choice"164 as surely as will adherence to a judgment of the medical community.

Whatever the merits of an "objective" standard of disclosure in highly routine interventions-when the very ordinariness of the medical procedures would suggest that a particular patient would be satisfied with information sufficient to satisfy the average, reasonable person, and where jurors would generally be better able to draw on their own experiences in applying the standard-it has no place in the case of the major and often experimental interventions used to treat catastrophic diseases. Since the purpose of requiring informed consent is to allow patient-subjects to participate in the course of therapy and research as informed decisionmakers, concern should focus on whether the patient-subject in question understood what the physician-investigator was proposing to do as compared with other ways of proceeding. To eliminate the "subjective" elements that relate to the particular patient-subject (which lead him, for example, not to be "reasonable" in deciding about certain kinds of interventions) is to make the informed con-

the jury consider the personal "position of the plaintiff" with an eye to such details as whether the patient-plaintiff deviates in some respects from the norm of reasonableness.

${ }^{162}$ See, e.g., Canterbury v. Spence, 464 F.2d 772, 787 (D.C. Gir.), cert. denied, 409 U.S. 1064 (1972); Waltz \& Scheuneman, supra note 20, at 639.

${ }^{163}$ Waltz \& Scheuneman, supra note 20, at 639.

164 Wilkinson v. Vesey, 110 R.I. 606, 625, 295 A.2d 676, 688 (1972). 
sent doctrine an engine of depersonalization rather than personalization. The after-the-fact application of this rule in the courtroom need cause no greater difficulty. Jurors are not fools; they know when to credit, and when not, a plaintiff's testimony that he needed to know a particular fact in order to reach an informed judgment. ${ }^{\mathbf{1 6 5}}$

The standard of reasonably prudent conduct is, of course, the one customarily employed in negligence actions, but there are reasons to question its application to the disclosure requirement of informed consent. First, the courts apparently seized upon reasonableness because, in Judge Robinson's words, it "would in any event ease the fact-finding process." ${ }^{166}$ It may be harder for jurors to assess the particular characteristics of individual patients, but they are called upon occasionally to take "subjective" factors into account, especially regarding plaintiff's conduct, even in negligence cases. ${ }^{167}$ Moreover, con-

${ }^{165}$ As Justice Kelleher of the Rhode Island supreme court observed, the plaintiff's description of the consenting process involves "issues of credibility to be resolved by the trier of fact." He expressed "every confidence that a juror will adhere to his oath and 'give a true verdict . . . according to law and the evidence given [him]." Id. at 626,295 A.2d at 688.

${ }^{166}$ Canterbury v. Spence, 464 F.2d 772, 791 (D.C. Cir.), cert. denied, 409 U.S. 1064 (1972). This comment was made in discussing the use of the reasonableness standard in determining causation, see text accompanying notes 192-204 infra, but Judge Robinson employed the same reasoning to justify that standard as was used in establishing the rule for disclosure.

167 "Subjective" judgments come in at both ends of the scale. The infirmities or handicaps of an actor are taken into account by the courts in charging juries to consider such factors as being among the circumstances affecting whether his or her conduct was reasonable or to consider what a prudent person with a like infirmity would do. A subjective standard, including such factors as age and insanity, is particularly prevalent in measuring contributory negligence. At the opposite extreme, an actor is held to the greater knowledge or skill which the jury concludes that he or she possessed or should have possessed as a result of experience with the activity in question.

To some extent, negligence cases do not provide complete analogies, since the issue for the factfinder in informed consent is not the reasonableness of the patient's conduct but simply what was understood and agreed to by the parties. From this angle, an analogy may be made to cases on the authorization of a gift from the estate of an incompetent person. In arriving at the necessary "substituted judgment," courts have applied a subjective standard to determine what the person would decide if competent, see, e.g., City Bank Farmers Trust Co. v. McGowan, 323 U.S. 594, 598-99 (1945); In re Guardianship of Brice, 233 Iowa 183, 186-87, 8 N.W.2d 576, 578-79 (1943); In re Flagler, 248 N.Y. 415, 418-20, 162 N.E. 471, $471-72$ (1928), even though the determination is rendered very difficult by the impossibility of receiving evidence directly from the incompetent. While the judicial willingness and ability to be "subjective" displayed by these cases supports the argument for a subjective standard in informed consent law, the other premise behind the cases-that the court must make a judgment on behalf of the incompetent-has, of course, no applicability to the doctrine of informed consent which is designed to protect the 
venience alone hardly seems an adequate rationale if substantive reasons do not lead to the same conclusion. Second, the greater ease of administration does not explain the general approbation for measuring by reasonableness; rather, "the strongest case for an external standard" 168 is to be found in its substantive effect, namely, that it protects people from unreasonably dangerous conduct on the part of others who may nevertheless have tried their best to be careful. As used by the courts in establishing the disclosure rule, however, the focus is on plaintiff's, not defendant's, actions, so the usual substantive justification is absent. The patient owes no one a duty to decide prudently or to require for his decision only the facts that an ordinary person would want. The rule established in the recent cases would bar recovery by a patient whose idiosyncratic decisionmaking takes him outside the realm of the "reasonably prudent person." This is equivalent to a defense of contributory negligence, which has no place in an action for failure to obtain informed consent.

Finally, the opinions verge on abandoning the negligence theory in all but name. They come close to adopting a theory similar to that used in post-negligence statutory duty cases; this theory would be better served if the courts were to complete the movement away from negligence. Liability may be established by a breach of a statutory duty that places responsibility for harm upon the defendant; since such an action is for harm caused by the statutory violation, and not for negligence, recovery is independent of the defendant's carefulness and is not barred by the plaintiff's lack of care, when the statute is "enacted to protect a class of persons from their inability to exercise self-protective care . . ."169 By analogy, the physician's duty to his patient in informed consent cases has been found to be established by the law (judge-made rather than statutory); its purpose is to protect the patient from choices that are uninformed-and hence unacceptable according to his own lights.

The way in which the courts approached their task in Canterbury and its siblings indicates that an analogy to statutory duties should prove instructive. The sweep of physicians' duty

competent patient's right to choose for him or herself, a matter on which his own testimony is usually available. But see note 194 infra.

1682 F. HARPER \& F. JAMES, THE LAW OF TORTS $\$ 16.2$ (1956).

169 Koenig v. Patrick Constr. Co., 298 N.Y. 313, 317, 83 N.E.2d 133, 134 (1948). 
to inform was limned but the details were left to be filled in case by case. The California supreme court, for example, dismissed the need for "a lengthy polysyllabic discourse on all possible complications" or a "mini-course in medical science"170 in favor of informing the patient undergoing an ordinary procedure of "the risk of death or bodily harm, and problems of recuperation." 171 The District of Columbia opinion went into still greater detail.

The topics importantly demanding a communication of information are the inherent and potential hazards of the proposed treatment, the alternatives to that treatment, if any, and the results likely if the patient remains untreated. The factors contributing significance to the dangerousness of a medical technique are, of course, the incidence of injury and the degree of the harm threatened. A very small chance of death or serious disablement may well be significant; a potential disability which dramatically outweighs the potential benefit of the therapy or the detriments of the existing malady may summons discussion with the patient. ${ }^{172}$

In the context of medical innovation, a further step in defining physician-investigators' obligation to inform their patient-subjects is provided by the HEW regulations described previously. ${ }^{173}$ The elements prescribed by those guidelines for valid consent centered around a description of the risks, discomforts, and benefits of the proposed procedure and of alternative procedures, and their experimental or established nature, ${ }^{174}$ particularly if the proposed intervention represents an initial trial of a new procedure in man. In addition to the points set out by HEW, others of primary importance in the context of the research and treatment of catastrophic diseases (1972)

${ }^{170}$ Cobbs v. Grant, 8 Cal. 3d 229, 244, 502 P.2d 1, 11, 104 Cal. Rptr. 505, 515

${ }_{171}$ Id. For more complicated procedures, such as the surgery performed on Mr. Cobbs, the minimal disclosure must include "the potential of death or serious bodily harm, and . . . in lay terms the complications that might possibly occur." Id.

${ }^{172}$ Canterbury v. Spence, 464 F.2d 772, 787-88 (D.C. Cir.), cert. denied, 409 U.S. 1064 (1972). Cf. Note, supra note 25, at 1561, urging "formal rules of disclosure stipulating the minimum amount of information," and setting forth nine substantive items to be included.

${ }^{173}$ See note 75 supra \& accompanying text.

${ }^{174}$ See also Fiorentino v. Wenger, 26 App. Div. 2d 693, 272 N.Y.S.2d 557 (1966), rev'd in part, 19 N.Y.2d 407, 227 N.E.2d 296, 280 N.Y.S.2d 373 (1967). 
include the physician-investigator's degree of personal experience with the proposed procedure, and the degree of uncertainty which surrounds the new technique and the extent to which its use on the patient may help in resolving that uncertainty. If the patient is to be a partner in this enterprise it will be necessary for him to be aware of the scientific as well as the personal purposes and objectives involved so that he can be alert for any important developments. It should be possible to discuss this information with him in such a way as not to increase the probability that his observations will be improperly colored by what he expects to find, any more than the physician-investigator's are by what he expects. ${ }^{175}$

The upshot of the opinions and regulations is the specification of a duty as definite as the duties of "safety" at issue in the statutory violation cases. An adoption of the rationale of those cases is not necessary for the use of a subjective standard in measuring disclosure, but it would fit more logically with the judicially articulated duty of disclosure. ${ }^{176}$ It would especially ad-

175 Special rules and procedures must be promulgated to govern instances in which double-blind studies are scientifically called for.

176 There remains the difficult question of what scope, if any, should be given to the "therapeutic privilege." See notes 112-14 supra \& accompanying text. Clearly, it must be narrowly confined, lest it swallow up the physicians' duty entirely and open the door to after-the-fact rationalization for a failure to inform. The so-called privilege was more or less created by Dr. Hubert W. Smith in a series of articles, particularly Therapeutic Privilege to Withhold Specific Diagnosis from Patient Sick with Serious or Fatal Illness, 19 TENN. L. REv. 349 (1946), on the basis of very scanty case law; since then, though often mentioned in opinions, it has only rarely been invoked in a court's holding. See Patrick v. Sedwick, 391 P.2d 453 (Alas. 1964); Nishi v. Hartwell, 52 Haw. 188, 473 P.2d 116 (1970) (criticized in Shaitsis, Informed Consent: Some Problems Revisited, 51 NeBr. L. Rev. 527 (1972)).

Although it might thus be tempting to junk the concept as being without precedent, it is too firmly established in medical thinking and in legal folklore to be completely interred. As distinguished a commentator as Professor Jon Waltz argues that a physician's "training and responsibilities" toward an "irrationally apprehensive" patient allow him to act "on the basis of his judgment rather than that of his patient." A physician should, Waltz writes, "be permitted to establish the medical propriety of his decision not to disclose the collateral risk." Waltz \& Scheuneman, supra note 20 , at 642-43. Beyond doubting that most physicians have sufficient training or acumen to detect "irrationality" on anything but a personal, ad hoc basis, one is also led to wonder whence does the profession derive its standard of "reason" by which is established the "medical propriety" of depriving the unreasonable (but not incompetent) patient of his authority to make his own decisions? This is likely to reduce to a physician-defendant producing colleagues who testify in effect that the course of treatment chosen by the defendant was wiser than the one the plaintiff apparently would have chosen. Yet if such becomes the rule, physicians could routinely act on the basis of their own judgment which will always be more medically "proper" than patients'. For both "rational" and "irrational" patients alike, the reasonableness of a 
vance the subjective version of the measure of materiality by eliminating the confusion caused by reference to the reasonableness of the physician's conduct in informing the patient of whatever the latter would reasonably want to know.

If this subjective standard of materiality places an additional burden on physician-investigators to inquire specially about the attitudes and biases, strengths and weaknesses of the persons whom they propose to treat, that would seem all to the good. Indeed, this might provide encouragement to physicians, and hence to courts, to make the patient's comprehension of the information conveyed the hallmark of a determination of valid consent. ${ }^{177}$ The mere relaying of information is not, in itself, more than a necessary precondition to the patientsubject's capacity to give informed consent. Although commentators have usefully observed that the doctrine has two parts, in-

medical procedure depends on personal views about risks and benefits, not on any objective touchstone.

The very foundation of the doctrine [of informed consent] is every man's right to forego treatment or even cure if it entails what for him are intolerable consequences or risks, however warped or perverted his sense of values may be in the eyes of the medical profession, or even of the community, so long as any distortion falls short of what the law regards as incompetency. Individual freedom here is guaranteed only if people are given the right to make choices which would generally be regarded as foolish ones.

2 F. HARPer \& F. JAMes, THe LAw of Torts, \& 17.1 n.15, at 61 (Supp. 1968).

If the "privilege" is to be retained to prevent direct and immediate harm to the patient which cannot be avoided by the manner and timing of the disclosure, it must be better policed; to make out the privilege, evidence would be needed about the harmful effects to be expected from disclosure so that the jury may decide whether the withholding was justified, just as it now decides whether an "emergency" was grave enough to justify the physician in proceeding without consent. See, e.g., Dunham v. Wright, 423 F.2d 940, 941-42 (3d Cir. 1970); Koury v. Follo, 272 N.C. 366, 374, 158 S.E.2d 548, 555 (1968).

The "duty" approach to the informed consent cause of action advances this objective, because it places an important limitation on the role of the "privilege" at trial. Under negligence theory, the physician should be able to claim that where he has a good reason not to inform he has not been negligent, since his withholding of information did not produce but rather diminished an unreasonable risk of harm. Consequently, the plaintiff should bear the burden of proving that the privilege was not applicable under the facts of the case. But the courts have, in fact, been unwilling to place this burden on the plaintiff. See, e.g., Canterbury v. Spence, 464 F.2d 772, 791 (D.C. Cir.), cert. denied, 409 U.S. 1064 (1972). This is a further indication of their movement toward the breach of duty rationale, since it does make sense under that theory for the physician to bear the burden of an affirmative defense of "therapeutic privilege" once the patient has made out a breach of duty.

${ }^{177}$ Attention to the question of "comprehension" reflects battery theory in the lineage of the emerging informed consent cause of action, which has been obscured but not abandoned as a result of the courts' greater reliance on negligence theory. In battery, the plaintiff's understanding of what the defendant was proposing to do was always an important element. 
formation and consent,"178 "information" and "informed" are not equivalents. It would be more accurate to say that its two parts are first, disclosure and comprehension, and second, voluntary consent. Information may, in the manner in which it is conveyed, even be used to decrease the likelihood that the choice is made with insight and understanding. One study suggests that untutored subjects' comprehension is inversely correlated with how elaborately the information is presented. ${ }^{179}$

Even when the information presented is adequate, therefore, the consenting process may be nothing more than a "ritual" if the patient-subject remains "uneducated and uncomprehending." 180 To avoid this result, the physician could be held responsible for taking reasonable steps to ascertain whether the information presented has been understood, so that if it has not he may supplement it as needed or may convey the same information in a manner more comprehensible to the particular patient. Such a process might also be expected to reveal additional factors whose materiality could not have been suspected before the physician questioned the patient. The continual exchange of information between patient and physician which the comprehension-testing requirement is likely to produce gives substance to the idea of mutuality in the catastrophic disease process.

The Department of Health, Education, and Welfare has rejected the suggestion that it include a requirement of comprehension as part of its guidelines on informed consent, because such a requirement would go beyond what the courts have demanded. ${ }^{181}$ The District of Columbia court, in Canterbury $v$. Spence, ${ }^{182}$ gave the most explicit recognition to the relationship between "a reasonable divulgence by physician to patient" and the "enlightenment with which [the latter can] reach an intelligent decision." ${ }^{83}$ Judge Robinson relegated to a footnote the

178 Waltz \& Scheuneman, supra note 20 , at 630.

${ }^{179}$ Epstein \& Lasagna, Obtaining Informed Consent: Form or Substance, 123 ARCH. INTERN. MED. 682 (1969).

${ }^{180}$ Ingelfinger, Informed (But Uneducated) Consent, 287 NEw. Eng. J. MED. 465, 466 (1972). Dr. Ingelfinger's pessimistic conclusion is that "the chances are remote that the subject really understands what he has consented to," so that it is vain to conceive of him as in any sense a partner of the physician-investigator. He believes that subjects must rely for their "real protection" on the "conscience and compassion of the investigator and his peers" rather than on informed consent. Id. 465-66.

181 See 39 Fed. Reg. 30649 (1974) (declining to amend 45 C.F.R. $\$ 46.3$ (c) (1974)).

182464 F.2d 772 (D.C. Cir.) cert. denied, 409 U.S. 1064 (1972).

${ }^{183}$ Id. at 780 . 
difficulties posed by looking to the former but not the latter as a measure of "informed" consent. The duty of the physician, he concluded, is to disclose rather than to inform. "Even though the factfinder may have occasion to draw an inference on the state of the patient's enlightenment, the factfinding process on performance of the duty ultimately reaches back to what the physician actually said or failed to say." ${ }^{184}$ His invitation to the trier of fact to develop inferences about the patient's comprehension-at odds with the rest of the opinion-may merely have been loose language. Or perhaps Judge Robinson intended by this formulation quietly to encourage the development in future cases of a duty to inform which places more emphasis on "the state of the patient's enlightenment." There are other indications in the informed consent opinions that the courts recognize the central importance of comprehension. The plainest of these is the limitation placed on the duty of disclosure; in the words of the Wilkinson court, "Obviously there is no need to disclose risks that are likely to be known by the average patient or that are in fact known to the patient usually because of a past experience with the procedure in question."185 If the disclosure duty were really the key to the cases, this conclusion would not be so obvious. But as the duty is instrumental to the real concern-that the patient be an educated and comprehending decisionmaker-it is obvious that further disclosure is superfluous when the patient is already acquainted with the information.

While Judge Robinson may thus have been opening the way for development of "comprehension" as the keystone of informed consent, the present formulation in Canterbury leaves the court with some basic difficulties, for in his words, "the factual conclusion on adequacy of the revelation will vary as between parties." $186 \mathrm{He}$ would have one discount the variations in the "duty-to-disclose" as merely incidental to "the kind of divulgence which may be reasonable under the circumstances,"187 given the variation in patients. But this only serves to empha-

${ }^{184}$ Id. n. 15.

185 Wilkinson v. Vesey, 110 R.I. 606, 627, 295 A.2d 676, 689 (1972). Accord, Canterbury v. Spence, 464 F.2d 772, 788 (D.C. Cir.), cert denied, 409 U. S. 1064 (1972); Cobbs v. Grant, 8 Cal. 3d 229, 244, 502 P.2d 1, 11, 104 Cal. Rptr. 505, 515 (1972); Waltz \& Scheuneman, supra note 20 , at 630.

186464 F.2d at 780 n. 15 .

187 Id. 
size rather than diminish the importance of comprehension, for the major difference in patients comes in how much they must be told in order to comprehend the risks and benefits of the alternatives which the physician is presenting to them.

The very factors which led the courts to base the disclosure requirement on "the patient's need" would seem to make necessary the inclusion of some measure of how well that need had been met as an element of the new cause of action. ${ }^{188}$ It was suggested previously that the courts might do well to complete the movement from disclosure only at the will of the medical community through standard negligence to a legally established duty. This development made sense in establishing an easily measured, and one hopes easily followed, rule of divulgence, free from the constraints of a negligence formulation. The focus of attention there was on what the physician-investigator did (adequate disclosure vel non). In speaking of comprehension, however, the focus is on the patient-subject and whether he was informed when he made his decision to proceed. Thus, policy as well as logic dictates that physician-investigators not be held to determine beyond peradventure the state of patient-subjects' knowledge but only to make reasonable efforts to ascertain that they adequately comprehend what is being proposed, including the risks and alternatives. ${ }^{189}$

The importance of a subjective rather than objective standard of materiality can be seen by comparing how well each standard would serve the functions of informed consent. For example, a physician-investigator's self-scrutiny is likely to be increased if he has to ask, "Is this procedure right for this patient, based on what I actually know about him or her?" and not on what is known about the "reasonable patient." The very routine nature of the latter does nothing to promote reexamination on the part of the physician-investigator as he plans how he will explain the proposed intervention to the patient-subject. The requirement that the physician-investigator individ-

${ }^{188}$ A means of increasing, and of measuring, patient-subjects' comprehension is contained in Miller \& Willner, A Suggestion for Promoting Free and Informed Consent, 290 New EnG. J. MED. 964 (1974).

${ }^{189}$ Waltz and Scheuneman likewise conclude that the patient's awareness is an element of a valid consent, so that the test becomes "whether a reasonable man would conclude from the patient's behavior that he was aware of the risk and that he manifested a willingness to encounter it." Waltz \& Scheuneman, supra note 20, at 645. 
ualize the informing process is consistent with the obligation to individualize the diagnostic and therapeutic processes. ${ }^{190}$ Similarly, the respect for the patient-subject as a full human being is better served by a subjective standard. As the courts have recognized, one reason why a physician might withhold information is a belief that if the patient knew it he would re-

${ }^{190}$ See, e.g., Cobbs v. Grant, 3 Cal. 3d 229, 245, 502 P.2d 1, 11, 104 Cal. Rptr. 505, 515 (1972) (" $[\mathrm{A}]$ doctor must, of course, make such inquiries as are required to determine if for the particular patient the treatment under consideration is contraindicated ....").

Using a "subjective" standard does not mean that physician-investigators need conduct a psychoanalytic probing of their patient-subjects nor even that they should do so. It is important that the informing process be individualized for each patient's needs; the lack of inclination for such a task exhibited by many physicianinvestigators, particularly the surgeons involved in catastrophic disease research and treatment, ought not excuse this task being left undone, though it is obvious that rules must be kept "within the reach of obedience," Fletcher, supra note 64, at 39, since a requirement which is too onerous and for which physician-investigators have neither time nor inclination will be routinely ignored. Rather than abandon the duty to inform, however, the obligation can be framed in such a way that it is performed by other members of the research/treatment team, see text accompanying note 114 supra, who are capable of responding to the individual patient-subject's ability to deal with various pieces of information. Or a special "physician-friend" from outside the team could be appointed as suggested by Otto Guttentag, among others, see Guttentag, supra note 124, at 210 , although the advocacy role imagined for such a person must be carefully cabined lest it usurp the patient-subject's own decisionmaking authority.

As was shown in Part II-B supra, from the empirical studies of decisionmaking by kidney donors and recipients, even sensitivity to the timing of the informed consent process and to the expectations of the patients may not fully overcome the qualms of physician-investigators about the "rationality" of some decisions reached. But the "subjective" standard of information disclosure provides no warrant for physicianinvestigators to reverse their patient-subjects' choices by probing into the underlying psychological processes and discovering "ambivalences," "fixations," or other unconscious elements, short of the extreme of legal incompetency. See text accompanying notes 147-49 supra. "Subjective" refers, in other words, to the recognition that a patient-subject may hold different beliefs and values than the average "reasonable person," and not to the interior mental processes which might be uncovered through a psychoanalytic investigation of the motivations and conflicts lying behind the consent of an apparently informed and coherent patient-subject. Since such probing is not part of the initial consenting process, it also has no place in after-the-fact review, provided that the physician-investigator has not intentionally manipulated the process to thwart the aims of comprehension and voluntariness. See text accompanying notes 123-26 supra.

"The weighing of these risks [of undergoing or foregoing a proposed treatment] against the individual subjective fears and hopes of the patient is not an expert skill," as the California Supreme Court declared. "A patient should be denied the opportunity to weigh the risks only when it is evident he cannot evaluate the data ...." Cobbs v. Grant, 8 Cal. 3d 229, 243, 502 P.2d 1, 10, 104 Cal. Rptr. 505, 514 (1972). As argued previously, see text accompanying note 127 supra, the patient's weighing of risks ought no more be filtered through the "expertise" of the lay community (as embodied in the jury) than through that of the medical community. 
fuse an intervention believed necessary by the physician. ${ }^{191}$ Yet such a substitution of judgment, permitted under the negligence rationale if nondisclosure were the professional norm, clearly deprives the patient of his power of self-determination and human dignity. The "objective" test has the same effect, for it asks the jury to decide whether the patient would have wanted to know something, had he been a "reasonable person." The paternalistic judgment that it would have been better not to know is thus shifted from the physician's sole discretion to the jury's. It seems highly dubious to say, in the case of the major and often experimental interventions which occur in the catastrophic disease process, that the right of the patient to say "no" on even the least rational grounds should ever be taken away.

\section{Causation}

The second major stumbling block posed by the choice between battery and negligence theories has been the determination of the extent of the defendant's liability for the injuries which resulted from the intervention. Under a battery rationale, if the information withheld were sufficiently important to have vitiated consent, causation would not be a major issue since a physician is liable for the "unauthorized touching" of his or her patient. ${ }^{192}$ In addition to exemplary damages, all harm actually resulting from the touching would be recoverable. Most judges have found this too harsh a result, however, since physicians typically act without "malice" in performing an inadequately consented intervention.

The negligence rationale has tended to the opposite extreme. Under it, courts and especially commentators have elevated causation to a central position. ${ }^{193}$ Unless the patient can

${ }^{191}$ Compare Canterbury v. Spence, 464 F.2d 772, 789 (D.C. Cir.), cert. denied, 409 U.S. 1064 (1972), rejecting "the paternalistic notion that the physician may remain silent simply because divulgence might prompt the patient to forego therapy the physician feels the patient really needs," with Zebarth v. Swedish Hosp. Med. Center, 81 Wash. 2d 12, 25-26, 499 P.2d 1, 9-10 (1972), holding that the physician need not "risk frightening the patient out of a course of treatment which sound medical judgment dictates the patient should undertake." Cf. Beeson, Moral Issues in Clinical Research, 36 YALE J. Bro. \& MED. 455, 465 (1964), arguing for limited disclosure because "if we were to tell a person of all the possible things that could go wrong in the course of the experiment he probably would not wish to submit to it."

192 See, e.g., Lacey v. Laird, 166 Ohio St. 12, 139 N.E.2d 25 (1956) (in absence of proper consent, surgery is actionable even if harmless or beneficial).

${ }^{193}$ For a recognition of the importance of proving causation for recovery under a 
prove that "but for" the withholding of a certain piece of information he would never have consented to the intervention, he is not permitted to recover. Moreover, some of the courts have employed the "objective" standard here, too. The question is thus framed as whether a "reasonable person" would have refused to undergo the intervention if he had known of the fact withheld by the physician. ${ }^{194}$

negligence theory, see (in addition to the recent informed consent trilogy of opinions) Shetter v. Rochelle, 2 Ariz. App. 358, 409 P.2d 74 (1965), modified, 2 Ariz. App. 607, 411 P.2d 45 (1966); Aiken v. Clary, 396 S.W.2d 668 (Mo. 1965); Comment, Informed Consent in Medical Malpractice, 55 Caurf. L. Rev. 1396 (1967).

${ }^{194}$ See Canterbury v. Spence, 464 F.2d 772, 791 (D.C. Cir.), cert. denied, 409 U.S. 1064 (1972); Cobbs v. Grant, 8 Cal. 3d 229, 245, 502 P.2d 1, 11-12, 104 Cal. Rptr. 505, 515-16 (1972). This holding appears to have originated with Waltz \& Scheuneman, supra note 20 , at 647 , who also discerned a bright line separating materiality and causality. Id. 638-39 \& n.40; but see note 195 infra. These commentators present two grounds, neither persuasive, for a "reasonable person" standard. First, they argue that whether the patient would have acted differently if properly informed "can only be a guess," so "posing the causation issue in that form does not promote rational resolution of it." Id. 647. Yet any after-the-fact assessment of the elements of an injury is in this sense always "a guess," based most often on the jurors' untutored sense of the probable (in actions of persons and movements of physical objects), aided by whatever "facts" the parties can supply to explain how something happened and, in some cases, how it would not have happened had the responsible party behaved differently. There are many times that in passing on causation, as Learned Hand wrote, "no certain conclusion [is] possible." Zinnel v. United States Shipping Bd. Emergency Fleet Corp., 10 F.2d 47, 49 (1925). The factfinder, of course, is not permitted to engage in "mere speculation," but there is no reason to believe that in every case the resolution of the hypothetical issue of what the patient would actually have done will fall into such a category. When the issue is capable of resolution, it would seem an eminently "rational" means of determining causation.

Second, Waltz and Scheuneman reason that since the plaintiff's testimony about what he would have done if informed "will be assessed primarily on the basis of its reasonableness" in the factfinder's view, the latter should be told that the standard for measuring causality is "the effect of disclosure or nondisclosure . . . on a reasonable person in the plaintiff's position ...." Waltz \& Scheuneman, supra note 20, at 647. This confuses the jury's common sense approach to credibility-that they will be highly skeptical of the plaintiff who claims that he would not have consented had he known of the very small probability of a very inconsequential injury-with the legal standard which will constrain the jury in determining causation in the case of "unreasonable" or otherwise idiosyncratic patients. If, in an attempt to avoid this difficulty, the weight of the rule is cast upon its concluding phrase, "in the plaintiff's position," rather than on reasonableness, then the rule becomes, in effect, subjective rather than objective.

A third difficulty with the Waltz-Scheuneman position is that the one case they relied on to support it, Aiken v. Clary, 396 S.W.2d 668 (Mo. 1965), does not adopt a "reasonable person" standard. Mr. Aiken was unable to testify (because the insulin shock therapy had left him brain-damaged, although not dead as Waltz and Scheuneman state), and on that basis the physician-defendant asserted that there could be no proof of causation. The court disagreed, holding that the jury could decide from the circumstances whether the operation would have been refused "even though plaintiff does not specifically so testify." Id. at 676. The Missouri court's conclusion is clearly correct, since it would be unjust to bar recovery when the harm caused by a 
Again, the battery/negligence dichotomy seems more concerned with the formalities of legal rules than with the functions which informed consent is to serve. Injuries which occur because the patient-subject has been prevented from being an informed decisionmaker should be compensable. Moreover, the importation of the "reasonable person" standard for causation is as misplaced here as it was in judging materiality of disclosure. ${ }^{195}$ An "individualized test of causation is indicated because informed consent seeks to assure patients the right to make even irrational decisions." 196 To deny recovery because the jury believes that a reasonable person would not have cared about a certain factor (although they also believe that the factor did matter to the particular patient-plaintiff) undermines the fundamental purpose of the informed consent rule, the promotion of individual autonomy. The danger that a physiciandefendant will be unfairly prejudiced by the patient-plaintiff's testimony is slight. It can be minimized through cross-examination and through defense counsel's perfectly legitimate suggestion in argument to the jury that the patient's statements be received with suspicion if they deviate too greatly from common experience without adequate explanation. Yet each person is his or her own decisionmaker, no matter how "unreasonable" the decisions made, because each is ultimately responsible for the outcomes of the decisions. To judge the refusal of a blood transfusion during surgery under the lens of the ordinary, prudent person is to deny the patient-subject with special "fears and hopes,"197 or the religious beliefs of a Jehovah's Witness, the right to make a decision.

Even without the "reasonable person" overlay, the negligence standard needs some refinement, lest it focus on the "but

possibly-unconsented medical procedure was so great as to prevent the injured party from testifying, just as defendants who killed their victims, before Lord Campbell's Act, were less in jeopardy than those whose conduct had not been fatal. The Aiken court said nothing, however, to indicate that in the ordinary case the jury ought not look to the plaintiff's own decisionmaking in assessing causation.

${ }^{195}$ Materiality and causation should be treated by the same standard in part because they are inseparable concepts. For a piece of information to be material to the patient-subject's decision must mean that the decision might come out differently without that information.

196 Note, Informed Consent and the Dying Patient, 83 YALE L.J. 1632, 1642 (1974); accord, Wilkinson v. Vesey, 110 R.I. 606, 629, 295 A.2d 676, 690 (1972). Contra, Waltz \& Scheuneman, supra note 20 , at 647 .

${ }_{197}$ Cobbs v. Grant, 8 Cal. 3d 229, 243, 502 P.2d 1, 10, 104 Cal. Rptr. 505, 514 (1972). 
for" nature of the particular piece of information which was withheld. If the courts are serious in seeking to promote rational decisionmaking, the fractionization of thinking hypothesized by such a theory of causation has no place. A single fact (not limited to facts about danger) may not seem important, but decisionmaking is not a matter of single facts but of relating many diverse facts, some "large" and others "small," to one another. ${ }^{198}$ The question of causation can therefore best be resolved by determining whether the patient-subject was injured in a way related to the information which was withheld. If the information which the jury determines the physician-investigator should have disclosed (using the standard of materiality previously set forth) would have led the patient-subject to decline the operation, the latter should be able to recover for any injuries. The extent of this liability has apparently been too great for some courts to accept, ${ }^{199}$ although it is the logical con-

${ }^{198}$ In discussing materiality, the District of Columbia court rejected the polar views that all risks, no matter how slight, must be revealed, see Oppenheim, Informed Consent to Medical Treatment, 11 Clev.-Mar. L. Rev. 249, 264-65 (1962); Comment, Valid Consent to Medical Treatment: Need the Patient Know?, 4 Duquesne L. Rev. 450, 457-58 (1966), and that only risks that would lead the patient to decline treatment must be divulged, see Johnson, Medical Malpractice-Doctrines of Res Ipsa Loquitur and Informed Consent, 37 U. Colo. L. Rev. 182, 185-91 (1965); Comment, Informed Consent in Medical Malpractice, 55 CALIF. L. REv. 1396, 1407 n.68 (1967), because "while a single risk might not have that effect, two or more might do so." Canterbury v. Spence, 464 F.2d 772, 788 n.89 (D.C. Cir.), cert. denied, 409 U.S. 1064 (1972). "Risks" may be the primary items of concern to patient-subjects, but other facts-concerning, for example, discomforts, restrictions on permissible activities, and degree of eventual recovery-are also important and sometimes determinative. See, e.g., P. Ramsey, The Patient as Person 225-27, 235-38 (1970); Daly, Don't Wave Goodbye, 4 Hastings Center ReP., Nov. 1974, at 7 (recounting the different expectations held by the author-patient and her physicians about the outcome of her treatment); text accompanying note 63 supra. The cases frequently take a view of what needs to be communicated that goes well beyond solely "risks," but it has apparently never been the point at issue in litigation. For instance, in granting plaintiff's motion for summary judgment against her physician for injuries resulting from an operation performed without informed consent, an Ohio trial court defined the items to be communicated as "the nature of the surgery . ... the probable consequences, risks and hazards of this procedure, and the benefits that can be anticipated from this procedure." Congrove v. Holmes, 37 Ohio Misc. 95, 101, 308 N.E.2d 765, 769 (C.P. Ross County 1973).

${ }^{199}$ See, e.g., Canterbury v. Spence, 464 F.2d 772, 790 (D.C. Cir.), cert. denied, 409 U.S. 1064 (1972) ("unrevealed risk that should have been made known must materialize"). The Rhode Island supreme court appears to accept the broader definition of compensable injury in declaring that plaintiff prevails when he proves (1) a causal connection between the defendant's failure to inform him and his consent and (2) "that he had been injured as a result of submitting to the procedure." Wilkinson v. Vesey, 110 R.I. 606, 629, 295 A.2d 676, 690 (1972) (citing Shetter v. Rochelle, 2 Ariz. App. 358, 409 P.2d 74 (1965)); the California supreme court did not advert to this issue in Cobbs v. Grant, 8 Cal. 3d 229, 502 P.2d 1, 104 Cal. Rptr. 505 (1972). 
clusion from their premise that "it is the prerogative of the patient . . . to determine for himself the direction in which his interests seem to lie."200

The rationale for allowing recovery is that although the patient may have been satisfied with a stated risk of $x$ that A would occur, he would not have proceeded had he known that the risk was $x^{\prime}$ and/or that there was a $y$ risk of B occurring, that "cure" would still leave him seriously impaired, and so forth. ${ }^{201}$ In many instances, the alternative to the treatment undertaken is not to forego treatment altogether but to undertake another mode of treatment, ${ }^{202}$ with its own set of projected risks and benefits; ${ }^{203}$ particularly in the treatment of catastrophic illness, for which many interventions are still experimental, the alternative is typically a more conservative procedure which is less risky but which promises less than a complete cure. Certainly, this is the sort of choice which should be governed by "the patient's right to be the final judge to do with his body as he wills."204

${ }^{200}$ Canterbury v. Spence, 464 F.2d 772, 781 (D.C. Cir.) (footnote omitted), cert. denied, 409 U.S. 1064 (1972); accord, Cobbs v. Grant, 8 Cal. 3d 229, 242, 502 P.2d 1, 10, 104 Cal. Rptr. 505, 514 (1972); Wilkinson v. Vesey, 110 R.I. 606, 625, 295 A.2d 676, 688 (1972).

201 Two commentators have argued that even limiting recovery to the occurrence of a risk which was not disclosed, see Natanson v. Kline, 186 Kan. 393, 411, 350 P.2d 1093, 1107, clarified and rehearing denied, $187 \mathrm{Kan} .186,354$ P.2d 670 (1960) (dictum), is "unduly harsh" on physicians, Waltz \& Scheuneman, supra note 20, at 649. They suggest that damages be calculated as "the difference between [the patient's] condition with no treatment and his condition after the undisclosed risk materialized." While not impossible of estimation, this assessment would seem to open the door to highly hypothetical speculation, see note 194 supra.

202 Or another alternative may be to delay the proposed treatment "in order to attend to personal or business matters," Note, supra note 196, at 1641 (footnote omitted); the Note writer suggests that damages are properly gauged by "the malpractice measure: the damage resulting from the breach of duty." In informed consent this is "the materialized undisclosed risk," as Natanson suggested. Id. A remaining problem with the Natanson formulation is that it ignores the situation in which an operation would have been declined on grounds other than an undisclosed risk. See note 198 supra \& accompanying text.

${ }^{203}$ As is admitted by the proponents of limiting damages by looking to the patient's hypothetical condition without treatment, the possibility of alternative treatments makes the case "more difficult." "A new variable would then be introduced-the probability of use of a technique that did not involve the risk [that materialized]. It is possible that this imponderable would justify reverting to the more stringent Natanson measure of damages." Waltz \& Scheuneman, supra note 20, at 649.

${ }^{204}$ Wilkinson v. Vesey, 110 R.I. 606, 625, 295 A.2d 676, 688 (1972). Although a physician may not be competent to offer all the alternative forms of treatment himself, see Kessenick \& Mankin, supra note 20 , at 279 , he is still obliged to acquaint the patient with general information about them and to point the patient to another 
This formulation uses the negligence standard of "cause in fact" but broadens it by looking to the subjective decisionmaking of the individual plaintiff. The result is, however, less sweeping than the measurement of injury provided by the battery approach. It seems appropriate to modify the latter, which would permit recovery for a dignitary injury without any showing of actual harm. Although the informed consent cause of action is intended in part to protect the dignity and autonomy of patient-subjects, this protection must be seen in the context of the risk-taking inherent in the treatment of, and research on, disease. Thus, the primary purpose of the doctrine is to hold physician-investigators, rather than patient-subjects, responsible for the harm inflicted when risks materialize if the agreement of the patient-subjects to enlist in the undertaking was not fully informed and voluntary. The punitive aspects of a battery action would therefore not ordinarily be appropriate; where the conduct of the physician justifies recovery for an intentionally wrongful invasion of the plaintiff's interests, such action should be maintained under a separate heading, as a battery rather than as a breach of the duty to obtain informed consent.

\section{C. "Consent" for the Legally Incompetent}

"Consent" for a procedure in catastrophic disease research and treatment must sometimes be sought from someone other than the patient-subject, since he is often legally incompetent. For example, when a patient is admitted to an emergency room, his condition may be such (due, for example, to a cardiac arrest or acute renal failure) that he is unable to participate in the deliberations about his treatment, and the decision must then be made instead by a member of his family. This was the situation with the first heart transplant in man, in which the recipient's sister gave permission for the operation. ${ }^{205}$ Additionally, many of the initial clinical trials of transplant procedures (renal grafts in the 1950's and bone marrow currently) have been performed

health professional who performs the treatment. At the least, a physician-defendant should not be heard to complain if the patient-plaintiff introduces proof that had he chosen another therapeutic modality - to which the defendant failed to alert himhis injuries would have been nonexistent or greatly reduced.

${ }^{205}$ See Hardy \& Chavez, The First Heart Transplant in Man-Historical Reexamination of the 1964 Case in the Light of Current Clinical Experience, 1 Transplant Proc. 717, 721 (1969). 
on children, who because of their age lack the legal, and often the actual, capacity to consent. ${ }^{206}$

The problems of intervening medically with the legally incompetent is usually resolved by reliance on what is termed "proxy consent." As an initial matter, it is necessary to distinguish between interventions which involve routine treatment and those which partake of the experimental. The former seldom raise serious problems in practice, although as a theoretical matter difficulties arise whenever one person is given power over another. The customary way to minimize these difficulties is to place the power with someone thought to be closely identified with the patient and who has interests highly congruent to his. This is typically the patient's parent, spouse, or other close relative, although it is recognized that occasionally the dangers of an abuse of power may be exacerbated rather than reduced when the persons involved are members of the same family. Yet there are reasons of sentiment, convenience and even good sense for this allocation of authority, ${ }^{207}$ and it is

${ }^{206}$ See Curran, A Problem of Consent-Kidney Transplantation in Minors, 34 N.Y.U.L. REv. 891 (1959).

In some instances the status of the minor-as "patient" or "subject"-is not clearly defined. This is illustrated by a case recounted by Dr. Francis Moore, the head surgeon at Peter Bent Brigham Hospital in Boston, where much of the pioneering renal transplant research took place in the 1950's. One early kidney recipient, Mrs. L., was given massive radiation treatment and then injections of bone marrow from 11 donors to restore health to her system and (it was hoped) to achieve "cross-acceptance" of the eventual kidney graft. Then a questionable step was taken:

As the days went by, it appeared inadvisable to take a kidney from a healthy normal donor. There were too many uncertainties and unknown variables in the plan. Therefore, a kidney that had to be removed from a young child having the hydrocephalus operation was placed in the patient's right thigh by Dr. Murray ....

Just before the kidney graft, the patient received another 170 million bone marrow cells from the same donor who gave the kidney. Thus, by adding this procedure, the identity of donor for both marrow and kidney was achieved.

F. Moore, Transplant: The Give and Take of Organ Transplantation 115 (1972). Dr. Moore goes on to tell how the four week survival of the kidney graft in Mrs. L. (who died of bleeding because the bone marrow injections were unsuccessful in restoring her platelet level) was a key event in the history of transplantation, since it showed that if the immunological barrier were sufficiently incapacitated, a transplanted organ could survive. No mention is made of the problematic nature of taking 170 million bone marrow cells from the infant kidney donor (apparently with the permission of his parents). Moore earlier observed that marrow donation "does not harm the donor at all," yet like all medical procedures it does carry some risk, pain and inconvenience. Indeed, officials of the National Institutes of Health have felt the need to seek judicial approval before aspirating bone marrow from minors for transplantation to their siblings. See note 209 infra.

207 There are any number of explanations for this societal allocation of author- 
a practice which is so well known in society at large that any individual who finds the prospect particularly odious has ample warning to make other arrangements better suited to protecting his own ends or interests.

More troublesome problems are raised when consent is sought for an experimental intervention or one which is otherwise not solely for the patient's benefit. It is generally assumed, though not authoritatively established, that a guardian lacks the authority to give consent in such circumstances. This issue has been raised in a number of the kidney transplants involving identical twins ${ }^{208}$ and bone marrow transplants between siblings. ${ }^{209}$ Where the potential donor is a minor, the apparent rule that a parent cannot consent to a nonbeneficial operation has been side-stepped by the courts' finding that the healthy child would benefit from the operation because the risk of emotional disturbance would be reduced. The decisions in the first cases, involving kidney transplants in teenage twins at the Peter Bent Brigham Hospital in Boston, have proven very influential with subsequent courts faced with similar issues. Therefore, it is particularly significant that in one of those cases the court went so far as to rule-after shifting the ultimate decision as to

ity [in the case of parental consent for interventions in their children]: respect for the family and a desire to foster the diversity it brings; the fitness of giving the power to decide to the same people who created the child and have the duty to support and protect him; the belief that a child cannot be much harmed by parental choices which fall within the range permitted by society and a willingness to bear the risks of harm this allocation entails or a belief that in most cases "harm" would be hard for society to distill and measure anyway; or simply the conclusion that the administrative costs of giving authority to anyone but the parents outweigh the risks for children and for society unless the parents are shown [in a particular case] to be unable to exercise their authority adequately.

Capron, Legal Considerations Affecting Clinical Pharmacological Studies in Children, 21 Clinical Research 141, 146 (1973) (arguing for a model of "successive limited approximations" under which authority to give permission might in some instances not be lodged with parents).

${ }^{208}$ Hart v. Brown, 29 Conn. Supp. 368, 289 A.2d 386 (1972); Strunk v. Strunk, 445 S.W.2d 145 (Ky. 1969); Foster v. Harrison, Eq. No. 68674 (Mass. Sup. Jud. Ct., Nov. 20, 1957); Huskey v. Harrison, Eq. No. 68666 (Mass. Sup. Jud. Ct., Aug. 30, 1957); Masden v. Harrison, Eq. No. 68651 (Mass. Sup. Jud. Ct., June 12, 1957).

${ }^{209}$ During 1971 and 1972, the National Institutes of Health received permission from the Maryland Circuit Court for Montgomery County to undertake bone marrow transplants from minor donors to their ailing siblings in a series of five cases. In re Sharpe, Eq. No. 44478 (Cir. Ct. Montgomery County, Md., Dec. 28, 1973); In re Landry, Eq. No. 44338 (Cir. Ct. Montgomery County, Md., Sept. 5, 1973); In re Martin, Eq. No. 44602 (Cir. Ct. Montgomery County, Md., Oct. 20, 1972); In re Jones, Eq. No. 44601 (Cir. Ct. Montgomery County, Md., Oct. 11, 1972); Smith v. Smith, Eq. No. 43919 (Cir. Ct. Montgomery County, Md., July 19, 1972). 
risks and benefits back to the physicians, "if [they] decide to perform the operation"- that the operation was not merely permissible but "necessary to [the well twin's] future welfare and happiness." 210

This rather unsatisfactory handling of the issue invites a number of responses. First, one might simply conclude, with Professor David Daube, that "[c]hildren should on no account be donors, and there should be no cheating by maintaining, for example, that the child would suffer a trauma if he were not allowed to give his twin a kidney or whatever it might be."211 Recent bone marrow transplants have presented this issue squarely to the judiciary because in at least one case a prospective donor was so young that any "psychological injury" from the death of the older, ailing sibling which resulted from the transplant being withheld was too dubious even to have been pleaded in the petition. Yet the petition was granted, without any attempt to justify the exposure of the nonconsenting child to an uncompensated risk. ${ }^{212}$

The necessity of seeking judicial approval in such circumstances appears to be denied by the position advanced by Professors Henry Beecher and William Curran. Their argument, diametrically opposed to that of Daube, is that American statutes, medical codes, and cases permit patients to give consent for medical interventions of no direct, and in some instances, no indirect, benefit to their child. ${ }^{213}$ They read the leading case in this area, Bonner $v$. Moran, ${ }^{214}$ which involved the validity of a

${ }^{210}$ Foster v. Harrison, Eq. No. 68674 (Mass. Sup. Jud. Ct., Nov. 20, 1957). When attempting to make a rule about a guardian's power to consent to nonbeneficial interventions, those drawing on the Massachusetts cases and their progeny seldom acknowledge the particular problems involved in such a situation where the guardian (parent) had a conflict of interest between helping the sick twin and protecting the well one, although this factor probably explains, at least in part, why the cases were litigated in the first place. $C f$. Shaw, Dilemmas of "Informed Consent" in Children, 289 NEw ENG. J. MED. 885 (1973).

${ }^{211}$ Daube, Transplantation: Acceptability of Procedures and the Required Legal Sanctions, in Ethics in Medical Progress: With Special Reference to Transplantation 188, 198 (G. Wolstenholme \& M. O'Connor eds. 1966).

${ }^{212}$ In re Martin, Eq. No. 44602 (Cir. Ct. Montgomery County, Md., Oct. 20, 1972).

${ }^{213}$ Curran \& Beecher, Experimentation in Children, 210 J.A.M.A. 77 (1969).

214126 F.2d 121 (D.C. Cir. 1941). The trial court had told the jury in Bonner that it could find that no parental approval was necessary for the fifteen-year-old plaintiff to have given valid consent to donate the skin graft if he was "capable of appreciating the nature, extent and consequences of the invasion." Id. at 122 (paraphrasing Restatement of TORTS $\$ 59$ (1934)). The jury found for the doctor-defendant, and on 
fifteen-year-old's donation of skin grafts to his cousin, to hold "that such procedures can be legally permitted as long as the parents (or other guardians) consent to the procedure."215 This casts more weight onto the opinion than it can bear. The actual ground for the decision appears to be that the young donor was simply too immature to give valid consent to the procedure, with the suggestion that there were no benefits to him being merely a judicial observation. (After all, the reasons which were given by the court for why his mother might have consentedthe newspaper acclaim and scholarship donations-are benefits which apply equally to the boy.) Moreover, the case is really one of a parent ratifying the consent of a youngster, rather than of a parent making the choice instead of the child's making it. The Bonner court nowhere suggests that a parent has independent authority to give consent for a "nonbeneficial" intervention in a child who is too young to give any consent or who opposes the intervention. This question remains unsettled, and the singularity of Bonner emphasizes that the judiciary has otherwise gone out of its way to avoid having to rule on this issue.

Although Professor Daube's position has more support in current law, it seems unlikely to persuade decisionmakers such as judges. Indeed, its uncompromising refusal to admit that there may be situations in which the very great benefits to be gained counterbalance small risks to an incompetent may be reflected in the less than candid way that "compromises" in this area have appeared in the case law. Midway between the poles of Daube and Curran-Beecher lies a formulation which builds on the present system in allowing permission for nonbeneficial interventions to be given on behalf of incompetents by someone, ${ }^{216}$ but which demands a clearer recognition of the competing interests. Only by acknowledging that certain interests are at war and then by attempting to balance them in each case can progress be made toward a satisfactory resolution

appeal the court reversed. It held that the consent of an "immature colored boy" was not sufficient for an operation on himself that was not for his benefit and that was "so involved in its technique as to require a mature mind to understand precisely what the donor was offering to give." Id. at 123. The case was returned to the lower court for a retrial in which the jury was to be instructed that the surgeon was liable unless the boy's mother had given her consent, directly or by implication.

215 Curran \& Beecher, supra note 213 , at 79.

${ }^{216}$ The authority to give permission need not, however, be vested as it presently is. See Capron, supra note 207, at 145-48. 
of this problem. On the one hand, there is the interest a person has in being protected from abuse and exploitation should he become unable to protect himself. On the other hand, each person has an interest in not having the right to choose taken away while he is still able to make choices which reflect his own view of his goals and values.

In the case of the adult competent to make his own choices, the former interest is protected through the latter. For someone who is legally incompetent, however, the latter interest does not operate, and attention is focused entirely upon the former. This has led to varied attempts to subject the "informed consent" given by one person for another to the analysis used for regular informed consent. Yet the model plainly does not attempt to answer when, for what reasons, and by whom permission may be given in lieu of personal informed consent. Indeed, a small but definite advance in analysis could be achieved by ceasing to call such substitute permission "consent." This would indicate that different considerations apply when talking about such permission from a guardian than when a person gives consent for interventions into his or her own sphere of privacy and bodily integrity. The reasons for relying on consent which were discussed earlier in this Article all relate back to the respect owing the individual and his right to autonomy and dignity. Wherever possible, the law tries not to second-guess decisions which a person makes for himself, once it is apparent that the framework within which the decisions are made is one which permits voluntary, knowledgeable consent. Just as the law must be concerned that as a general principle patient-subjects are adequately protected by the methods that are employed to gain consent, so too it must give meaning to the process of making a choice by holding the parties to the burdens and costs inherent in their choices. Where the permission is given on behalf of someone else, however, these considerations do not attach. Accordingly, it would not only be acceptable but also advisable for such grants of permission to be subject to review as to their competency and motivation, so as to screen out those which are made maliciously or unwisely. ${ }^{217}$ This only serves, however,

${ }^{217}$ An initial attempt at devising special protections for children and other nonconsenting subjects of biomedical and behavioral research appears in U.S. Dep't of Health, Education, and Welfare, National Institutes of Health, Protection of $\mathrm{Hu}-$ man Subjects-Policies and Procedures, 38 Fed. Reg. 31738 (1973), which has been 
to emphasize the importance of keeping analytically separate the "permission" and "consent" situations, so that the process of scrutiny and possible rejection which is appropriate in permission cases will not erroneously be carried over to the case where a person "unwisely" consents to a medical procedure on himself.

\section{EPILOGUe}

The law of informed consent is still very much in a process of evolution and has not yet developed to a point coincident with the "model" of decisionmaking that was derived from the functional analysis earlier in this Article. The action for a violation of the duty to obtain informed consent owes more to the law of negligence than of trespass, but it is an amalgam of both. To the extent that "reasonableness" sets the standard, the better view is that the conduct being judged be that of the physician (in ascertaining whether the patient comprehends the proposed intervention and assents voluntarily to its performance) and not that of the patient.

The evolutionary development of the law not only reflects the incremental cast of judicial thinking, but very properly permits conduct to be adjusted over time, rather than at a fell swoop, to changes in requirements set by the law. It may be too much to hope that legal rules will have any great impact on most types of human behavior; but that premise seems less unrealistic for medical practice than for other activities, given physicians' concern to avoid liability. ${ }^{218}$ There is no reliable way to predict the effects which the unfolding rules on informed consent will have on the amount of litigation, ${ }^{219}$ but they should at least not increase it if health professionals adjust their conduct. ${ }^{20}$ If the law is to provide reasonable protection

\footnotetext{
partially revised and published as proposed amendments to departmental guidelines on human experimentation, U.S. Dep't of Health, Education, and Welfare, Protection of Human Subjects-Proposed Policy, 39 Fed. Reg. 30648 (1974).

${ }^{218}$ This concern is reflected in the activities of insurance carriers and professional associations. See, e.g., Kessenick \& Mankin, supra note 20, at 261-62 (describing educational campaign of California Medical Association in the wake of the Cobbs decision).

${ }^{219}$ An accurate prediction is no more possible than knowing whether the model of decisionmaking propounded here will increase or decrease the total cost of medical care.

${ }^{220}$ As suggested by Irving Janis, see note 114 supra \& accompanying text, the patient who is prepared for the risks, discomfort, and other consequences of his treatment is better equipped to deal with it without emotional disturbance. Consequently,
} 
for the interests of patient-subjects, such a change in the behavior of physician-investigators seems the most likely to succeed. Neither prospective review by a physician-investigator's colleagues and others (which is required in the case of experimentation $^{221}$ and sometimes employed in other $\operatorname{cases}^{222}$ ) nor retrospective review through litigation or professional censure is likely to safeguard those interests adequately.

The importance of physician-investigators' adjusting their behavior according to the model of informed decisionmaking is made painfully clear by the Houston artificial heart case. ${ }^{223}$ It is apparent that the existing means of control failed there. ${ }^{224}$ The case, however, not only demonstrates the need for informed consent, but also illustrates the barriers to its achievement.

The failure of the Houston artificial heart team to make Haskell Karp a knowledgeable collaborator came back to haunt them even though they eventually escaped legal liability. Their experience, although in some ways unique, points up an aspect of the informing process seldom considered in the cases: the degree to which treatment plans for the patient are to be disclosed to his relatives. Revelations of diagnosis or plans to anyone but the patient without his consent violate the physician's ethical and legal obligations of confidentiality, despite the offhand endorsement of such a practice by courts and scholars when, in the exercise of his "therapeutic privilege,"225 a physician proceeds with treatment without having obtained his pa-

a physician who is candid with his patients is less likely to become the subject of their "bitterness," as the courts seem to fear, see Canterbury v. Spence, 464 F.2d 772, 791 (D.C. Cir.), cert. denied, 409 U.S. 1064 (1972), and as Dr. Janis found in uninformed patients who railed against their doctors as "amateurs" and expressed great annoyance at not being told what to expect. I. JANIS, supra note 114, at 359 .

${ }^{221}$ See 45 C.F.R. Part 46 (1975); 39 Fed. Reg. 18914 (1974).

${ }^{222}$ Professors Parsons, Fox, and Lidz recount how physicians are "[w]idening the orbit of colleagues whose advice they seek" outside of medicine into ethics, law, and social science, not only for ex post facto analyses of cases or discussions of general principles, but also while the physicians are still deliberating about what course to take. Parsons, Fox \& Lidz, supra note 97, at 410.

${ }^{223}$ See notes 1-16 supra \& accompanying text.

224 Although they conclude that Mrs. Karp's lawsuit against her husband's doctors was, more than any other "formal and informal sanctions," the "strongest action taken in the case of the artificial heart," Professors Fox and Swazey nevertheless doubt that "persons like Haskell Karp, on whom therapeutic innovations are tried, are adequately protected by the present legal process." R. Fox \& J. Swazey, The Courage to FaIL: A Social View of Organ Transplants and Dialysis 210-11 (1974).

${ }^{225}$ See note 176 supra. 
tient's informed consent. ${ }^{226}$ A patient may, of course, permit disclosure, through an explicit or, as would appear to have been the case with Mr. Karp, implicit waiver of the duty of confidentiality. The unusual aspect of the Karp-Cooley case is that the information given to Mrs. Karp was relevant not only to her husband's treatment, but to the demands which were placed on her to assist the transplant team in obtaining a donor. In her pleas, issued by the hospital's publicity office, she extolled Drs. Cooley and Liotta as gifted, God-given saviors of dying patients. ${ }^{227}$ This cannot help but have increased her bitterness when, having lost her husband despite the doctors' high expectations, she concluded that the men she had praised so highly had misled and exploited her.

In addition to avoiding the bitterness of disappointed expectations, adherence to the informed consent model would have performed a number of other basic functions in the artificial heart case. It would, most fundamentally, have protected Mr. Karp's autonomy and dignity as the first patient-subject for a radical innovation in treatment. His widow contended on appeal

that Mr. Karp was not told about the number of animals tested or the results of those tests; that he was not told there was a chance of permanent injury to his body by the mechanical heart, that complete renal shutdown could result from the use of the prosthesis, that the device was "completely experimental" . . . .228

Such information was of particular importance in this case because there was apparently some attempt to falsify the results of experiments with the artificial heart in calves, ${ }^{229}$ and because the results of those experiments led Dr. DeBakey and his col-

${ }^{226}$ See, e.g., Canterbury v. Spence, 464 F.2d 772, 789 (D.C. Cir.), cert. denied, 409 U.S. 1064 (1972); 75 HARv. L. REv. 1445, 1448 (1962).

${ }^{227}$ R. Fox \& J. SwAZEY, supra note 224, at 152.

${ }^{228}$ Karp v. Cooley, 493 F.2d 408, 420 (5th Cir. 1974).

${ }^{229} \mathrm{Dr}$. Liotta apparently submitted an abstract describing ten successful trials of the pump in calves before having begun the first experiment; the series was eventually limited to seven, not ten, calves, implanted between January 30 and March 20, 1969. Four of them died on the operating table; the other three all had renal failure and general weakness before dying at $81 \frac{1}{2}, 12 \frac{1}{2}$, and 44 hours. R. Fox \& J. SwAZEY, supra note 224, at 159-60. Dr. Cooley publicly suggested that other animal experiments had been conducted by his team, Schmeck, Dr. Cooley Defends His Use of Artificial Heart to Save Patient, N.Y. Times, Apr. 11, 1969, at 31, col. 4, but he never published the results. 
laborators to conclude that use of the heart device in humans was premature. ${ }^{230}$

The lack of candor to which Mr. Karp was treated may only reflect the secrecy with which the entire production was shrouded by the principal actors; with the exception of Dr. Liotta, none of the persons who aided Dr. Cooley were informed decisionmakers. ${ }^{231}$ Behind the secrecy lay Denton Cooley's apparent desire to achieve another "first,"232 which was complicated by the tangled question of the "authorship" of the artificial heart. ${ }^{233}$ These factors may also explain why, in violation of HEW rules, the protocol was not reviewed. In addition to the usual displeasure with the delay inherent in such review which is expressed by researchers who are "racing to establish priority of discovery or those who feel that some case or situation presents them with 'now or never' opportunities,"234 Dr. Cooley may have feared that if the project had become known it would not have been permitted to continue. ${ }^{235}$ Thus, the rules for informed consent would in all likelihood have had the indirect effect, had they been honored, of preventing the implantation, because the review procedure, intended in part to approve the format of consent, would have lifted the veil of concealment from the plans.

Just as it illustrates the need for informed consent, Karp $v$. Cooley also makes apparent the difficulties which will be faced by the participants in the decisionmaking process, particularly

${ }^{230}$ See DeBakey \& Hall, supra note 13, at 142; Letter from Dr. Michael DeBakey to Dr. Harold Brown, July 1969 (quoted in R. Fox \& J. Swazey, supra note 224, at 175). ${ }^{231}$ See note 66 supra \& accompanying text.

${ }^{232}$ See, e.g., H. Minetree, Cooley: The Career of a Great Heart Surgeon 21 25 (1973).

${ }^{233}$ Professors Fox and Swazey provide a particularly illuminating analysis of this question. See R. Fox \& J. SwazEy, supra note 224, at 167-70.

${ }^{234}$ BARBER, supra note 35 , at 150 .

${ }^{235}$ Dr. DeBakey was not only unaware of the implantation in advance; it was conducted on a day that he was away from Houston. T. Thompson, Hearts: Of Surgeons and Transplants, Miracles and Disasters Along the Cardiac Frontier 212 (1971). Dr. Cooley has offered an unabashed defense of his conduct, based on the belief

that he had not only the right, but in a sense the obligation to bypass his "seniors," the Baylor Committee on Research Involving Human Beings and a "government agency," as he did in conducting the implantation without informing any of them. He has argued that his status at the summit of cardiac surgery permitted this and that the nature of the situation required such bold and secretive action.

R. Fox \& J. SwAZEy, supra note 224, at 194. 
in cases of catastrophic illness. First, there are the problems of the emotional bonds created by the physician-patient relationship. Haskell Karp, after years of suffering, ${ }^{236}$ flew to Houston to be treated by a world-famous surgeon after his own medical advisors felt there was nothing more they could do. It is not difficult to imagine the hopes which he attached to his medical odyssey, and he felt Dr. Cooley to be the force which was driving him onward. ${ }^{237}$ The transference process ran the other way as well: The surgeon, rushing ahead with his urgent plans, perceived the impatience not in himself but in $\mathrm{Mr}$. Karp. ${ }^{238}$ Each may have been able to allay his own anxiety by attributing greater sureness to the other than he actually possessed-although Mr. Karp's lack of knowledge plainly tinged with uncertainty any assurance he derived from Dr. Cooley's inspiration.

A second difficulty is closely related to the first. Even had Mr. Karp been better informed, could he have decided against the operation? For patients suffering and near death, ${ }^{239}$ is there a real chance of turning away from any measure which offers the possibility of recovery? Perhaps the answer to the question is moot-so long as choices have to be made in desperate medical straits (and they do), the coercion inherent in the situation may have to be overlooked even though it denies the patient the freedom to say "no." Yet the Houston case suggests that such a pessimistic verdict is not justified. Indeed, in the face of death, Haskell Karp continued to insist for weeks that all he wanted was the ventricular resection, not the more radi-

${ }^{236}$ Mrs. Karp is said to have told Dr. Cooley, "My husband had already died a thousand times," H. MINETREE, supra note 232 at 8 , which reflects both his pain and his desperation.

${ }^{237}$ Such, at least, was Mrs. Karp's recollection. See Karp v. Cooley, 493 F.2d 408, 413 (5th Cir. 1974).

${ }^{238}$ Id. at 414 . Dr. Cooley may also have been sensitive to any signs of impatience on the Karps' part because he was aware that the delay in the operation was due in part to the time needed to prepare for the artificial heart maneuver. See R. Fox \& $\mathrm{J}$. SwazeY, supra note 224, at 161-64, 166-67.

${ }^{239} \mathrm{Karp}$, for example, "had incurred four heart attacks, thirteen cardiac hospitalizations and considerable medical care culminating in the insertion of an electronic pacemaker in May, 1968. Subsequent hospitalizations in September and October, 1968 occurred," Karp v. Cooley, 493 F.2d 408, 412 (5th Cir. 1974), during which "his pacemaker rate was increased to 72 beats per minute" and diagnostic procedures revealed "three vessel disease, occluded right coronary [artery], and . . anterior descending and circumflex branches [which] were occluded somewhat distally." Karp v. Cooley, 349 F. Supp. 827, 829 (S.D. Tex. 1972), aff'd, 493 F.2d 408 (5th Cir. 1974). 
cal transplant pressed on him by Dr. Cooley. There is every reason to suppose that for every patient who seeks out the daring medical innovator, there is at least one other patient who is satisfied with conventional (if less promising) treatment or with no treatment at all.

Finally, the possibility of achieving informed consent is reduced by the difficulties in communication made apparent by the artificial heart case. Dr. Cooley is an extremely busy cardiac surgeon. He had four other open-heart operations on the same day as Karp's, and he had to expedite the previous surgery when the anesthesiologist sent word that the operation should not be delayed because Mr. Karp was in poor shape. ${ }^{240}$ Due to the press of his cases, and perhaps to a reluctance to confront his own fears and uncertainties over what he planned to do, ${ }^{241}$ Dr. Cooley had seen Mr. Karp only occasionally, and then at hours as late as 10:30 p.m. Moreover, the delicacy of the matter of the heart pump's origin and ownership doubtless contributed to the ambiguous way in which $\mathrm{Dr}$. Cooley conveyed to Mr. Karp the nature of his own involvement and experience with the device. ${ }^{242}$

In light of the apparent needs for informed consent and for a creative attempt to overcome the limitations that inhere in decisionmaking about medical innovation, the judicial decisions in Karp v. Cooley are particularly disappointing. Neither the district nor the appellate court went as far as what Circuit Judge Bell termed the "minority" Canterbury rule, ${ }^{243}$ to say nothing of the further refinements developed above. Although the decisions can be explained in large measure as resulting from the "well-settled and stringent" ${ }^{244}$ Texas case law, ${ }^{245}$ which requires expert testimony on the reasonableness of disclosure, they must also be ascribed to the courts' weighing of the evidence $^{246}$ and especially to their exclusion of some evidence

240 See 493 F.2d at 416.

241 See Katz, supra note 71 , at 787.

242 Beyond this ambiguity, Mrs. Karp's testimony adds another. According to her, the artificial heart was explained to her husband and herself as just a "newer model" of the regular heart-lung bypass machine used during open-heart surgery. Karp v. Cooley, 493 F.2d 408, 413 (5th Cir. 1974).

${ }^{243}$ Id. at $419 \mathrm{n} .11$.

244 Id. at 419.

245 See Wilson v. Scott, 412 S.W.2d 299 (Tex. 1967).

${ }^{246}$ See notes 4-5 supra \& accompanying text. 
which might well have provided the factual predicate required by Texas law. ${ }^{247}$

Beyond the question whether the case was correctly decided (which would require examination of issues other than informed consent vel non), the Karp case is also valuable for the light it sheds on the importance of the rules about disclosure, comprehension, and causation which have been urged here as the proper aims of the developing law of informed consent.

The courts found the plaintiffs' evidence of inadequate disclosure not to be supported by the necessary expert testimony. A more dramatic demonstration of the vagaries and injustice of the expert testimony requirement is difficult to imagine. As the district judge observed, "[t]he only testimony

${ }^{247}$ Of the three pieces of evidence excluded, the testimony of Dr. DeBakey was probably most central to plaintiffs' case. Professors Fox and Swazey nicely summarize the lay disbelief that the exclusion of evidence is proper when it seems to serve "more as a deterrent than as an aid to the truth's being fully known ...."

The judge's holding that DeBakey's testimony was not "evidence of any probative value to present to the jury" is hard to understand or justify. DeBakey surely was a singularly important expert witness. Personally and professionally, he had intimate and perhaps unique knowledge of many facets of the case. Furthermore, the brief on appeal filed by the plaintiff contains extensive verbatim materials from DeBakey's "excluded testimony" that seem highly relevant to what Mrs. Karp's lawyer was attempting to argue, and appropriate for a jury's impartial determination:

Dr. Michael DeBakey's excluded testimony indicates that "the pump was not ready for use in human beings" because in reasonable medical probability its use "will jeopardize the life of the individual," and on that basis it was not acceptable medical practice in April of 1969 to use a mechanical heart of this kind in a patient. As of date of trial, he "still would not recommend it on the basis of our experimental observations." His review of the Karp surgery indicated a deterioration of renal functions and "this is a pattern of part of the picture of the terminal events that take place in animals" from their experiences with the mechanical heart.

On deposition, Dr. DeBakey stated Dr. Cooley was subject to the rule requiring prior approval of the Human Research Committee of the College, and that if he did not have approval of this committee he would violate this rule in using the heart device.

... One might ask why a physician-because he has an "international reputation," and because a potentially "inflammatory situation" exists between him and a fellow physician who is the defendant in a case-should be granted the option of refusing to testify in open court. This would not have happened with any ordinary citizen, or probably even any ordinary physician. Perhaps under the glare of a public courtroom hearing, DeBakey might have been reluctant to assert that privilege. ...

The interplay of factors that led Judge Singleton to make the decision he did could well constitute a study in itself.

R. Fox \& J. Swazey, supra note 224, at 208, 210 (footnote omitted). 
presented by doctors from this community in the same or similar school, on the information given to patients about their surgeries in this community" was "that each doctor must use his own medical judgment." ${ }^{48}$ Yet this amounts to no standard at all. Moreover, the emphasis on local standards rings particularly oddly when one is dealing with physicians who draw their patients from around the nation. The potential for the medical profession, under the "expert" requirement, to prevent justice from being done is starkly displayed in Michael DeBakey's refusal to testify, in which he was upheld by the courts. There is no question of DeBakey's disapproval of what Denton Cooley had done; he was angered at what he believed to be the piracy of a medical invention from his laboratory, embarrassed at being surprised in front of his peers by the surgery of which he had been kept ignorant, and concerned that the $\mathrm{Na}$ tional Heart Institute, which had funded the Baylor-Rice artificial heart program, might withdraw its support. A number of investigations were launched, and "DeBakey built a careful case against Cooley." 249 But, having achieved quick "vengeance" within the privacy of the medical fraternity and of his own medical school, ${ }^{250}$ DeBakey apparently felt that " the need to punish Cooley for what he had done" 251 had been fulfilled. Citing the very intensity of his distress over Dr. Cooley's acts, Dr. DeBakey persuaded the court that the "friction between [himself] and Dr. Cooley would be highly inflammatory and [his appearance would] serve no purpose except to introduce issues into the case before the jury that were not properly before the court."252 Dr. DeBakey's feelings were obviously very genuine and strongly felt; he probably had no desire to deprive Mrs. Karp of her day in court. But his behavior, aided by the courts' rulings, demonstrates again how the medical profession regards disciplining of physician-investigators for overreaching their patient-subjects as its own province and so "resentfully clams up when one of its members is attacked."253

${ }^{248}$ Karp v. Cooley, 349 F. Supp. 827, 834 (S.D. Tex. 1972), aff'd, 493 F.2d 408 (5th Cir. 1974).

$249 \mathrm{~T}$. ThOMPSON, supra note 235 , at 216.

${ }^{250} \mathrm{Dr}$. Liotta was fired from Baylor and $\mathrm{Dr}$. Cooley resigned.

${ }^{251} \mathrm{~T}$. Thompson, supra note 235 , at 217 , quoting a person who observed De-

Bakey's "possession" with the need to punish Cooley during the hearings.

${ }^{252} 349$ F. Supp. at 836.

${ }^{253}$ Jaffe, Law as a System of Control, 98 Daedalus 406, 408 (1969). 
Given the nature of Mr. Karp's consenting process, the case not surprisingly has little to say on the matter of comprehension. But it is perhaps noteworthy that Dr. Cooley himself clearly regarded this as an important factor. He testified, in Judge Bell's words, that he had "assured himself that Mr. Karp understood the gravity of his personal situation and the nature of the operation to be performed."254

Finally, the issue of causation played an important role in Karp v. Cooley. On this point, each side to the lawsuit was pushed to the extreme positions often brought about by litigation. In Mrs. Karp's version, her husband was "as normal as any man in the courtroom," from the time he entered the hospital to the morning of surgery. ${ }^{255}$ The defendants' position, which was accepted by the courts, was that Mr. Karp was near death as the moment of the operation approached. ${ }^{256}$ Two conclusions followed from this: first, that whatever the doctors did cannot have harmed him, and alternatively, that his condition was so bad that it was the ventriculoplasty which brought about his death, not the subsequent steps. At this point the problem of establishing causation became technical; the courts agreed with the defendants that the causes of death were pneumonia and, secondarily, renal failure, and these were known consequences of major surgery and only "possibly" caused by the mechanical heart. ${ }^{257}$ The plaintiffs would have had the court conclude that the heart device was a probable "cause of the cause" of the death. ${ }^{258}$ Although Mrs. Karp did "not complain of the informed consent" for the ventriculoplasty, ${ }^{259}$ that would matter little under the view taken of causation in the informed consent model, since the operations were, in the physicians' own terms, an integrated three-step process. The lack of information about the risks of renal failure, as shown in the calf experiments, would certainly seem to point to an adequate causal nexus when that very complication arose following the procedure.

254493 F. 2d at 415.

255 Id. at $412-13$.

${ }^{256} I d$. at $414-15,422$.

${ }^{257}$ Id. at 422.

${ }^{258}$ This argument was based on the expressed views of Dr. DeBakey that the physiological changes experienced by Mr. Karp "resemble those observed in the animal experiments" conducted with the artificial heart and that all his complications "were secondary to the problem of inadequate perfusion, due to the effects of the implanted pump." R. Fox \& J. Swazey, supra note 224, at 174-75 (quoting M. DeBakey).

${ }^{239} 493$ F.2d at 422. 
The Karp-Cooley episode, which provides what is perhaps the most stunning example of advanced and highly technological research and treatment in the catastrophic disease field, thus adds little to the substantive law of informed consent. Yet it illustrates well the need for further evolution of the law if patient-subjects are to be adequately protected as informed decisionmakers about their own medical procedures. 